Check for updates

Cite this: RSC Adv., 2020, 10, 18978

Received 6th April 2020

Accepted 4th May 2020

DOI: 10.1039/d0ra03096a

rsc.li/rsc-advances

\section{Isolation and synthesis of cryptosanguinolentine (isocryptolepine), a naturally-occurring bioactive indoloquinoline alkaloid}

\author{
Elida N. Thobokholt, (D) Enrique L. Larghi, (D) Andrea B. J. Bracca (D)* \\ and Teodoro S. Kaufman (D) *
}

Cryptosanguinolentine (isocryptolepine) is one of the minor naturally-occurring monomeric indoloquinoline alkaloids, isolated from the West African climbing shrub Cryptolepis sanguinolenta. The natural product displays such a simple and unique skeleton, which chemists became interested in well before it was found in Nature. Because of its structure and biological activity, the natural product has been targeted for synthesis on numerous occasions, employing a wide range of different strategies. Hence, discussed here are aspects related to the isolation of isocryptolepine, as well as the various approaches toward its total synthesis.

\section{Introduction}

It is now common knowledge that after millions of years of coexisting under different external pressures (territory, food, predators, etc.), the communities of organisms sharing the same ecosystem underwent co-evolution as a survival strategy. As a result, some of their secondary metabolic routes suffered changes over time, gaining the ability to become resistant to their environment by producing certain low molecular weight

Instituto de Química Rosario (IQUIR, CONICET-UNR), Facultad de Ciencias Bioquimicas y Farmacéuticas, Universidad Nacional de Rosario, Suipacha 531, S2002LRK Rosario, Argentina. E-mail: kaufman@iquir-conicet.gov.ar; bracca@ iquir-conicet.gov.ar; Fax: +54-341-4370477; Tel: +54-341-4370477 metabolites. These small molecules are collectively known as natural products.

It has been found that the natural products may act as small ligands for certain macromolecular targets found within the living organisms or, more often, within other living organisms of the same ecosystem. ${ }^{1}$ In this way, the natural products assist the producing organism to sustain the hostilities of the environmental pressures and survive. Interestingly, many human proteins contain structural domains that are very similar to some of the macromolecular targets affected by natural products; therefore, it was not unexpected to find out that the small molecule natural products originally produced with a different aim (reproduction, signaling, communication, defense), can

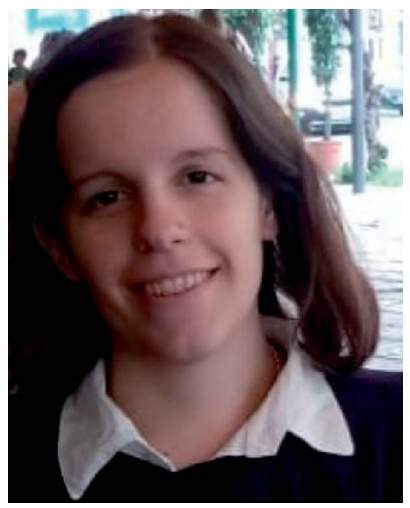

Elida N. Thobokholt was born in Rosario (Santa Fe, Argentina) and studied at the School of Biochemical and Pharmaceutical Sciences at the National University of Rosario, where she earned her BS degree in Food Science and Technology in 2018. Shortly after, she joined the group of Dr Kaufman as a Doctoral student at IQUIR. Currently, she is developing novel approaches to the synthesis of naturally occurring indoloquinoline alkaloids, under the supervision of Drs Bracca and Larghi.

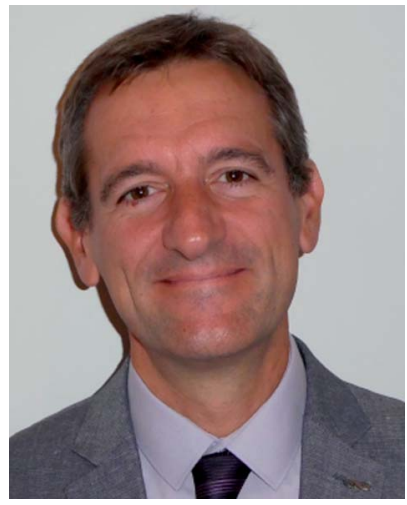

Enrique L. Larghi was born in Rosario (Santa Fe, Argentina). He received his B.S. from the UNR (Argentina) in 1997 and immediately after he moved to the UFSM (RS-Brazil) where he obtained $M S c$ and $P h . D$. degrees under the advice of Profs. Silveira (1997) and Morel (1999). After a short experience in the Argentine pharmaceutical industry, he returned to IQUIR, joining Prof. Kaufman's group as a postdoctoral fellow first, and then as a staff member of CONICET. Currently, he is an Independent Researcher and Adjunct Professor at the UNR. His current interests cover the synthesis of heterocyclic natural products and their derivatives. 
interact with human proteins and modulate different responses. $^{2}$

As a result of the natural selection process, natural products display wide chemical diversity and chemical specificity, which enhances their ability to interact with diverse biorelevant macromolecules, turning them into a unique and rich source of compounds for new drug development.

Empirically, humankind took advantage of the general properties of these natural products, and medicinal plants have been used in virtually all cultures as a source of medicines since the beginning of time. ${ }^{3}$ Furthermore, statistical analysis performed on the new chemical entities reported between 1981 and 2018 confirmed this situation, revealing that $40 \%$ of them were derived from natural products or were natural products themselves. This proportion increases to $64 \%$ among anticancer drugs and to $75 \%$ when only antibiotics are considered. ${ }^{4}$

Since the abundance of natural products in extracts is invariably low and therefore the former are often isolated in tiny amounts, when they show signs of being useful, it is usually found that their natural supply is not enough to satisfy the demand at a reasonable scale, such as that needed for biological testing. At this point, the development of efficient synthetic pathways to guarantee convenient access to these compounds becomes a requirement.

Furthermore, natural products are currently seen not only as potential sources of inspiration for the development of new medicines through structural diversification; they are also highly regarded as potentially suitable probes to explore the interactions within and between cells, as a logical means to understand the inner-workings of the complex molecular machinery that sustains life. ${ }^{5}$ However, since Nature has produced such wonderfully complex molecules that no synthetic chemist could ever dream of, natural products are still a relevant challenge to organic chemists, who advance the frontiers of knowledge by devising new strategies and reagents for their synthesis.

\section{Known naturally-occurring indoloquinoline alkaloids}

Naturally-occurring indoloquinolines are a small family of alkaloids, which have been isolated mainly from Cryptolepis sanguinolenta (Lind.) Schlechter, family Asclepiadaceae. ${ }^{6}$ However, other plants such as Justicia betonica L. (Acanthaceae), ${ }^{7}$ J. secund ${ }^{8}$ and Sida rhombifolia L. (Malvaceae) ${ }^{9}$ are also natural sources of alkaloids that exhibit the indoloquinoline motif. These unique natural heterocycles bear both indole and quinoline rings, fused through their pyrrole and pyridine rings.

Considering this limiting characteristic, only four isomeric ring systems are possible (Fig. 1), namely indolo[3,2-c] quinoline (1), indolo[3,2- $b]$ quinoline (quinindoline, 2), indolo [2,3- $b]$ quinoline (3) and indolo[2,3-c]quinoline (4). The cores of natural indoloquinolines correspond to isomers 1-3, and despite the skeleton of $\mathbf{4}$ being synthesized, there are no natural examples of compounds of class $\mathbf{4}^{\mathbf{1 0}}$<smiles>c1ccc2c(c1)ncc1c3ccccc3[nH]c21</smiles>

1

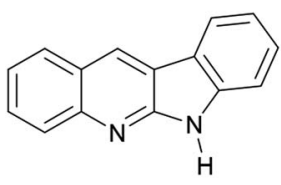

3<smiles></smiles>

2<smiles>c1ccc2c(c1)ncc1[nH]c3ccccc3c12</smiles>

Fig. 1 Some isomers of the indoloquinoline skeleton.

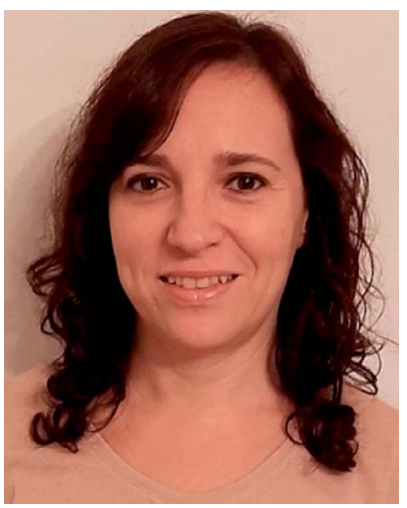

Andrea B. J. Bracca was born in Rosario (Santa Fe, Argentina) and graduated in 2001 with a BS in Biotechnology from the National University of Rosario. She received her $P h$. D. in 2009 under the guidance of Prof. Kaufman. After a two year period of postdoctoral training, she returned to work in Dr Kaufman's group as an Assistant Research Scientist at the Argentine National Research Council (CONICET) at the Institute of Chemistry of Rosario (IQUIR). Currently, Dr Bracca is an Adjunct Researcher and develops research work in the area of the total synthesis of heterocyclic natural products and their most relevant analogues.

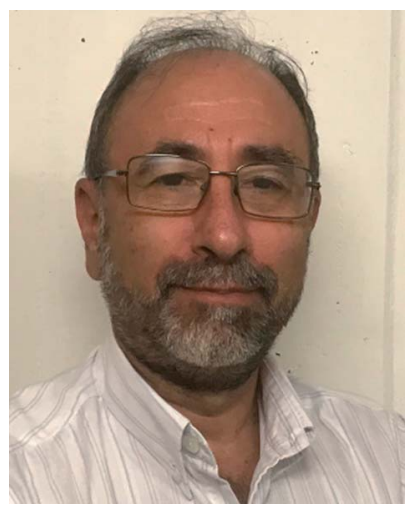

Teodoro S. Kaufman was born near Moisés Ville (Santa Fe, Argentina). He graduated in Biochemistry (1982) and Pharmacy (1985) at the National University of Rosario (UNR), and received his Ph. D. (1987) under the guidance of Prof. Edmundo A. Rúveda. After two years of postdoctoral training at The University of Mississippi (USA), he returned to Rosario. Currently, he is a full Professor of the UNR, Research Head of the Argentine National Research Council (CONICET) and Head of the Institute of Chemistry of Rosario (IQUIR). His research interests include heterocyclic chemistry and the synthesis and evaluation of bioactive natural products and analogues. 
<smiles>c1ccc2nc3[nH]c4ccccc4c3cc2c1</smiles><smiles>c1ccc2nc3c(cc2c1)[nH]c1ccccc13</smiles><smiles>O=c1c2ccccc2[nH]c2c1[nH]c1ccccc12</smiles>

2<smiles>Cn1c2nc3ccccc3c-2cc2ccccc21</smiles><smiles>Cn1cc2c3ccccc3nc-2c2ccccc21</smiles>

Their main source of indoloquinolines in Nature, Cryptolepis sanguinolenta, is a tropical scrambling and twinning shrub, indigenous to West and Central Africa. ${ }^{11}$ The study of the plant began in the early 1950s and cryptolepine was the first alkaloid to be isolated. ${ }^{12}$ To date, over a dozen naturally occurring indoloquinolines have been discovered, including quinindoline (3), ${ }^{7}$ quindoline (2), ${ }^{13}$ quindolinone (5), ${ }^{14}$ neocryptolepine (6), ${ }^{15}$ cryptosanguinolentine (isocryptolepine, 7$),{ }^{16}$ cryptolepine $(8),{ }^{17}$ 11-isopropylcryptolepine $(\mathbf{9})^{18}$ and cryptolepinone (hydroxycryptolepine, 10). ${ }^{19}$ These are monomeric members of this family (Fig. 2), however, several dimeric natural indoloquinolines have also been reported. ${ }^{19-21}$

The plant has long been employed in the dyeing of textiles and leather. ${ }^{22}$ In addition, a decoction of its roots is frequently used in traditional folk medicine, to treat fevers, malaria, ${ }^{23}$ upper respiratory infections and venereal diseases. ${ }^{24}$ The root has been used in the Congo as a bitter stomachic, ${ }^{24 c}$ and in Nigeria for the therapy of colics, rheumatism, and urogenital infections. ${ }^{25}$ The plant has been demonstrated to possess antibacterial activity and to exert vasodilation. ${ }^{21 \boldsymbol{b}}$ The pharmacological activities of different indoloquinoline alkaloids, their analogs and derivatives, have been reported in several articles. The most relevant ones are their antitumoral and antiparasitic activities. ${ }^{26}$

\section{Isocryptolepine: its isolation and properties}

Isocryptolepine was first obtained as a degradation product during investigations on the constitution of indigo-yellow. ${ }^{27}$ However, the heterocycle was first isolated from a natural source (Cryptolepis sanguinolenta) in 1995 by the Bodo group as a non-crystalline substance, along with cryptolepine and quindoline. Only $5 \mathrm{mg}$ were obtained from $60 \mathrm{~g}$ of air-dried roots ground to a fine powder $(0.08 \% \mathrm{w} / \mathrm{w})$. Its chemical structure was determined after exhaustive analysis of its infrared (IR) and nuclear magnetic resonance (NMR) spectroscopic and mass spectrometric (MS) and data. ${ }^{16}$ Interestingly, on the bases of spectral grounds, it has also been conjectured that the previously isolated and partially characterized alkaloid CSA-3 may be identical to isocryptolepine. ${ }^{13}$

Shortly after, the same alkaloid was isolated again by the Tackie group, from the same source in 1996, under the name cryptosanguinolentine. ${ }^{28}$ The natural product, obtained as a yellowish residue $(1.7 \mathrm{mg}$ from $3.14 \mathrm{~kg}$ of plant roots; $0.5 \times$ $10^{-4} \% \mathrm{w} / \mathrm{w}$ ), was isolated along with cryptotackieine (neocryptolepine); due to the scarcity of the material, preparative reverse-phase high-performance liquid chromatography (HPLC) and micro NMR techniques were required to confirm its structure. At a later date, the same group reported a more detailed account of their isolation, with the obtaining of another 15 alkaloids. ${ }^{21 a}$

The ${ }^{1} \mathrm{H},{ }^{13} \mathrm{C}$ and ${ }^{15} \mathrm{~N}$ NMR spectra of isocryptolepine and its protonated form were assigned as part of a systematic NMR study of four isomeric indoloquinoline alkaloids. ${ }^{29}$ All of the NMR signals were assigned using 2D correlation techniques. Interestingly, in the ${ }^{15} \mathrm{~N}$ NMR [a gradient selected singlequantum multiple-bond correlation (GSQMBC) experiment], the quinoline- $\mathrm{N}(\mathrm{N}-5)$ was observed in the usual range at $\delta 135.6 \mathrm{ppm}$, whereas the indole- $\mathrm{N}(\mathrm{N}-11)$, which has is iminelike in nature, was found to be significantly deshielded $(\delta$ 248.1 ppm).

Density functional theory (DFT) calculations of the chemical shielding constants were also performed, allowing a detailed investigation of the effects of protonation and solvation. The calculations were able to reproduce the main experimental trends observed upon protonation, and it was observed that the inclusion of solvent effects in the computations improved the agreement with the experimental ${ }^{13} \mathrm{C}$ NMR data.

${ }^{1} \mathrm{H}$ NMR data was also recorded in order to determine that the $\mathrm{p} K_{\mathrm{a}}$ of the natural product is 9.8. This result was obtained through a graphical estimation of the inflection point and also by the use of the Henderson-Hasselbalch equation [eqn (1)], ${ }^{30}$ which showed a linear dependence of the chemical shift on the pH of the sample: ${ }^{31}$

$$
\mathrm{pH}=\mathrm{p} K_{\mathrm{a}}+\log \left[\delta_{\max }-\delta\right] /\left[\delta-\delta_{\min }\right]
$$

The effect of cyclodextrin (CD) encapsulation on the photophysics of isocryptolepine, was studied using steady state and time-resolved fluorescence spectroscopy. ${ }^{32}$ In the excited state, it was observed that the natural product exists mainly in its zwitterionic form, exhibiting appreciable emission from the $\pi-$ $\pi *$ state upon excitation at a specific wavelength.

Due to the presence of the hydrophobic nanocavities of CDs, the existence of zwitterions in the excited state allows a mutual interaction to form dimers, triggered through coulombic interactions. This was evidenced by treating the fluorophores with CDs with different cavity spaces and employing steady state fluorescence measurements. Moreover, the photophysical behavior of the heterocycle was found to be modulated by the nature of the cyclodextrin. In addition, trapped water molecules 
inside the bigger cavity of $\gamma$-CD seemed to quench the fluorescence of the zwitterions.

Isocryptolepine has been demonstrated to show antimicrobial, ${ }^{33}$ anti-trypanosomal, ${ }^{34}$ antifungal, ${ }^{35}$ anti-inflammatory, antimalarial (including $\beta$-haematin inhibition), ${ }^{36}$ antitrypanosomal, antileishmanial and cytotoxic activities, ${ }^{\mathbf{3 4 , 3 6 c , 3 7}}$ as well as the ability to interact with DNA, ${ }^{38}$ promote low density lipoprotein uptake in HepG2 cells, ${ }^{39}$ and be useful as a treatment for intestinal disorders. Most of these properties are common to other natural indoloquinolines, which differing in potency and selectivity.

As a result of its profile, during the last 20 years, this natural product became a recurrent target for total synthesis as well as a useful scaffold for the preparation of analogs ${ }^{40}$ and derivatives, ${ }^{41}$ with the aim of improving its activity profile (mainly its potency and selectivity). Furthermore, its attractive structure turned its synthesis into a fertile field for testing the scope and efficiency of new and imaginative $\mathrm{C}-\mathrm{C}$ and $\mathrm{C}-\mathrm{N}$ bond forming reactions. Detailed below are the different approaches that have been designed to synthesize isocryptolepine.

\section{Total syntheses of isocryptolepine}

Isocryptolepine is an angularly fused indoloquinoline. As observed in the case of other indoloquinolines, there has been some relevant synthetic work that focused on targeting isocryptolepine before it was found in nature, in 1996. However, most of the synthetic efforts toward the alkaloid have been carried out over the last 20 years, where the natural product has been totally synthesized over 25 times, by different groups around the world; furthermore, some of them can be credited with more than one synthesis.

We have previously classified the synthetic approaches toward the indoloquinoline alkaloids neocryptolepine (6) and quindoline (2) into three main groups, based on the chemical structure of the starting materials involved in the sequence, including: (a) benzenoids, (b) quinolines and (c) indoles. ${ }^{42}$ Accordingly, except for the advances recorded before the isolation of isocryptolepine from $C$. sanguinolenta, the total syntheses of the natural product are classified here to fit into these three categories. In addition, for the sake of clarity, the syntheses are ordered chronologically.

\section{4a. Early synthetic studies before the isolation of isocryptolepine from a natural source}

The first reported total synthesis of the structure of isocryptolepine was disclosed in 1950 by Kermack and Storey, ${ }^{43}$ who synthesized derivatives of the tetracycle $\mathbf{1}$ for biological testing, in an attempt to find new antimalarials. These authors employed a modification of the Graebe-Ullmann carbazole synthesis for the preparation of the tetracyclic framework of their prospective compounds and also synthesized isocryptolepine via the $N$-methylation of $\mathbf{1}$.

Thus, 4-chloroquinoline (11) was condensed with orthophenylenediamine (12) at $140{ }^{\circ} \mathrm{C}$ at $20-30 \mathrm{mmHg}$ for $10-20 \mathrm{~min}$, resulting in 4 -(2-aminoanilino)quinoline (13), in $76 \%$ yield

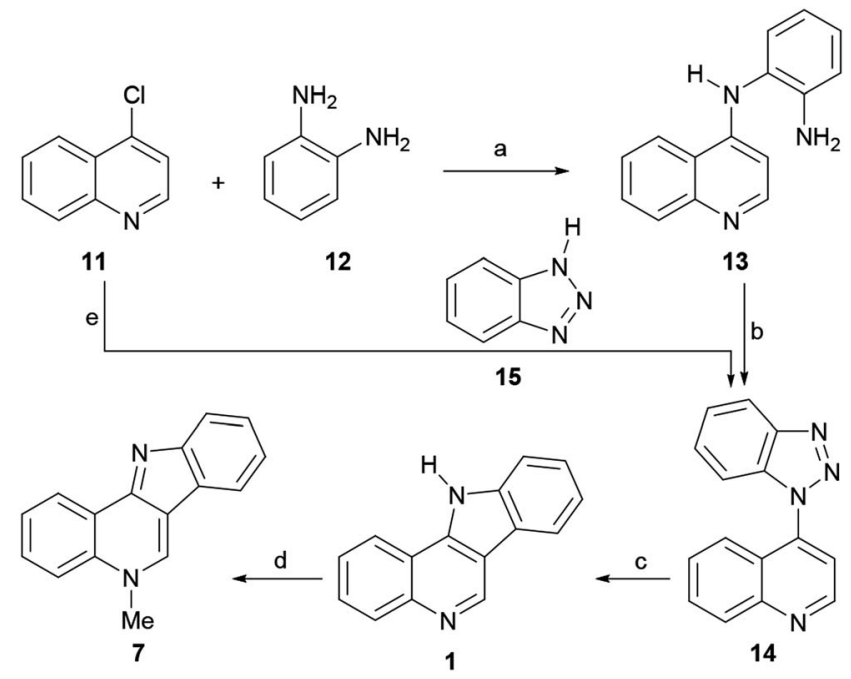

Scheme 1 Reagents and conditions: (a) $140{ }^{\circ} \mathrm{C}, 20-30 \mathrm{~mm} \mathrm{Hg}, 10-$ 20 min (76\%); (b) $\mathrm{NaNO}_{2}, 1 \mathrm{~N} \mathrm{HCl}, \mathrm{H}_{2} \mathrm{O}, 5^{\circ} \mathrm{C}$ (70\%); (c) $\mathrm{H}_{3} \mathrm{PO}_{4}$, heat (77\%); (d) Mel, $\mathrm{PhNO}_{2}, 2 \mathrm{~h}, 100{ }^{\circ} \mathrm{C}(72 \%)$; (e) (1) 15, MW (160 W); (2) pyrophosphoric acid, $160 \mathrm{~W}, 4-6 \mathrm{~min}$ (60\% overall).

(Scheme 1). After this, 13 was submitted to a Graebe-Ullmann protocol by diazotization with $\mathrm{HNO}_{2}$ to afford the benzotriazole derivative 14 in $70 \%$ yield. Further heating of 14 with syrupy phosphoric acid, gave $\mathbf{1}$ in $77 \%$ yield, after the loss of nitrogen and rearrangement.<smiles>Nc1ccccc1Nc1ccnc2ccccc12</smiles>

13<smiles>CN(c1ccccc1)c1ccnc2ccccc12</smiles>

D<smiles>CC1=C[c-]2c1nc1ccccc1c2=Nc1ccccc1</smiles>

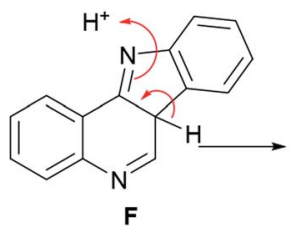

A<smiles></smiles><smiles></smiles>

B<smiles></smiles>

14

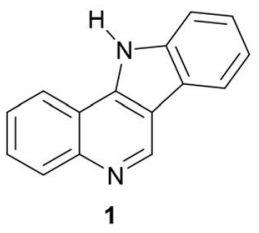

Scheme 2 Proposed mechanism of the Graebe-Ullmann synthesis of isocryptolepine. 
The product was obtained as a violet fluorescent compound, which exhibited increased fluorescence when dissolved in concentrated sulfuric acid. Finally, the tetracycle was heated in a steam bath with excess methyl iodide in nitrobenzene, furnishing the methiodide of 7 in $72 \%$ yield. The base of the latter could be freed by treatment with aqueous ammonia, followed by drying of the resulting isocryptolepine monohydrate.

In the reaction mechanism (Scheme 2), the primary amino group of 13 is diazotized with $\mathrm{HNO}_{2}$ to give the diazonium salt intermediate $\mathbf{A}$, which undergoes an intramolecular cyclization to the protonated benzotriazole intermediate B. After deprotonation, benzotriazole 14 loses nitrogen to afford the diradical species $\mathbf{C}$, which in its conformation $\mathbf{D}$ undergoes a radical rearrangement to the carbene intermediate $\mathbf{E}$. Then, cyclization takes place to afford intermediate $\mathbf{F}$, which further aromatizes to 1 , via a $[1,3]$ proton shift.

This contribution complemented the earlier findings by Clemo and Perkin, ${ }^{44}$ which can be regarded as a synthesis of an advanced intermediate of the natural product. These authors demonstrated that upon heating with aqueous sulfuric acid, the phenylhydrazone of 1,2,3,4-tetrahydroquinolin-4-one underwent a one-pot Fischer indolization and subsequent dehydrogenation to give 1. Employing the same approach but starting with the phenylhydrazone of $N$-methyl-1,2,3,4tetrahydroquinolin-4-one (obtained from $\mathrm{N}$-methylaniline in $15 \%$ yield) Braunholtz and Mann also synthesized isocryptolepine in 1955 in an unspecified yield..$^{45}$

In 1965, Roussel et al. reported an alternative approach toward $\mathbf{1}$ (Scheme 3) by way of the 1,2,3,4-tetrahydroquinolin-4-one $\mathbf{1 6 .}{ }^{\mathbf{4 6}}$ The ketone was best prepared in $68 \%$ yield by direct cyclization of $\beta$ - $N$-phenylalanine $(\mathbf{1 5}$, obtained in turn from aniline and methyl acrylate) with PPA at $130{ }^{\circ} \mathrm{C}$ for $20 \mathrm{~min}$. However, 16 could also be accessed in three steps and in substantially the same yield via the aza-Michael addition of aniline to methyl acrylate, followed by ester hydrolysis and cyclization.

The latter was converted into the tosylamide $\mathbf{1 7}$ and further indolized in $50 \%$ overall yield by first heating it for $90 \mathrm{~min}$ at

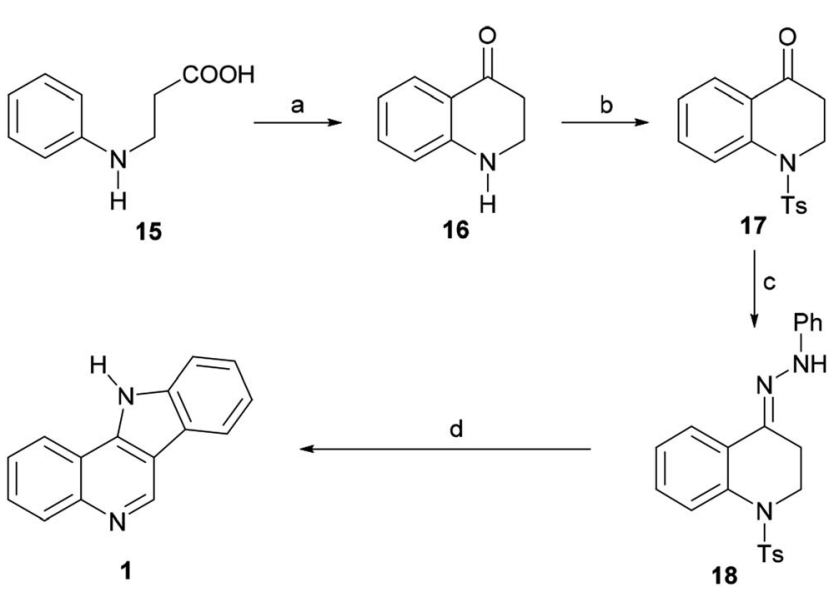

Scheme 3 Reagents and conditions: (a) PPA, $130{ }^{\circ} \mathrm{C}, 20 \mathrm{~min}(68 \%)$; (b) $\mathrm{TsCl}, \mathrm{Et}_{3} \mathrm{~N}, \mathrm{CH}_{2} \mathrm{Cl}_{2}$; (c) $\mathrm{PhNHNH}_{2}, \mathrm{EtOH}, \mathrm{AcOH}$ (cat), $80^{\circ} \mathrm{C}, 90 \mathrm{~min}$, $74 \%$; (d) $\mathrm{AcOH}, \mathrm{H}_{2} \mathrm{SO}_{4}, 10$ min, $\Delta, 50 \%$.

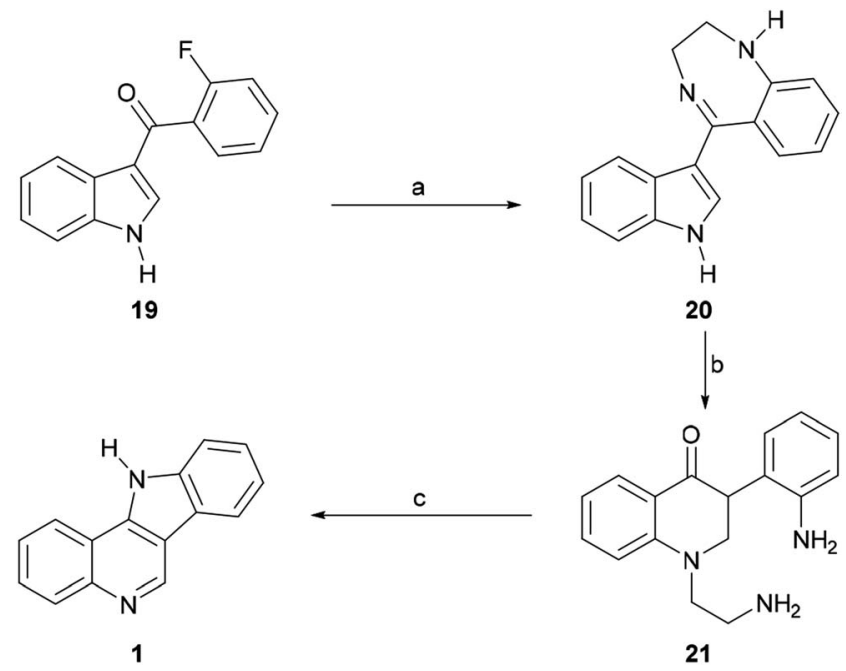

Scheme 4 Reagents and conditions: (a) $\mathrm{H}_{2} \mathrm{NCH}_{2} \mathrm{CH}_{2} \mathrm{NH}_{2}$, pyridine, reflux, 20 h (54\%); (b) $2 \mathrm{~N} \mathrm{H}_{2} \mathrm{SO}_{4}, \mathrm{EtOH}$, reflux, 72 h (70\%); (c) $\mathrm{Ph}_{2} \mathrm{O}$, reflux (low yield).

$80{ }^{\circ} \mathrm{C}$ with phenylhydrazine in $\mathrm{EtOH}$, to give the hydrazone 18, and then heating it for $10 \mathrm{~min}$ in $\mathrm{AcOH}$, under $\mathrm{H}_{2} \mathrm{SO}_{4}$ promotion. The cyclization stage was accompanied by both detosylation and dehydrogenation toward $\mathbf{1}$.<smiles>C[123I]C[123I]</smiles>

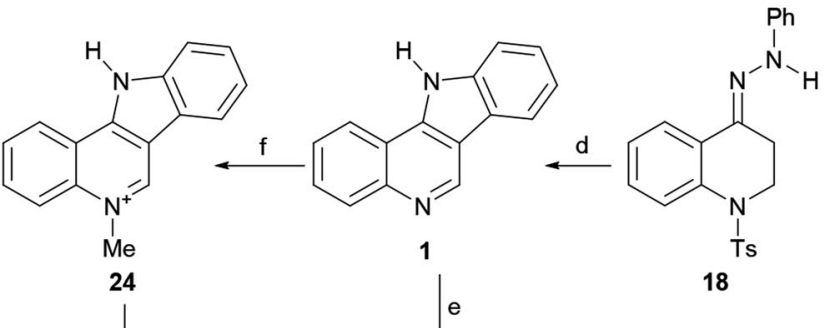<smiles>CN(C)c1ccccc1-c1cc2ccccc2n1C</smiles>

Scheme 5 Reagents and conditions: (a) $\mathrm{ClCH}_{2} \mathrm{CO}_{2} \mathrm{H}, \mathrm{NaOH}(69 \%)$; (b) PPA, $130{ }^{\circ} \mathrm{C}, 10 \min (96 \%) ;(c) \mathrm{PhNHNH}_{2}, \mathrm{AcOH}$ (cat.), $\mathrm{EtOH}, 80^{\circ} \mathrm{C}$, $1.5 \mathrm{~h}(87 \%) ;\left(\right.$ d) $\mathrm{H}_{2} \mathrm{SO}_{4}, \mathrm{AcOH}, 100{ }^{\circ} \mathrm{C}, 10$ min (56\%); (e) $\mathrm{Mel}, \mathrm{K}_{2} \mathrm{CO}_{3}$, $\mathrm{Me}_{2} \mathrm{CO}$, reflux, $3 \mathrm{~h}$ (82\%); (f) Mel, PhMe, $22{ }^{\circ} \mathrm{C}(64 \%) ;$ (g) $\mathrm{K}_{2} \mathrm{CO}_{3}, \mathrm{H}_{2} \mathrm{O}$, $\sim 20{ }^{\circ} \mathrm{C}(93 \%)$; (f) I $2, \mathrm{TBHP}, \mathrm{CHCl}_{3}, \mathrm{rt}, 14 \mathrm{~h}(75 \%)$. 
In 1968, García et al. disclosed an additional alternative process of synthesizing [3,2-c]indoloquinoline (1). ${ }^{47}$ These authors prepared 3-(2-fluorobenzoyl)indole (19) via the acylation of indolylmagnesium bromide with $o$-fluorobenzoyl chloride (Scheme 4) and found that the subsequent treatment of the latter with ethylenediamine in refluxing pyridine gave the substituted aminobenzoylindole imine derivative 20 in 54\% yield via the nucleophilic exchange of fluorine for an amine. ${ }^{48}$ Upon acid treatment, 20 underwent rearrangement to afford a mixture of the quinolone $\mathbf{2 1}$ and the indoloquinoline $\mathbf{1}$. However, heating the quinolone in diphenyl ether under reflux gave the fused heterocycle $\mathbf{1}$ as the sole product, apparently in very low yield.

In 1993, the Alvarez-Builla group improved and simplified the original sequence of Kermack and Storey, ${ }^{38 a, 49}$ by reporting a one-pot Graebe-Ullmann approach to the tetracyclic precursor $\mathbf{1}$ of the natural product, as a surrogate for the traditional Fischer indolization approach (Scheme 1). The process, which was later employed by Murray et al. for the preparation of analogs for biological evaluation as antimalarials, ${ }^{36 \boldsymbol{d}}$ could be carried out in an open vessel using a domestic microwave oven.

The strategy involved two irradiation stages; first, a solventless mixture of $\mathbf{1 1}$ and $\mathbf{1 5}$ was irradiated at $160 \mathrm{~W}$ to obtain the benzotriazole derivative 14 in $90 \%$ yield; then, without purification of the benzotriazole, a second irradiation process was performed at $160 \mathrm{~W}$ in the presence of pyrophosphoric acid to produce the tetracycle 1 in $60 \%$ yield after $4-6 \mathrm{~min}$. Interestingly, it was observed that the attained yield under these conditions was similar to that obtained by applying conventional heating. It was also concluded that irradiation of a solventless mixture of the pure reactants was more efficient than using their supported forms, over silica gel or montmorillonite.

\section{4b. Syntheses from benzenoids}

Synthesis by Novikov et al. The first total synthesis of isocryptolepine after its isolation as a natural product was carried out starting from simple benzenoid compounds, reported in 1996 by the Novikov group (Scheme 5). ${ }^{50}$ The synthetic pathway, which was reported in few details, followed the indolization strategy originally devised by Clemo and Perkin. ${ }^{\mathbf{4 4}}$

The final product was obtained from $N$-tosylaniline (22) via a six-step sequence in an overall yield of $19.2 \%$. To that end, the authors performed the $N$-alkylation of 22 with $\beta$-chloropropionic acid ${ }^{51}$ to obtain the sulfonamide 23 in $69 \%$ yield and cyclized the latter by heating at $130{ }^{\circ} \mathrm{C}$ with polyphosphoric acid, ${ }^{52}$ to access the required intermediate carbonyl derivative 17 in $96 \%$ yield.

In turn, the 1,2,3,4-tetrahydroquinolin-4-one 17 was exposed to phenylhydrazine under $\mathrm{AcOH}$ catalysis, furnishing $87 \%$ yield of the intermediate hydrazone 18. Subsequently, this compound was subjected to indolization with $\mathrm{H}_{2} \mathrm{SO}_{4}$ in acetic acid at $100{ }^{\circ} \mathrm{C}$, to give 1 in $56 \%$ yield. Exposure of the tetracycle 1 to MeI afforded the mono-methiodide 24 in 64\% yield. Final basic treatment to free the base gave isocryptolepine (7) in 93\% yield. Interestingly, in the presence of $\mathrm{K}_{2} \mathrm{CO}_{3}$, the bis- $N$-methylated isocryptolepinium derivative 26 was obtained in $82 \%$ yield. More recently, 26 was accessed by Volvoikar and Tilve in 75\% yield from 25, employing a cross-dehydrogenative coupling reaction with TBHP and $\mathrm{I}_{2} \cdot{ }^{53}$

The mechanism of the transformation of the hydrazone intermediate $\mathbf{1 8}$ into the tetracycle $\mathbf{1}$ is depicted in Scheme 6. It is proposed that the protonation of $\mathbf{1 8}$ to afford $\mathbf{A}$ would give $\mathbf{B}$ after tautomerization. In turn, the latter could become protonated $(\mathbf{C})$ and rearrange to $\mathbf{D}$ followed by rearomatization to give the anilino-iminium ion $\mathbf{E}$. Nucleophilic attack of the aniline of the iminium moiety would afford intermediate $\mathbf{F}$, which could then provide 1 after losing ammonia and then toluenesulfinic acid, driven by the possibility of aromatization.

Synthesis by Molina et al.. The Molina group, which has been active in the synthesis of indoloquinolines and related heterocycles through the use of intramolecular aza-Wittig reactions, presented in 1999 their total syntheses of both cryptotackieine (neocryptolepine) and isocryptolepine from a common key intermediate, via a selective indolization process. $^{54}$

In their rather long synthetic sequence, the phosphonium salt 27 was condensed with the azidobenzaldehyde 28 employing $\mathrm{K}_{2} \mathrm{CO}_{3}$ and dibenzo-18-crown-6, to give the stilbene

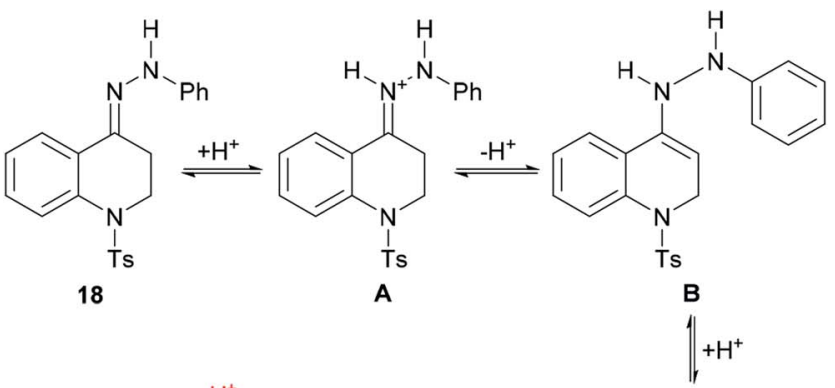

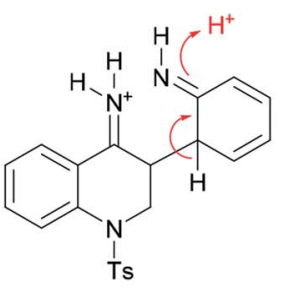

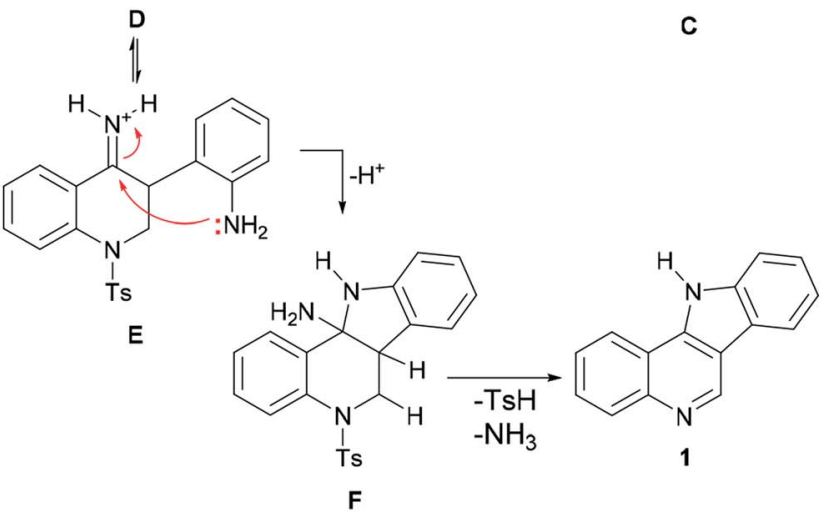

Scheme 6 Mechanism of the indolization of hydrazone 18 toward indoloquinoline 1. 
<smiles>O=[N+]([O-])c1ccccc1C[PbH3]</smiles><smiles>N#Cc1ccccc1N</smiles>

28
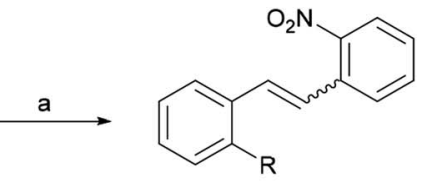

$29 \mathrm{R}=\mathrm{N}_{3}$

$\mathrm{b} \longrightarrow 30 \mathrm{R}=\mathrm{N}=\mathrm{Pn}-\mathrm{Bu}_{3}$
$\mathrm{c} \longrightarrow 31 \mathrm{R}=\mathrm{NH}_{2}$ d<smiles>Cc1ccccc1/C=C/c1ccccc1N=C=O</smiles><smiles>[R]n1c(=O)c(-c2ccccc2[N+](=O)[O-])cc2ccccc21</smiles><smiles>[R]c1ccccc1-c1cc2ccccc2n(C)c1=O</smiles>

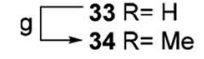<smiles></smiles><smiles>CCc1ccccc1NN</smiles>

\section{j}

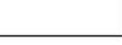

$\mathrm{R}=\mathrm{N}$

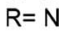

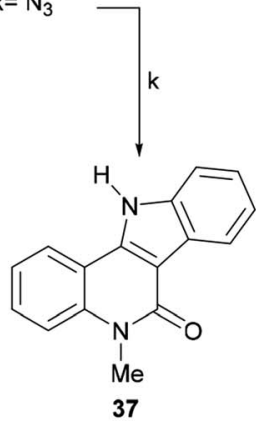

Scheme 7 Reagents and conditions: (a) $\mathrm{K}_{2} \mathrm{CO}_{3}$, dibenzo-18-crown-6, $\mathrm{CH}_{2} \mathrm{Cl}_{2}$, rt (85\%, Z/E = 4 : 1); (b) $n-\mathrm{Bu}_{3} \mathrm{P}, \mathrm{CH}_{2} \mathrm{Cl}_{2}, \mathrm{rt}$; (c) $\mathrm{THF}-\mathrm{H}_{2} \mathrm{O}$, rt $(84 \%, Z / E=7: 1)$; (d) $\mathrm{PhSH}, \mathrm{AlBN}, \mathrm{PhH}$, reflux (92\%); (e) triphosgene, $\mathrm{CH}_{2} \mathrm{Cl}_{2}, \mathrm{Et}_{3} \mathrm{~N}, 0{ }^{\circ} \mathrm{C} \rightarrow \mathrm{rt}, 1 \mathrm{~h}$; (f) $\mathrm{PhNO}_{2}, \mathrm{MW}, 150{ }^{\circ} \mathrm{C}, 12 \min (80 \%$ overall); (g) $\mathrm{CH}_{3} \mathrm{l}, \mathrm{DMF}, 60{ }^{\circ} \mathrm{C}(82 \%) ;(\mathrm{h}) \mathrm{H}_{2}, \mathrm{Pd} / \mathrm{C}, \mathrm{EtOH}, \mathrm{rt}(91 \%)$; (i) (1) $\mathrm{NaNO}_{2}, \mathrm{H}_{2} \mathrm{SO}_{4}$; (2) $\mathrm{NaN}_{3}, \mathrm{H}_{2} \mathrm{O}$ (85\%); (j) (1) $\mathrm{Me}_{3} \mathrm{P}, \mathrm{PhNO}_{2}, \mathrm{rt}, 45$ min; (2) $\mathrm{MW}, 180^{\circ} \mathrm{C}, 30 \mathrm{~min}$ ( $40 \%$ overall); (k) o-xylene, $150{ }^{\circ} \mathrm{C}$ (82\%); (l) Red-Al, PhMe, reflux, 32 h (90\%).

derivative 29 in $85 \%$ yield as a $4: 1$ mixture of $Z: E$ isomers (Scheme 7). Next, the Staudinger reaction of the azide 29 with $n$ $\mathrm{Bu}_{3} \mathrm{P}$ provided the iminophosphorane $\mathbf{3 0}$ which was hydrolyzed to the aniline 31 in $84 \%$ overall yield, as a mixture of isomers $(Z: E=7: 1)$. Subsequently, the catalytic isomerization of the double bond with the thiophenol/AIBN reagent system afforded $E$-aminostilbene 31 in $92 \%$ yield. This compound contains the nitrogen atoms required to install both heterocyclic rings.

Treatment of $\boldsymbol{E}-\mathbf{3 1}$ with triphosgene and further microwavepromoted cyclization of the resulting isocyanate 32 furnished the quinolin-2-one derivative 33 in $80 \%$ overall yield. ${ }^{55}$ The latter was next transformed into the common intermediate 36 by means of a three-step sequence involving $N$-methylation to give 34 ( $82 \%$ yield) followed by Pd/C-mediated catalytic hydrogenation to afford 35 in 91\% yield and final one-pot treatment of the amine with $\mathrm{HNO}_{2}$, and subsequent reaction of the resulting diazo intermediate with $\mathrm{NaN}_{3}$ to provide the azide derivative 36 in $85 \%$ yield.

The indolization of the azide $\mathbf{3 6}$ toward the framework of isocryptolepine was performed by refluxing the azide in orthoxylene, which afforded 37 (isocryptolepinone) in $82 \%$ yield. Interestingly, 37 was previously prepared from $N$-methyl-4azido-3-phenylquinolin-2-one, by refluxing in dimethylformamide (DMF) for $2 \mathrm{~h}$ (72\% yield) through quite a similar nitrenebased reaction, and in $61 \%$ yield via irradiation with a low pressure mercury lamp at room temperature for 4 h. ${ }^{56}$ More recently, the Sagar group reported the synthesis of the lactam 37 in $68 \%$ yield via the reductive cyclization of 34 under $\mathrm{MoO}_{2}$ $\mathrm{Cl}_{2}(\mathrm{DMF})_{2}$ catalysis. $^{57}$

Final reduction of the carbonyl moiety with Red-Al in toluene at reflux gave isocryptolepine (7) in 90\% yield. Interestingly, treatment of 36 with the highly reactive $\mathrm{Me}_{3} \mathrm{P}$ gave an intermediate iminophosphorane, which upon microwave irradiation in nitrobenzene at $150-180{ }^{\circ} \mathrm{C}$ for $30 \mathrm{~min}$ furnished cryptotackieine (6) in $40 \%$ yield via an aza-Wittig type reaction. ${ }^{58}$

Synthesis by Kundu et al. In 2009, the Kundu group reported an alternative synthesis of isocryptolepine.

Unlike most of the previous strategies, which relied predominantly on the formation of the indole by ring closure to culminate the synthesis, their approach was characterized by the formation of the quinoline ring in the final step. ${ }^{59}$

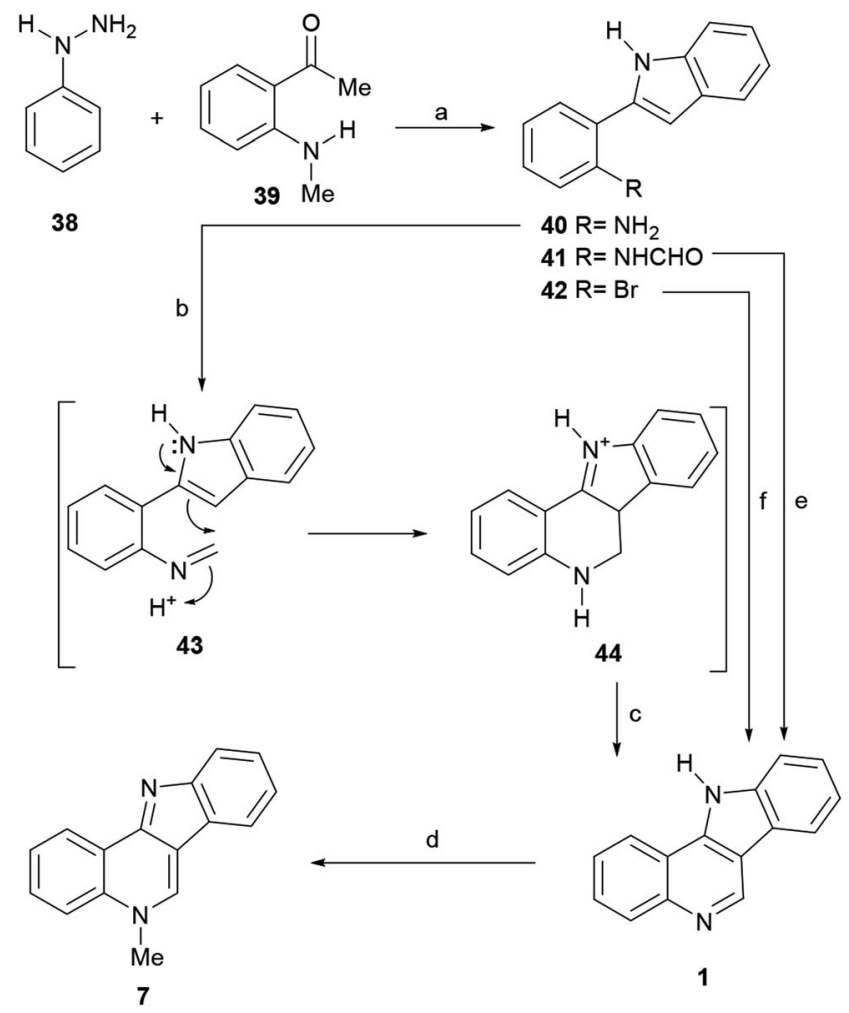

Scheme 8 Reagents and conditions: (a) (1) $\mathrm{AcOH}(5 \mathrm{~mol} \%), \mathrm{EtOH}, 6 \mathrm{~h}$; (2) PPA, $100{ }^{\circ} \mathrm{C}, 10 \mathrm{~min}$; (b) $\left(\mathrm{CH}_{2} \mathrm{O}\right)_{n}, \mathrm{TFA}, \mathrm{MeCN}, 80^{\circ} \mathrm{C}$ (sealed tube), 2 h; (c) air [O] (86\% overall); (d) Mel, PhMe, reflux, 2 h; (e) $\mathrm{Tf}_{2} \mathrm{O}, \mathrm{Ph}_{3} \mathrm{PO}$, r.t., $15 \mathrm{~min}$ (75\%), (f) (1) $\mathrm{HCOH}, \mathrm{Cul}$, L-proline, $\mathrm{NH}_{3} \cdot \mathrm{H}_{2} \mathrm{O}, \mathrm{K}_{2} \mathrm{CO}_{3}$, DMSO $100{ }^{\circ} \mathrm{C}, 12 \mathrm{~h}$; (2) $\mathrm{HCl}$, air, $120{ }^{\circ} \mathrm{C}, 8 \mathrm{~h}(32 \%)$. 
The sequence was based on Kundu's modified version of the Pictet-Spengler cyclization. ${ }^{60}$ To find the correct conditions, they first put in place a Fischer indole synthesis between phenylhydrazine (38) and 2-methylaminoacetophenone $(39)^{61}$ to afford the intermediate 40 (Scheme 8). ${ }^{62}$

The latter was then subjected to a Pictet-Spengler reaction with paraformaldehyde in the presence of TFA, to directly furnish the indoloquinoline 44. Presumably 44 was formed through the intermediacy of imine 43. In turn, 44 underwent spontaneous aerobic oxidation to afford 1 in $86 \%$ yield. ${ }^{63}$ Then, the tetracycle was subjected to selective $N$-methylation, by treatment with MeI in refluxing toluene to furnish isocryptolepine.

Interestingly, when exposed to Hendrickson's reagent $\left(\mathrm{Tf}_{2} \mathrm{O}\right.$ $\mathrm{PPh}_{3} \mathrm{O}$ ), the $N$-formyl derivative $\mathbf{4 1}$ gave $\mathbf{1}$ in $75 \%$ yield, through a regioselective 6-endo-cyclization. ${ }^{64}$ The precursor 41 was elaborated efficiently via a gold(III)-catalyzed 5-endo-dig cyclization. ${ }^{65}$ On the other hand, a regioselective copper-catalyzed onepot cascade reaction of bromoarene $\mathbf{4 2}$ with formaldehyde and aqueous ammonia in DMSO has been developed, which affords 1 in $32 \%$ yield. $^{66}$

First synthesis by Kraus et al. Kraus and coworkers developed a flexible and high yield synthesis of indoles based on the electrocyclic ring closure of the anion of a Schiff base derived

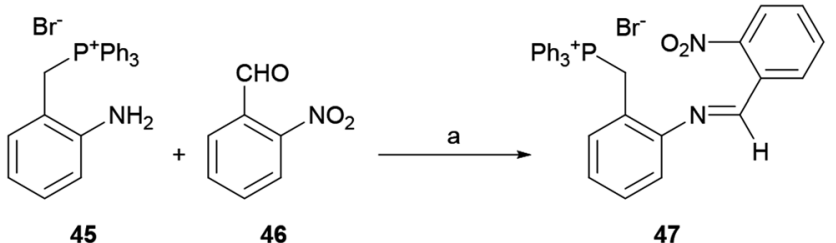

45

46
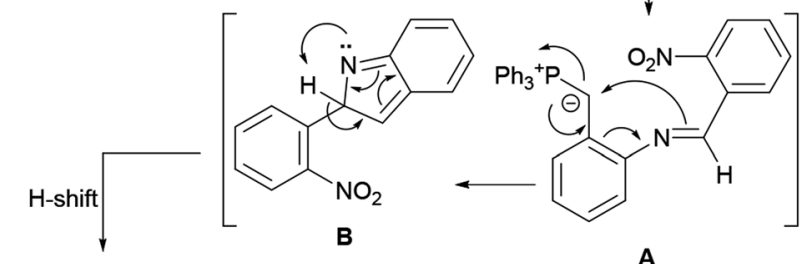

A<smiles>O=[N+]([O-])c1ccccc1-c1cc2ccccc2[nH]1</smiles>

48

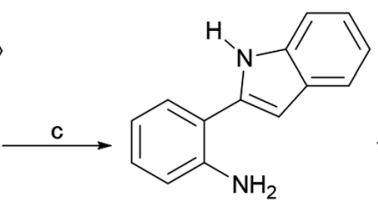

40

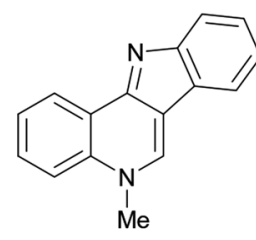

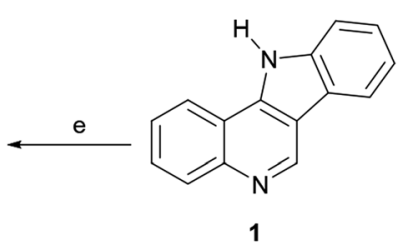

Scheme 9 Reagents and conditions: (a) (1) $\mathrm{AcOH}, \mathrm{MeOH}, \mathrm{MW}\left(80^{\circ} \mathrm{C}\right)$, $10 \min (72 \%) ;\left(\right.$ b) $\mathrm{K}^{t} \mathrm{BuO}, \mathrm{THF}, 25^{\circ} \mathrm{C}, 1 \mathrm{~h}$; (c) $\mathrm{Fe}^{0}, \mathrm{HCl}, \mathrm{EtOH}(90 \%)$; (d) $\left(\mathrm{CH}_{2} \mathrm{O}\right)_{n}$, TFA, MeCN, $80{ }^{\circ} \mathrm{C}(81 \%)$; (e) Mel, PhMe (91\%). from the reaction of the commercial 2-aminoarylbenzylphosphonium salt 45 with an aromatic aldehyde. ${ }^{67}$ In 2010, they applied their strategy to develop a formal total synthesis of isocryptolepine, starting with 2-nitrobenzaldehyde $(46) .{ }^{68}$

Thus, the required imine $\mathbf{4 7}$ was synthesized by a reaction between 45 and 46 under $\mathrm{AcOH}$ catalysis, employing microwave irradiation at $80{ }^{\circ} \mathrm{C}$ on a methanolic solution of the reactants (Scheme 9). The reaction of the as-formed nitro-imine 47 with $\mathrm{K}^{t} \mathrm{BuO}$ in $\mathrm{THF}$ at $0{ }^{\circ} \mathrm{C}$ gave the indole 48 in $72 \%$ overall yield, presumably through the anionic species $\mathbf{A}$, which may lose $\mathrm{PPh}_{3}$ after undergoing cyclization to the intermediate $\mathbf{B}$, which in turn undergoes a final $\mathrm{H}$-shift and aromatization.

Reduction of the nitro group with elemental iron $\left(\mathrm{Fe}^{0}\right)$ and $\mathrm{HCl}$ in $\mathrm{EtOH}$ to aniline $\mathbf{4 0}$ and further formylation of the indole moiety with paraformaldehyde and TFA with subsequent in situ cyclization completed the tetracycle 1 in $82 \%$ yield. Finally, according to Agarwal et al., ${ }^{59}$ the methylation of $\mathbf{1}$ with MeI in toluene gave 7 in $91 \%$ yield.

Second synthesis by Kraus et al. In 2010, the same group reported another application of the commercial 2-aminoarylbenzylphosphonium salt $\mathbf{4 5}$ as an alternative formal total synthesis of isocryptolepine. ${ }^{69}$ To that end (Scheme 10), they started with the known carboxylic acid 49, easily available from isatin in $92 \%$ yield, ${ }^{70}$ and prepared the acid chloride $\mathbf{5 0}$ by reaction with thionyl chloride or oxalyl chloride.

The product was coupled with the phosphonium bromide $\mathbf{4 5}$ and the resulting amide $\mathbf{5 1}$ was treated with potassium tertbutoxide at room temperature, where it underwent an intramolecular Wittig reaction to afford lactam 52 in $62 \%$ overall yield from 49.

The $N$-methylation of $\mathbf{5 2}$ with methyl iodide in the presence of $\mathrm{K}_{2} \mathrm{CO}_{3}$ in DMF gave 36 in $98 \%$ yield. This lactam is a key intermediate in the total synthesis of isocryptolepine by Molina. ${ }^{54 b}$ The latter group invested in nine steps to arrive at the intermediate 36 , in $22 \%$ overall yield, whereas this shortcut advantageously accomplished the same purpose in $60 \%$ yield over 4 steps in only two steps.

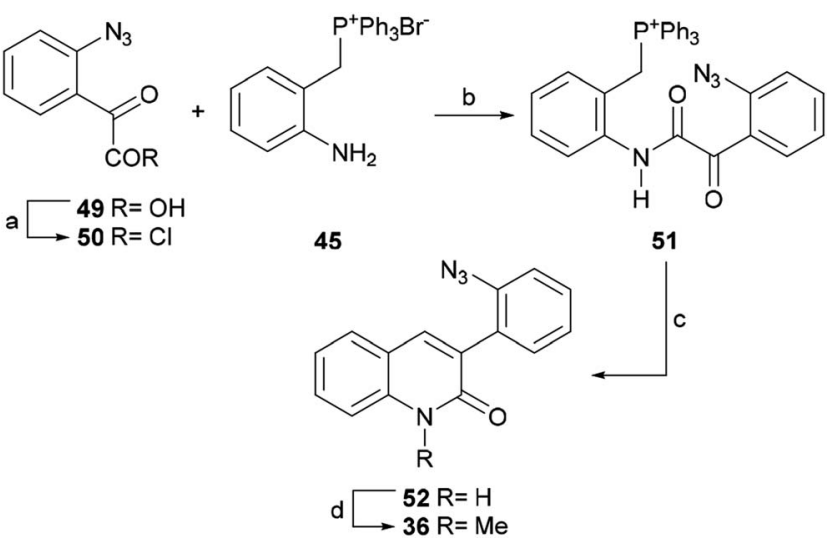

Scheme 10 Reagents and conditions: (a) $\mathrm{SOCl}_{2}, \mathrm{PhH}$, reflux, $1 \mathrm{~h}$ or $(\mathrm{COCl})_{2}, \mathrm{CH}_{2} \mathrm{Cl}_{2}, \mathrm{rt}, 3 \mathrm{~h}$; (b) $\mathrm{CH}_{2} \mathrm{Cl}_{2}, \mathrm{rt}, 12 \mathrm{~h}$; (c) $\mathrm{K}^{t} \mathrm{BuO}, \mathrm{THF}, \mathrm{rt}, 5 \mathrm{~h}(62 \%$ overall); (d) $\mathrm{Mel}, \mathrm{K}_{2} \mathrm{CO}_{3}, \mathrm{DMF}, 60{ }^{\circ} \mathrm{C}, 8 \mathrm{~h}(98 \%)$. 
<smiles>CCCCc1cccc(N)c1-c1ccc(C)o1</smiles><smiles>CC[PH2+]=Nc1ccccc1-c1ccc(C)o1</smiles>

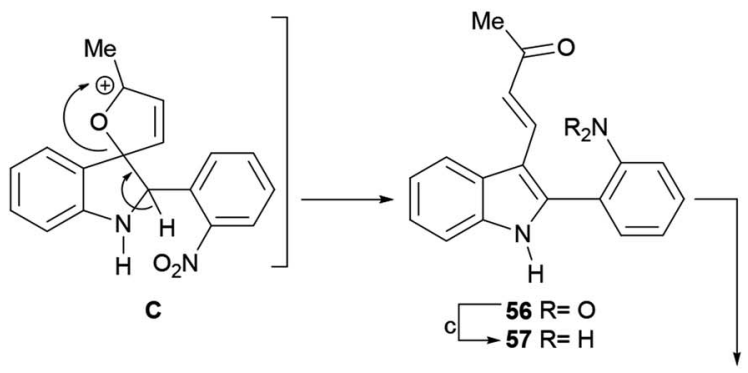

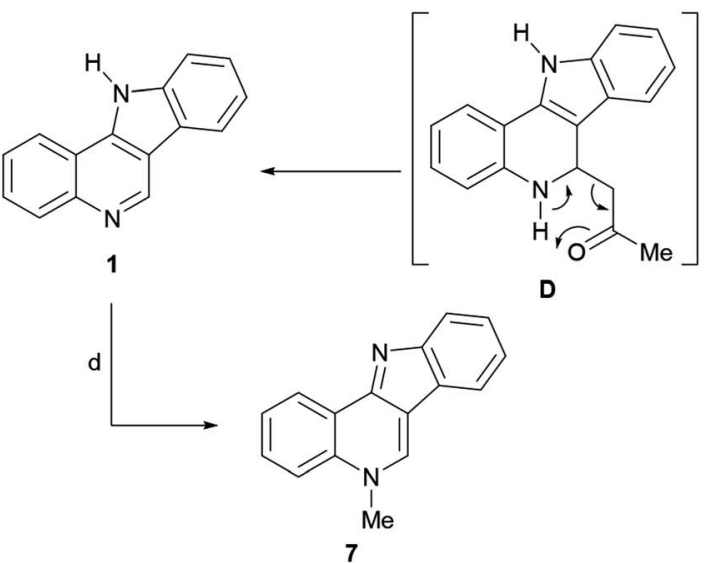

Scheme 11 Reagents and conditions: (a) (1) $\mathrm{HCl}, 30 \mathrm{~min}, 80{ }^{\circ} \mathrm{C}$; (2) $\mathrm{NaNO}_{2}, 0^{\circ} \mathrm{C}, 40$ min; (3) furfural, $\mathrm{CuCl}_{2}, \mathrm{H}_{2} \mathrm{O}$ (53\%); (4) $\mathrm{NaBH}_{4}, \mathrm{AlCl}_{3}$, THF, $0{ }^{\circ} \mathrm{C}, 20 \mathrm{~min}$; then reflux, $2 \mathrm{~h}(67 \%) ;(5) \mathrm{RANEY} \otimes$ nickel, $\mathrm{NH}_{2} \mathrm{NH}_{2}$, EtOH, reflux, $2 \mathrm{~h}(76 \%)$; (b) $2-\mathrm{NO}_{2} \mathrm{C}_{6} \mathrm{H}_{4} \mathrm{CHO}, \mathrm{HCl}, \mathrm{AcOH}, 30-35{ }^{\circ} \mathrm{C}$, $1.5 \mathrm{~h}(58 \%) ;$ (c) $\mathrm{Fe}^{\mathrm{O}}, \mathrm{AcOH}$, reflux, $5 \mathrm{~min}$ (86\%); (d) (1) $\mathrm{Mel} \mathrm{PhNO}_{2}$; (2) $\mathrm{NH}_{4} \mathrm{OH}, \mathrm{H}_{2} \mathrm{O}(86 \%)$.

Synthesis by Butin et al.. The Butin group developed a procedure for the transformation of furfural (53) into 2-furylaniline (55). This was performed via a coupling reaction between 53 and the diazo-derivative of 2-nitroaniline (54), followed by sequential reductive deoxygenation of the nitro and formyl moieties. ${ }^{71}$ The authors demonstrated that compound $\mathbf{5 5}$ can be further transformed into 3-(2-acylvinyl)-2-(hetero) arylindole (56) through an unusual furan-to-indole recyclization process (Scheme 11). ${ }^{72}$ The substrate scope of this imaginative approach to the synthesis of more complex indole derivatives was demonstrated by the authors through the total synthesis of isocryptolepine (7) and the preparation of differently decorated analogs of the natural product. ${ }^{73}$

The reaction of $\mathbf{5 5}$ with 2-nitrobenzaldehyde afforded the expected indole derivative 56, but in comparative lower yield $(58 \%)$ than for other aldehydes. This was explained as being the result of a combination of unfavorable steric and electronic effects of the ortho-nitro moiety, which affected the iminium ion attack on the furan ring.

A possible reaction mechanism includes a first step, where the Schiff base $\mathbf{A}$ is formed by the condensation of $\mathbf{5 5}$ with the aldehyde. Then, protonation of this intermediate (B) should drive the ring opening of the furan motif and afford the oxaazaspirocyclic intermediate $\mathbf{C}$, which after undergoing ring opening of the dihydrofuran moiety triggered by aromatization of the nitrogen ring, affords the 2-substituted indole 56.

In the next stage, the reduction of the nitro group, various reagent systems were studied $\left(\mathrm{Zn} / \mathrm{AcOH}, \mathrm{Zn} / \mathrm{NaOH}, \mathrm{RANEY}{ }^{\circledR}\right.$ nickel, $\mathrm{Fe} / \mathrm{AcOH}$ ), with the finding that $\mathrm{Fe}$ in $\mathrm{AcOH}$ directly affords the indoloquinoline 1 in $86 \%$ yield. The formation of 1 could result from the reduction of the nitro group to the corresponding aniline 57, followed by an intramolecular Michael addition to give intermediate $\mathbf{D},{ }^{74}$ and aromatization of the pyridine ring of the latter via the rather unusual elimination of acetone. ${ }^{75}$ For the $N$-methylation stage, the best result $(86 \%$ yield) was obtained using the Kermack-Storey procedure, employing MeI in nitrobenzene. ${ }^{43}$

Synthesis by Bogányi and Kámán. In 2013, Bogányi and Kámán synthesized different indoloquinoline skeletons from bromoiodoquinolines via the consecutive application of two Pd-

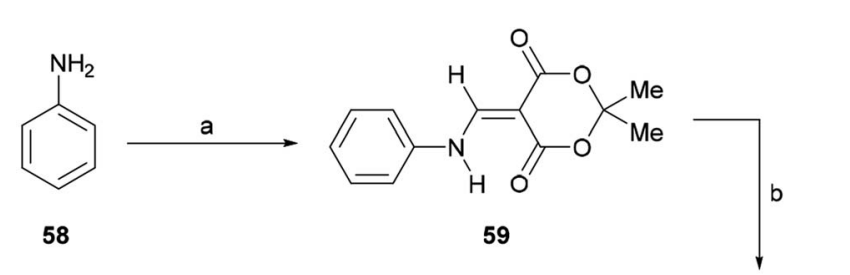<smiles>O=c1cc[nH]c2ccccc12</smiles><smiles>O=C(Cc1ccccc1)c1ccc2ncc(Br)c(Nc3ccccc3)c2c1</smiles>

Scheme 12 Reagents and conditions: (a) Meldrum's acid, $\mathrm{HC}(\mathrm{OMe})_{3}$, reflux (77\%); (b) $\mathrm{Ph}_{2} \mathrm{O}, 250{ }^{\circ} \mathrm{C}$ (92\%); (c) $\mathrm{Br}_{2}, \mathrm{AcOH}$, reflux (99\%); (d) $\mathrm{POCl}_{3}, \mathrm{MeCN}$, reflux (93\%); (e) Nal, MeCN, reflux (55\%); (f) $\mathrm{PhNH}_{2}$, $\mathrm{Pd}(\mathrm{OAc})_{2}$, Xantphos, $\mathrm{Cs}_{2} \mathrm{CO}_{3}, \mathrm{PhMe}, \mathrm{MW}\left(120{ }^{\circ} \mathrm{C}\right), 1.5 \mathrm{~h}(95 \%) ;(\mathrm{g})$ $\mathrm{PdCl}_{2}\left(\mathrm{PPh}_{3}\right)_{2}, \mathrm{NaOAc}, \mathrm{DMA}, \mathrm{MW}\left(150^{\circ} \mathrm{C}\right), 1 \mathrm{~h}(64 \%)$. 
catalyzed reactions, namely a regioselective Buchwald-Hartwig amination and a subsequent Heck-type biaryl coupling.

Their contribution included the preparation of the tetracycle 1, which constitutes a formal total synthesis of isocryptolepine. $^{76}$ For this purpose, the authors specifically prepared the 3,4-dihaloquinoline 63 (Scheme 12).

The key $1 H$-quinolin-4-one intermediate $\mathbf{6 0}$ was obtained in $77 \%$ yield, via the condensation of the aniline 58 with Meldrum's acid in the presence of trimethyl orthoformate to afford 59, followed by cyclative thermolysis of the latter in diphenyl ether. ${ }^{77}$ The direct halogenation of 60 with bromine in $\mathrm{AcOH}^{78}$ gave the expected 3-bromo-1H-quinolin-4-one 61 in $99 \%$ yield, whilst treatment of the latter with $\mathrm{POCl}_{3}$ afforded 3-bromo-4chloroquinoline (62) in93\% yield. Final installation of an iodide motif was accomplished via a Finkelstein-like displacement of the chloride with $\mathrm{NaI}$ in MeCN, affording the desired heterocycle 63 in $55 \%$ yield. ${ }^{79}$

Next, the dihaloquinoline $\mathbf{6 3}$ was coupled with aniline in toluene, employing palladium catalysis, with Xantphos as a ligand and $\mathrm{Cs}_{2} \mathrm{CO}_{3}$ as a base, under microwave irradiation at $120{ }^{\circ} \mathrm{C}$ for $90 \mathrm{~min}$, to selectively afford 64 in 95\% yield. Final cyclization of $\mathbf{6 4}$ to the indoloquinoline motif $\mathbf{1}$ was performed in $64 \%$ yield, through an intramolecular Heck-type reaction in DMA, under microwave irradiation $\left(1 \mathrm{~h}\right.$ at $\left.150{ }^{\circ} \mathrm{C}\right)$, using $\mathrm{PdCl}_{2}\left(\mathrm{PPh}_{3}\right)_{2}$ as a catalyst and NaOAc as a base. ${ }^{\mathbf{8 0}}$

The Maes group prepared analogous intermediates through a different synthetic sequence and developed several syntheses of various indoloquinolines. An interesting advantage of the Kámán synthesis over the previous reports by Maes et al. on the tandem palladium-catalyzed approaches to indoloquinolines is that in the latter cases, small amounts of the undesired regioisomer were detected after the ring closure. ${ }^{10 a, 80}$

Synthesis by Lu, Xu et al.. Organic electrosynthesis, which employs electrons as reagents, ${ }^{\mathbf{1 1}}$ has been demonstrated to be a versatile and environmentally friendly tool for the synthesis of structurally complex compounds. ${ }^{82} \mathrm{Lu}, \mathrm{Xu}$ and coworkers developed an electrochemical method for generating amidyl radicals and demonstrated that these species could participate in cascade cyclization reactions ${ }^{83}$ to afford indolines. ${ }^{84}$

Their approach was applied in 2016 to the synthesis of highly functionalized indoles, including isocryptolepine, via $\mathrm{C}-\mathrm{H} / \mathrm{N}-\mathrm{H}$ functionalization of (hetero)-arylamines with tethered alkynes. ${ }^{85}$ The synthesis (Scheme 13) commenced with a Sonogashira cross-coupling between $N$-methyl-2-iodoaniline (65) and the acetylenic acetal 66 in $\mathrm{Et}_{3} \mathrm{~N}-\mathrm{THF}$ at room temperature. The subsequent reaction of the resulting intermediate, obtained in $81 \%$ yield, with phenylisocyanate in toluene, gave the urea 67 in $78 \%$ yield.

Compound 67 became a suitable substrate for the electrolysis, which was carried out at a constant current of $10 \mathrm{~mA}$ on the gram-scale, in the presence of ferrocene as a redox relay reagent. The electrolyte was a mixture of sodium carbonate and tetrabutylammonium tetrafluorborate in THF-MeOH. A platinum plate was used as a cathode and reticulated vitreous carbon served as an anode.

This process afforded the tetracyclic acetalic compound 68, which after its subsequent acid-promoted hydrolysis resulted in

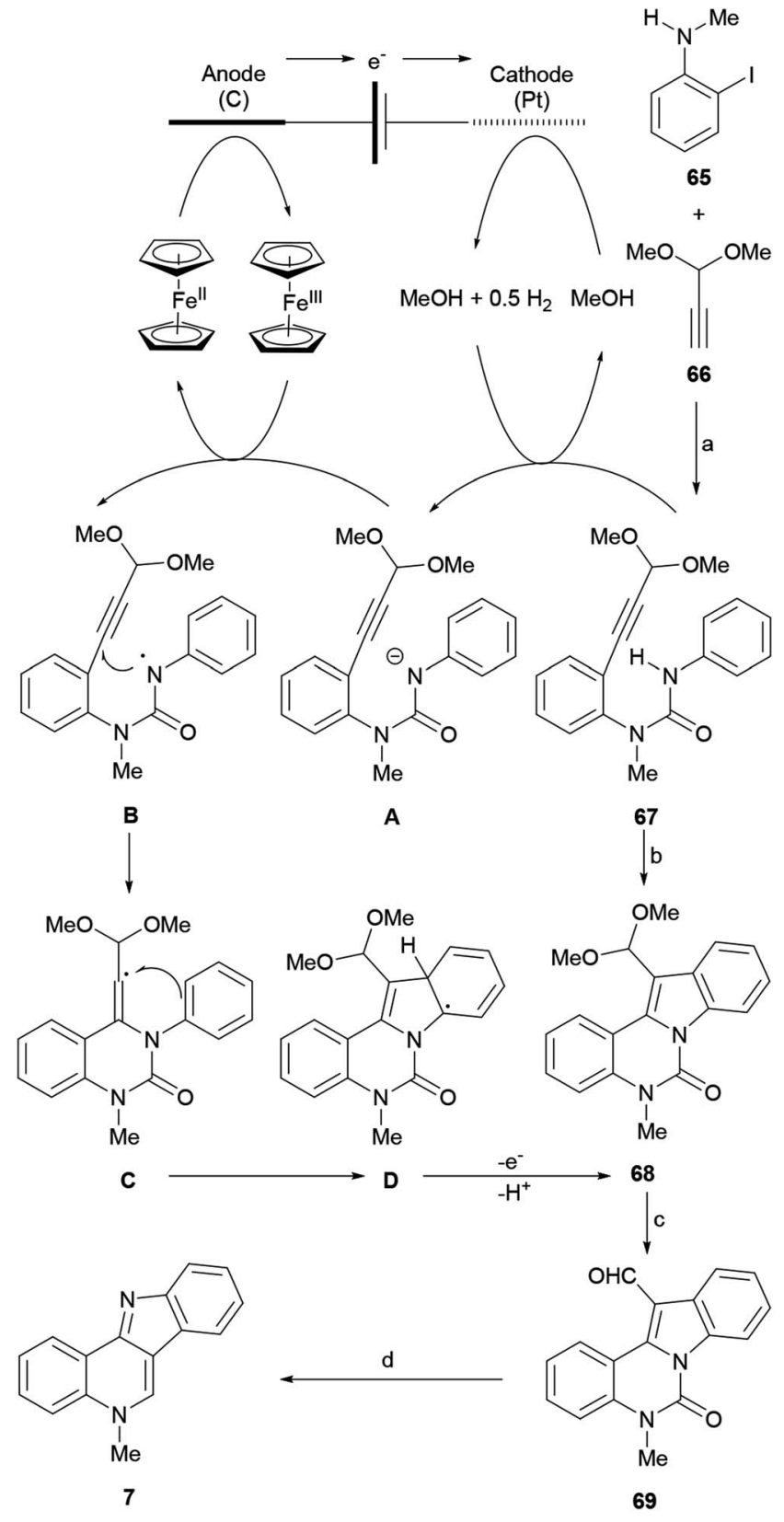

Scheme 13 Reagents and conditions: (a) (1) $\mathrm{Pd}\left(\mathrm{Ph}_{3} \mathrm{P}\right)_{2} \mathrm{Cl}_{2}, \mathrm{Cul}, \mathrm{Et}_{3}-$ $\mathrm{N}: \operatorname{THF}(1: 1, \mathrm{v} / \mathrm{v}), \mathrm{rt}, 12 \mathrm{~h}(81 \%)$; (2) PhNCO, $\mathrm{Et}_{3} \mathrm{~N}, \mathrm{PhMe}, \mathrm{rt}, 48 \mathrm{~h}(78 \%)$; (b) $\mathrm{Cp}_{2} \mathrm{Fe}, \mathrm{MeOH}: \operatorname{THF}(1: 5, \mathrm{v} / \mathrm{v}), \mathrm{Na}_{2} \mathrm{CO}_{3},{ }^{n} \mathrm{Bu}_{4} \mathrm{NBF}_{4}$, reflux, $20 \mathrm{~h}$; electrolysis at constant current $(5 \mathrm{~mA})$ with a reticulated vitreous carbon anode, Pt cathode; (c) $0.2 \mathrm{~N} \mathrm{HCl}, \mathrm{rt}, 30 \mathrm{~min}$ (63\% overall); (d) $\mathrm{NaOH}, \mathrm{EtOH}$, reflux, $2 \mathrm{~h}(91 \%)$.

the formation of the formyl-substituted indole 69 in $63 \%$ overall yield. Compound 69 was readily transformed into isocryptolepine (7) in one step and 91\% yield, via the basepromoted hydrolysis of the urea motif, which freed the $\mathrm{N}$ methylaniline moiety, enabling its spontaneous intramolecular condensation with the free formyl group. Among the advantages of this approach are the facts that it proceeds through the liberation of $\mathrm{H}_{2}$ and does not require the use of noble-metal catalysts and external oxidants for the cyclization stages. 
A plausible mechanism for the electrochemical formation of the product was proposed based on previous studies. ${ }^{84}$ Accordingly, the anodic oxidation of $\left[\mathrm{Cp}_{2} \mathrm{Fe}\right]$ to $\left[\mathrm{Cp}_{2} \mathrm{Fe}\right]^{+}$takes place with the concomitant cathodic reduction of $\mathrm{MeOH}$ to form the methoxide anion and release $\mathrm{H}_{2}$. Then, the base deprotonates the amino group of the substrate $\mathbf{6 7}$ to furnish the anion $\mathbf{A}$, which is a much better electron donor than its neutral precursor.

Therefore, single-electron transfer (SET) takes place between intermediate $\mathbf{A}$ and $\left[\mathrm{Cp}^{2} \mathrm{Fe}\right]^{+}$to afford the electron-deficient nitrogen-centered radical $\mathbf{B}^{86}$ and regenerate $\mathrm{Cp}_{2} \mathrm{Fe}^{87}$ It was suggested that the SET is so efficient, that it competes well with the cathodic reduction of $\left[\mathrm{Cp}_{2} \mathrm{Fe}\right]^{+}$, enabling the electrolysis to be executed in an undivided cell. Next, the intermediate $\mathbf{B}$ participates in a rare 6-exo-dig cyclization ${ }^{83}$ to give the vinyl radical $\mathbf{C}$, which then undergoes a second cyclization with the aryl ring, to afford the delocalized tetracyclic radical D. Finally, the rearomatization of the latter by electron and proton eliminations generates the product 68 .

Synthesis by Aksenov et al. The 2009 synthesis of isocryptolepine by Kundu and co-workers comprised four steps, which involved a Fischer indolization to build a suitable 2-arylindole intermediate and the installation of the quinoline ring via an oxidative Pictet-Spengler type reaction of an $\mathrm{N}$-arylmethanimine, in $\sim 50 \%$ overall yield. Shortly after, Aksenov and coworkers developed a sequential three-component heteroannulation reaction toward 3-aryl-2-quinolones that proceeds via a cascade transformation and involves a Fisher indole synthesis with PPA as the reaction medium. The authors observed that the $\mathrm{P}_{2} \mathrm{O}_{5}$-water ratio can be accurately tuned in the promoter to provide optimal yields of the cyclized product, and proposed to use their development for a simplified and improved total synthesis of isocryptolepine, under the original retrosynthetic guidelines of Kundu. ${ }^{88}$

In that direction, in 2017 Aksenov et al. conjectured that PPA could promote a one pot synthesis of the intermediate hydrazone 70 required $^{89}$ for Fischer indolization (Scheme 14), as well as drive to completion the formation of the indole moiety (71), and also participate in the subsequent intramolecular Vilsmeier reaction between an aromatic amine and a carboxylic acid, for the final cyclization leading to isocryptolepine (7). ${ }^{\mathbf{9 0}}$

However, PPA failed to promote the synthesis of the hydrazone between ortho-aminoacetophenone (39) and phenylhydrazine (38), favoring self-condensation of the ketone, and this step had to be performed in $\mathrm{EtOH}$ under formic acid catalysis $^{\mathbf{9 1}}$ or even better, under solventless conditions, for $10 \mathrm{~min}$ at $120^{\circ} \mathrm{C}$. Furthermore, despite PPA was able to promote the Vilsmeier cyclization with various carboxylic acids, but formic acid proved to be unstable to the reaction conditions, decomposing into $\mathrm{CO}$ and $\mathrm{CO}_{2}$ and furnishing 7 in only $25 \%$ yield. ${ }^{92}$

Therefore, a formic acid surrogate was sought and triazine was proposed to fulfill this place. The authors found that once hydrazone $\mathbf{7 0}$ was formed, it could be treated with PPA to afford indole $\mathbf{7 1}$, and shortly after with triazine (72) to produce isocryptolepine as the sole reaction product in an optimized $82 \%$ yield, using a convenient metal-free process.

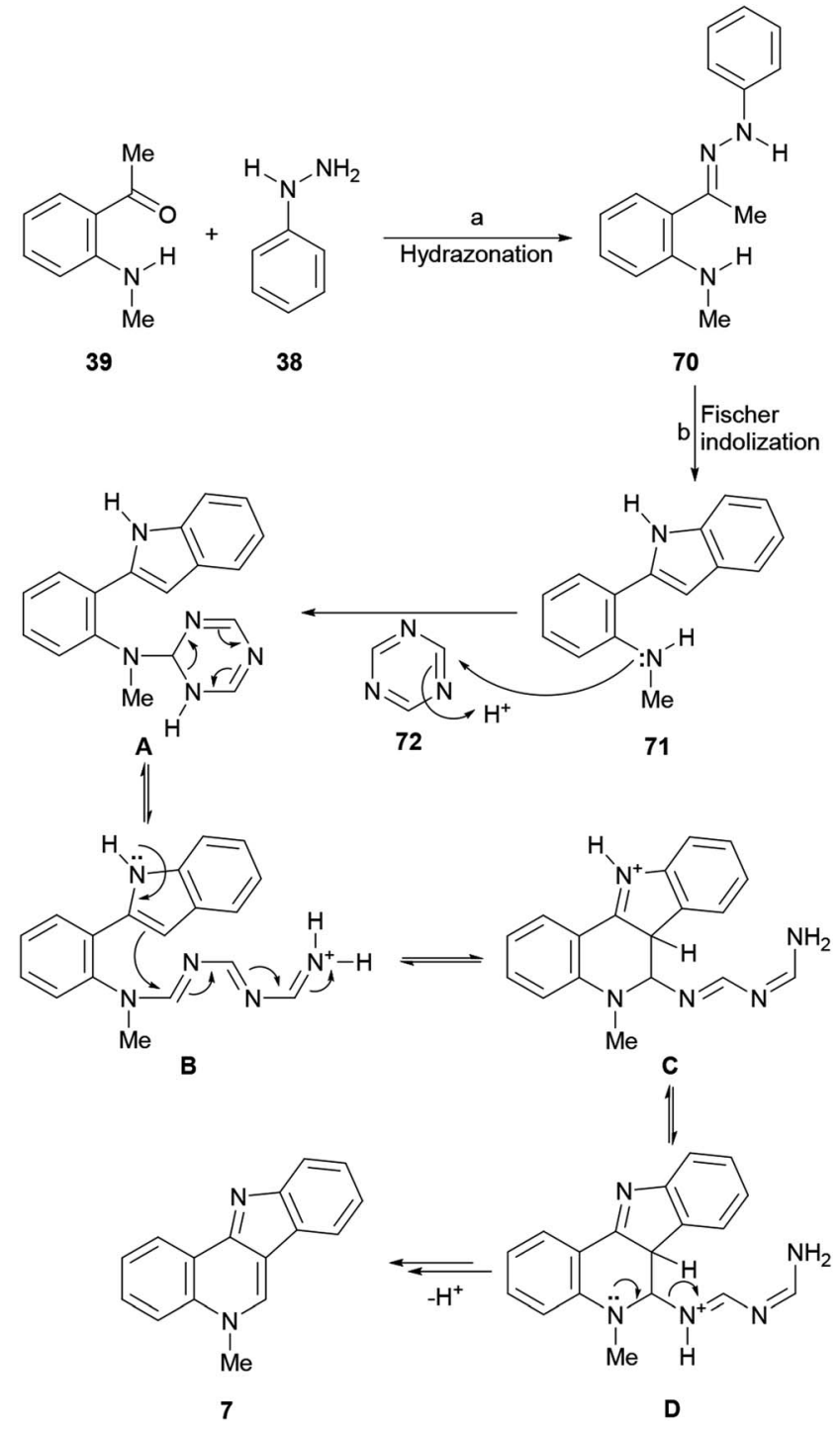

Scheme 14 Reagents and conditions: (a) $\mathrm{HCO}_{2} \mathrm{H}$ (cat.), EtOH, reflux, $30 \mathrm{~min}$, or neat, $120^{\circ} \mathrm{C}, 20 \mathrm{~min}$; (b) $80 \% \mathrm{PPA}, 80^{\circ} \mathrm{C}, 2 \mathrm{~h}$; $130{ }^{\circ} \mathrm{C}, 90 \mathrm{~min}$ (83\%).

The proposed reaction mechanism of the transformation involving triazine as a formic acid equivalent comprises the addition of the triazine (72) to the Fischer indolization product 71 to produce species A. Next, ring opening of the dihydrotriazine and subsequent intramolecular electrophilic attack of the resulting linear species B at C3 of the indole furnishes the six-membered heterocyclic ring (C). Finally, proton transfer, followed by an elimination (D) anchimerically-assisted by the quinoline nitrogen, affords isocryptolepine. An alternate deprotonation/elimination sequence leading to 7 has also been proposed. In addition, the same group devised a second generation PPA-mediated one-pot three-component synthesis of the indoloquinoline scaffold employing nitroalkanes. The use of $\mathrm{MeNO}_{2}$ in place of the triazine 72 furnished $7 .{ }^{93}$

Interestingly, the use of dimethyl sulfoxide (DMSO) as a onecarbon atom synthon in a similar transformation leading to the unsubstituted indoloquinoline skeleton in $69 \%$ yield was 
recently reported. ${ }^{94}$ In this case, it was proposed that two mechanistic pathways are possible. In the first case, at high temperature, DMSO may generate methyl radicals $\left(\mathrm{Me}^{\circ}\right)$, which can react with $\mathrm{O}_{2}$ to produce a peroxy radical and then $\mathrm{CH}_{2} \mathrm{O} .{ }^{95}$ In turn, this could result in imine formation and a subsequent electrophilic aromatic substitution to produce the observed product. It is also possible that DMSO could decompose at high temperature, and produce $\mathrm{CH}_{2} \mathrm{O}$ directly. ${ }^{\mathbf{9 6}}$

\section{4c. Syntheses from quinolines}

The total syntheses of isocryptolepine, which employs quinolines as starting materials, comprise synthetic efforts where haloquinolines or 1,2,3,4-tetrahydroquinolin-4-one derivatives were employed. They complement other accomplishments, such as that of Bogányi and Kámán, ${ }^{76}$ where quinolines were prepared as intermediates from structurally simple benzenoids.

Synthesis by Tímari et al.. The first total synthesis of isocryptolepine starting from quinolines was reported in 1997 by the Tímari group (Scheme 15). ${ }^{97}$ The sequence resorted to a Suzuki cross-coupling ${ }^{98}$ reaction between $N$-pivaloylamino phenylboronic acid (74) ${ }^{99}$ and 3-bromoquinoline (73) to afford the biaryl derivative 75 in $90 \%$ yield. Next, the acid-catalyzed removal of the protecting group furnished $93 \%$ yield of the free amine 76, which was subjected to a one-pot diazotization and subsequent reaction with $\mathrm{NaN}_{3}$ to deliver the azide derivative 77 in $80 \%$ overall yield. ${ }^{\mathbf{1 0 0}}$

The thermal cyclization of 77 was executed in refluxing dichlorobenzene, and proceeded in $70 \%$ yield to exclusively furnish the required tetracycle 1 in $75 \%$ yield, ${ }^{101}$ by way of a singlet nitrene intermediate that inserts into the $\mathrm{C} 4-\mathrm{H}$ bond. The reaction of 1 with $\mathrm{Me}_{2} \mathrm{SO}_{4}$ in $\mathrm{MeCN}$ resulted in the

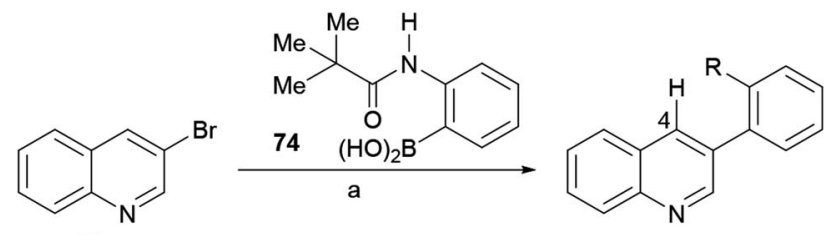

73

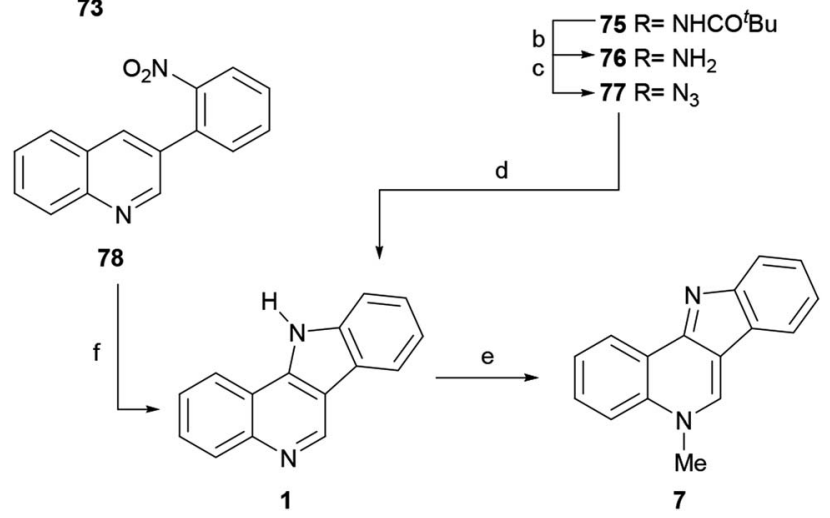

Scheme 15 Reagents and conditions: (a) $\mathrm{Pd}(0), \mathrm{DME}, \mathrm{H}_{2} \mathrm{O}, \mathrm{NaHCO}_{3}$, reflux, $4 \mathrm{~h}$ (90\%); (b) $20 \% \mathrm{H}_{2} \mathrm{SO}_{4}$, reflux, $24 \mathrm{~h} \mathrm{(93 \% );} \mathrm{(c)} \mathrm{(1)} \mathrm{NaNO}_{2}, \mathrm{HCl}$ (conc.), $0{ }^{\circ} \mathrm{C}, 1 \mathrm{~h}$; (2) $\mathrm{NaN}_{3}, 0{ }^{\circ} \mathrm{C}, 1 \mathrm{~h}(80 \%)$; (d) $1,2-\mathrm{Cl}_{2} \mathrm{C}_{6} \mathrm{H}_{4}, 180{ }^{\circ} \mathrm{C}, 5 \mathrm{~h}$ (75\%); (e) (1) $\mathrm{Me}_{2} \mathrm{SO}_{4}, \mathrm{CH}_{3} \mathrm{CN}$, reflux, $5 \mathrm{~h}$; (2) $\mathrm{K}_{2} \mathrm{CO}_{3}, \mathrm{H}_{2} \mathrm{O}$ (93\%); (f) $\mathrm{PhMgBr}, \mathrm{THF}, \mathrm{O}^{\circ} \mathrm{C}, 15 \mathrm{~min}(46 \%)$. regioselective alkylation of the pyridine nitrogen, affording isocryptolepine (7) in 93\% yield after freeing the base by treatment with potassium carbonate.

An alternate pathway for accessing 1 in one pot and $46 \%$ yield from $\mathbf{7 8}$ was recently disclosed by Ess, Kürti and coworkers, through the electrophilic amination of the quinoline C4-H bond with PhMgBr. ${ }^{\mathbf{1 0 2}}$ On the other hand, the Sydnes group disclosed the preparation of tetracycle 1 from the aniline derivative 76 in $73 \%$ yield, employing a palladium-catalyzed $\mathrm{C}-\mathrm{H}$ activation/C-N bond formation strategy. ${ }^{103}$

Syntheses by Maes et al.. In 2003, the Maes group ${ }^{\mathbf{1 0 4}}$ developed a three-step synthesis of isocryptolepine (Scheme 16) based on the combination of two selective Pd-catalyzed transformations, namely a Buchwald-Hartwig reaction ${ }^{105}$ and an intramolecular direct arylation. ${ }^{\mathbf{1 0 6}}$ Thus, the arylamination of 4chloroquinoline ${ }^{\mathbf{1 0 7}}$ (11) and 79 with $\mathrm{Pd}(\mathrm{OAc})_{2}$ and $\mathrm{K}_{2} \mathrm{CO}_{3}$ as a base, in refluxing dioxane, afforded the amine 81 in $60 \%$ yield when BINAP was employed as the metal ligand.

However, the use of Xantphos as a ligand improved the yield to $81 \%$ when $\mathrm{Cs}_{2} \mathrm{CO}_{3}$ was employed as a base. ${ }^{108}$ In order to execute the required direct arylation of $\mathbf{8 1}$, a nucleophilic palladium catalyst system better than Pd/BINAP was deemed necessary. ${ }^{109}$ Therefore, trialkylphosphine ligands, which are more electron rich than their triaryl counterparts, were examined, with the finding that the cyclization could be carried out to afford a 95\% yield of 1 when tributylphosphine was used, ${ }^{110}$ in the presence of potassium phosphate.

The direct arylation leading to $\mathbf{1}$ was considered a notable example of the intramolecular Pd-catalyzed arylation of an electron-deficient heteroaromatic. Examples of these reactions are scarcer in the literature compared to those of electron-rich

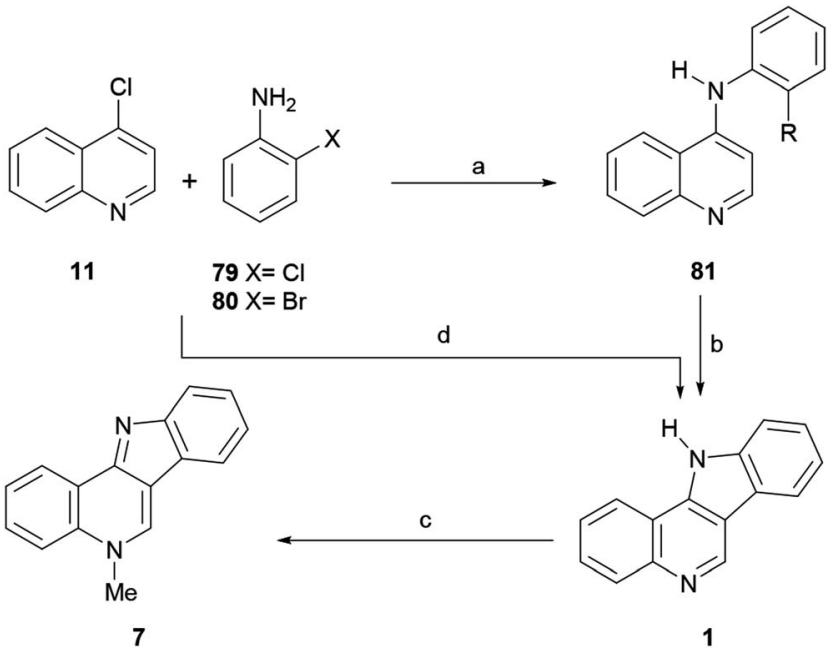

Scheme 16 Reagents and conditions: (a) $\mathrm{Pd}(\mathrm{OAc})_{2}, \mathrm{BINAP}, \mathrm{K}_{2} \mathrm{CO}_{3}$, dioxane, reflux, overnight $(60 \%)$, or $\mathrm{Pd}_{2}(\mathrm{dba})_{3}$, Xantphos, $\mathrm{Cs}_{2} \mathrm{CO}_{3}$, dioxane, reflux, overnight $(81 \%) ;\left(\right.$ b) $\mathrm{Pd}_{2}(\mathrm{dba})_{3}, \mathrm{P}(t-\mathrm{Bu})_{3}, \mathrm{~K}_{3} \mathrm{PO}_{4}$, dioxane, $120{ }^{\circ} \mathrm{C}$ (closed vessel), $3 \mathrm{~h} \mathrm{(95 \% );} \mathrm{(c)} \mathrm{(1)} \mathrm{CH}_{3} \mathrm{l}, \mathrm{DMF}, 80^{\circ} \mathrm{C}, 1 \mathrm{~h}$; (2) overnight, r.t.; (3) aq. $\mathrm{Na}_{2} \mathrm{CO}_{3}$ (57\%); (d) $\mathrm{Pd}_{2} \mathrm{Cl}_{2}(\mathrm{dba})_{3}$ (5 mol\%), $\mathrm{P}(\mathrm{Bu})_{3}(20 \mathrm{~mol} \%), \mathrm{K}_{3} \mathrm{PO}_{4}(20 \mathrm{~mol} \%)$, dioxane, $125^{\circ} \mathrm{C}$ closed vessel, $24 \mathrm{~h}$ (82\%, from 79, $\mathrm{R}=\mathrm{Cl}$ ) or $\mathrm{PdCl}_{2}\left(\mathrm{PPh}_{3}\right)_{2}$ (1 mol\%), $\mathrm{NaOAc} \cdot 3 \mathrm{H}_{2} \mathrm{O}$ (1.47 mol\%), DMA, MW, $200{ }^{\circ} \mathrm{C}, 10$ min (79\%, from 80, R = Br). 
<smiles>Cn1c(=O)cc(O)c2ccccc21</smiles>

82<smiles></smiles><smiles>NNc1ccccc1</smiles>

38

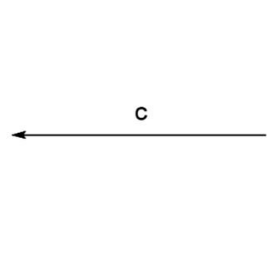<smiles></smiles><smiles>C=CC</smiles><smiles>[R]c1c2c3ccccc3nc-2c2ccccc2n1C</smiles>

$\mathrm{b}-83 \mathrm{R}=\mathrm{OH}$
Scheme 17 Reagents and conditions: (a) $\mathrm{AcOH}_{\mathrm{gl}} / 12 \mathrm{~N} \mathrm{HCl}$ (4:1), $135{ }^{\circ} \mathrm{C}, 5 \mathrm{~h}(65 \%) ;\left(\right.$ b) $\mathrm{POCl}_{3}, 100{ }^{\circ} \mathrm{C}, 8$ h (62\%); (c) $\mathrm{H}_{2}, 10 \% \mathrm{Pd} / \mathrm{C}(70 \%)$.

heteroarenes. ${ }^{111}$ Final, methylation of 1 with MeI in DMF, followed by treatment with $\mathrm{Na}_{2} \mathrm{CO}_{3}$ to release the base, afforded isocryptolepine (7) in 57\% yield.

The synthetic strategy was further improved by these authors in $2008,{ }^{112}$ with the development of an auto-tandem palladiumcatalyzed consecutive $\mathrm{C}-\mathrm{N}$ and $\mathrm{C}-\mathrm{C}$ bond forming process, which enabled the coupling of 4-chloroquinoline (11) and 2chloroaniline (79), somehow reminiscent of the auto-tandem syntheses of other carbazole systems. ${ }^{\mathbf{1 0 6}, \mathbf{1 1 3}}$ Employing the catalytic system previously used for the direct arylation $\left[\mathrm{Pd}_{2}\right.$ $\left.\mathrm{Cl}_{2}(\mathrm{dba})_{3}, \mathrm{P}\left({ }^{t} \mathrm{Bu}\right)_{3}\right]$, with $\mathrm{K}_{3} \mathrm{PO}_{4}$ as a mild base for improved compatibility, the tetracyclic compound 1 was obtained in $82 \%$ yield. It was also observed that despite $\mathrm{K}_{3} \mathrm{PO}_{4}$ not dissolving completely in the reaction medium, the addition of an excess of reagent can speed-up the reaction.

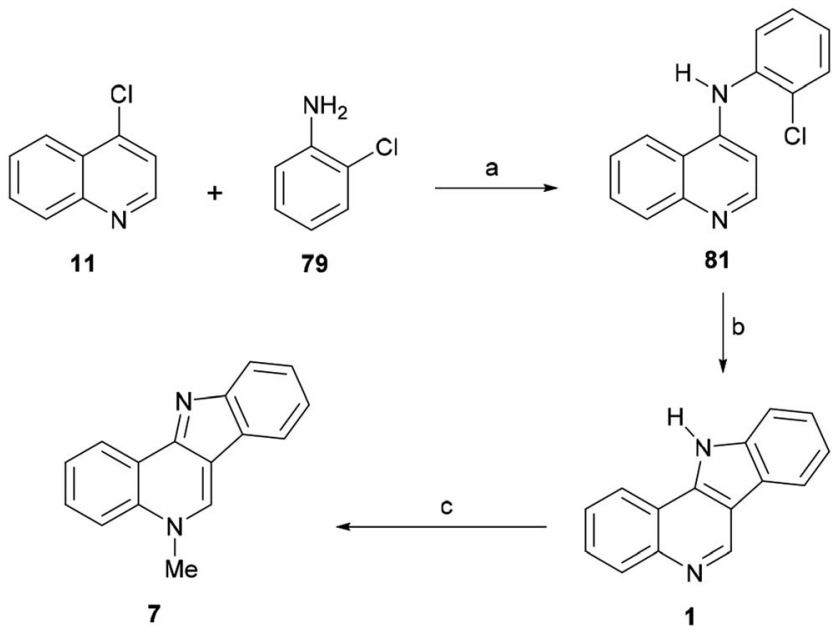

Scheme 18 Reagents and conditions: (a) $200{ }^{\circ} \mathrm{C}, 5 \mathrm{~h}$ (74\%); (b) $h \nu$, $\mathrm{PhH}: \mathrm{MeOH}: \mathrm{H}_{2} \mathrm{SO}_{4}(60: 30: 1, \mathrm{v} / \mathrm{v} / \mathrm{v}), \mathrm{I}_{2}, \mathrm{rt}(78 \%)$; (c) $\mathrm{Me}_{2} \mathrm{SO}_{4}, \mathrm{MeCN}$, reflux, $6 \mathrm{~h}, \mathrm{~K}_{2} \mathrm{CO}_{3}(83 \%)$.

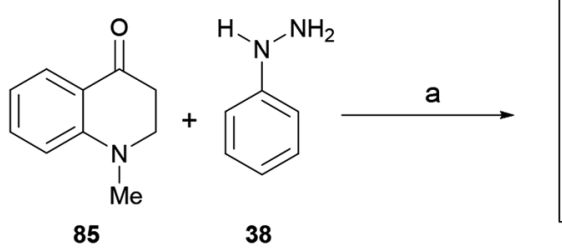<smiles>CN1Cc2c([nH]c3ccccc23)-c2ccccc21</smiles>

\begin{tabular}{lcc|}
\hline Promoter & $\begin{array}{c}\text { Time } \\
\text { (min) }\end{array}$ & $\begin{array}{c}\text { Yield } \\
\text { (\%) }\end{array}$ \\
\hline $\mathrm{ZnCl}_{2}$ & 120 & 40 \\
$\mathrm{SnCl}_{4}$ & 90 & 35 \\
$\mathrm{TFA}$ & 240 & 40 \\
$\mathrm{H}_{3} \mathrm{PW}_{12} \mathrm{O}_{40} \times . \mathrm{H}_{2} \mathrm{O}$ & 150 & 28 \\
$\mathrm{TsOH}$ & 20 & 83 \\
$\mathrm{FeCl}_{3}$ & 120 & 30 \\
\hline
\end{tabular}

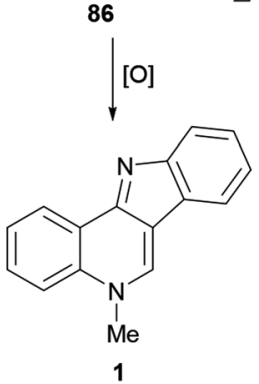

Scheme 19 Reagents and conditions: (a) Promoter (1.1 equiv.), neat, air, $100{ }^{\circ} \mathrm{C}$. Reaction times and overall yields are shown in the table.

Syntheses by Mohan et al. . The Mohan group achieved many advances in the synthesis of indoloquinolines, with two of their total syntheses of isocryptolepine employing quinoline derivatives as starting materials. In 2005 they reported the first of these total syntheses, which was based on the Fischer indole cyclization of the 1,3-dicarbonyl derivative 82 (Scheme 17). ${ }^{\mathbf{1 1 4}}$

To that end, 82 was exposed to phenylhydrazine hydrochloride (38), in a $4: 1$ mixture of glacial $\mathrm{AcOH}$ and concentrated $\mathrm{HCl}$, to give the indoloquinolinone 37 in $65 \%$ yield. The latter existed predominantly in the hydroxy form (83); therefore, the required aromatizative deoxygenation of $\mathbf{8 3}$ was performed as a two-step process, by reaction with $\mathrm{POCl}_{3}$ (ref. 115) to easily form the intermediate chloro-derivative 84 (62\% yield), which was hydrogenolyzed over $10 \% \mathrm{Pd} / \mathrm{C}$ to give isocryptolepine (7) in $70 \%$ yield.

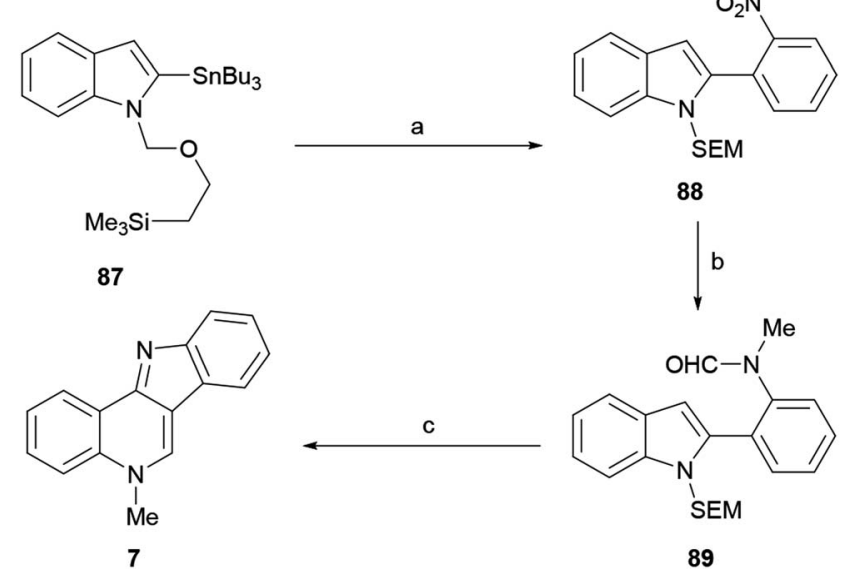

Scheme 20 Reagents and conditions: (a) $\mathrm{Pd}\left(\mathrm{PPh}_{3}\right)_{4}, 2-\mathrm{IC}_{6} \mathrm{H}_{4} \mathrm{NO}_{2}$, THF, reflux (98\%); (b) (1) $\mathrm{H}_{2}, \mathrm{Pd} / \mathrm{C}$, EtOH, rt (98\%); (2) AFA, THF, $-20{ }^{\circ} \mathrm{C}$; (3) $\mathrm{NaH}, \mathrm{THF}, \mathrm{rt}$; (4) $\mathrm{Mel}$ (95\% overall); (c) $\mathrm{EtOH}, 10 \% \mathrm{H}_{2} \mathrm{SO}_{4}$, reflux (50\%). 
The authors observed that the yield of product for the photocyclization in protic solvents was significantly higher than that in benzene alone; hence, the reactions were carried out in a benzene : methanol : sulfuric acid $(60: 30: 1, \mathrm{v} / \mathrm{v} / \mathrm{v})$ solution, to afford the tetracycle 1 in $78 \%$ yield. ${ }^{10 b}$ The final $N$-methylation of $\mathbf{1}$ was performed with methyl sulfate in acetonitrile, furnishing isocryptolepine (7) in $83 \%$ yield after freeing the base with $\mathrm{K}_{2} \mathrm{CO}_{3}$. Furthermore, a similar approach culminating with the photoannulation of a 3-iodoquinoline derivative was employed by this group for the synthesis of a 6-methyl derivative of isocryptolepine. ${ }^{116}$

In 2006, the same group reported an efficient three-step heteroatom directed photoannulation approach toward the natural product (Scheme 18). ${ }^{10 b}$ In their synthetic sequence, 4chloroquinoline (1) was thermally aminated at $200{ }^{\circ} \mathrm{C}$ in $74 \%$ yield with 2-chloroaniline (79), ${ }^{117}$ and the resulting 4 -anilinoquinoline derivative $\mathbf{8 1}$ (also prepared by Maes et al.) was submitted to an oxidative photoannulation in various solvents and in the presence of iodine, as a mild oxidant.

Synthesis by Kumar $\boldsymbol{e t}$ al. . Inspired by a strategically similar approach to 1,2,3,4-tetrahydroisoquinolines, ${ }^{118}$ in 2009 the Kumar group disclosed (Scheme 19) an interesting solventfree ${ }^{119}$ variation of one of the syntheses of Mohan, ${ }^{114}$ and the early work of Braunholtz and Mann, ${ }^{45 a}$ leading to isocryptolepine. The sequence features the one step Fischer indolization-aerobic oxidation of $\mathrm{N}$-methyl dihydroquinolin-4one 85 with phenylhydrazine (38) under acid promotion. ${ }^{120}$

The transformation involves the cyclocondensation toward the tetracycle 86 and its further dehydrogenation in situ $u^{\mathbf{1 0 b}, 89 a, 121}$ to afford the final product. The authors tested different alternative acidic promoters, discovering that heating with a 1.1 equiv. $\mathrm{TsOH}$ at $100{ }^{\circ} \mathrm{C}$ gave the best result ( $83 \%$ yield).

\section{4d. Syntheses from indoles}

The approaches to the total synthesis of isocryptolepine from indoles are characterized by the use of $\mathrm{N}$-protected and/or 3substituted indoles as starting materials. Although certain syntheses have used an unprotected indole derivative and others have started with 2-substituted indoles, they are fewer in number. Electron withdrawing groups (benzenesulfonyl, Boc) do not always meet $\mathrm{C}-\mathrm{C}$ or $\mathrm{C}-\mathrm{N}$ bond formation requirements; in such cases protective groups such as SEM, MOM and benzyl ether have been used.

Synthesis by Joule et al.. The first indole-based total synthesis of isocryptolepine was reported in 1998 by the Joule group, as a different approach toward the natural product (Scheme 20). The sequence employed the indole-stannane derivative $\mathbf{8 7}$ as a starting material and resorted to an intramolecular Vilsmeier reaction to build the 3-aminoalkylidene$3 H$-indole motif of the natural product. ${ }^{122}$

Therefore, the 2-tributylstannyl indole 87 was $N$-protected as the SEM derivative and coupled with 2-iodonitrobenzene under palladium catalysis, to give the 2-(ortho-nitrophenyl)indole $\mathbf{8 8}$ in $98 \%$ yield. The catalytic hydrogenation of the nitro group (98\% yield), followed by $N$-formylation with acetic formic anhydride

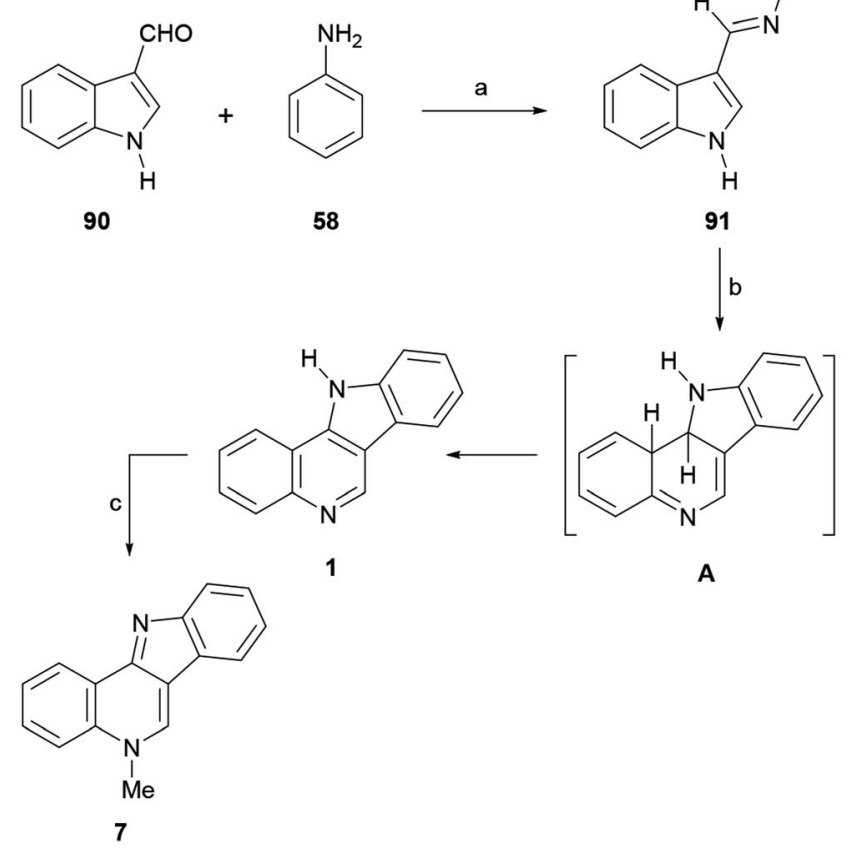

Scheme 21 Reactions and conditions: (a) $\mathrm{AcOH}_{\mathrm{gl}}$, reflux, $3 \mathrm{~h}$ (85\%); (b) (1) $h \nu$ (254 nm), $\mathrm{PhH}-\mathrm{MeOH}, \mathrm{rt}, 2: 1$; (2) $\mathrm{I}_{2}, 48 \mathrm{~h}$ (67\% overall); (c) $\mathrm{Me}_{2} \mathrm{SO}_{4}, \mathrm{MeCN}$, reflux, $6 \mathrm{~h}, \mathrm{~K}_{2} \mathrm{CO}_{3}(83 \%)$.

$(\mathrm{AFA})^{123}$ and subsequent $N$-methylation of the resulting amine with methyl iodide, gave 89 in $95 \%$ overall yield.

The latter was subjected to an intramolecular Vilsmeier ring closure with sulfuric acid in ethanol, to afford 7 in $50 \%$ yield. Interestingly, protection of the starting indole as the $\mathrm{N}$-phenylsulfonyl derivative produced complex mixtures, presumably

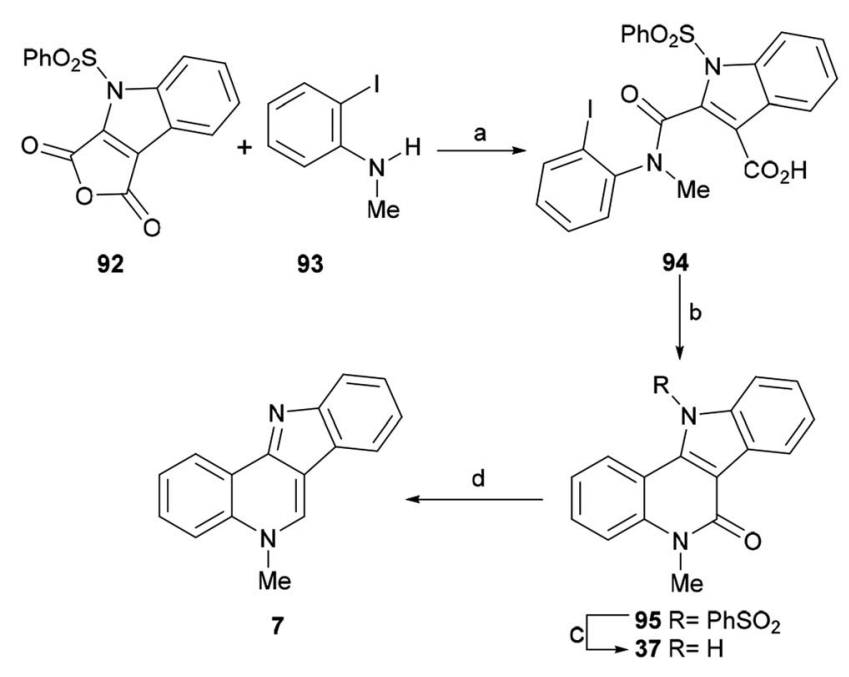

Scheme 22 Reagents and conditions: (a) MeCN, rt, 72 h (77\%); (b) $\mathrm{Pd}(\mathrm{TFA})_{2}, \mathrm{Ag}_{2} \mathrm{CO}_{3}, 5 \% \mathrm{DMSO}, \mathrm{DMF}, 50{ }^{\circ} \mathrm{C}, 48 \mathrm{~h}(50 \%)$; (c) TBAF, THF, rt, $6 \mathrm{~h} \mathrm{(80 \% );} \mathrm{(d)} \mathrm{LiAlH}_{4}$, dioxane, $1 \mathrm{~h}(98 \%)$. 


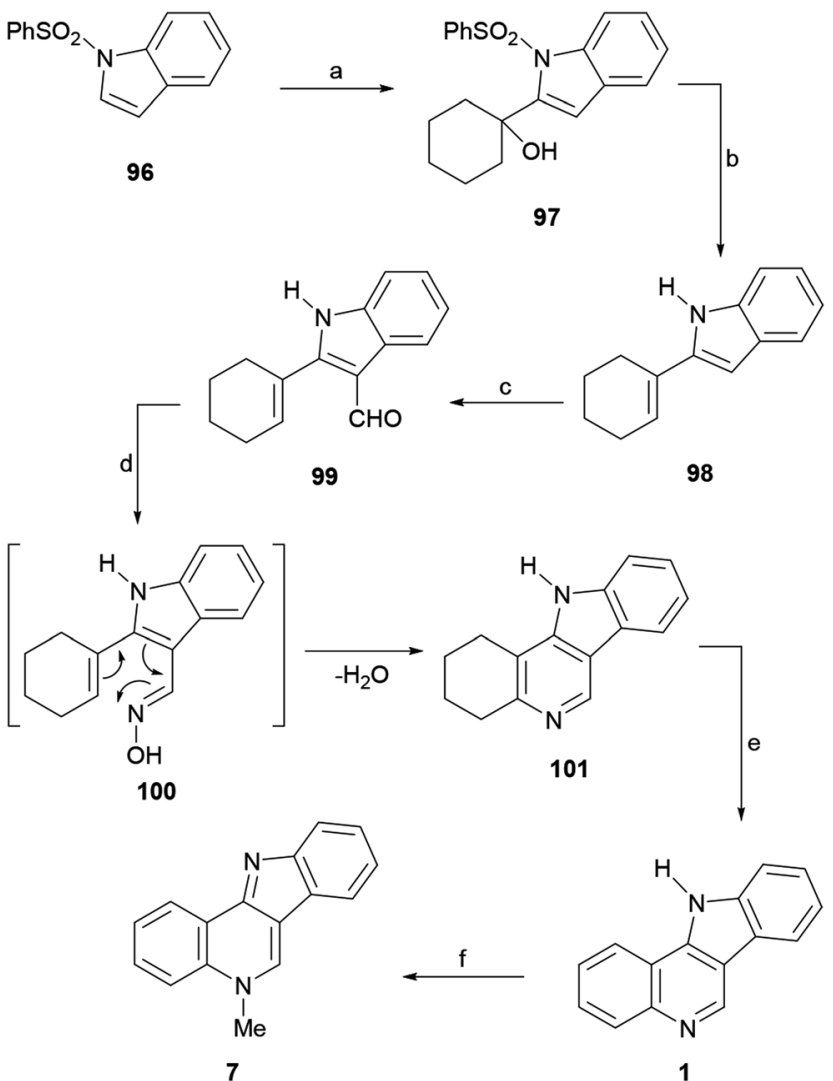

Scheme 23 Reagents and conditions: (a) LDA, THF, $-78{ }^{\circ} \mathrm{C}$, cyclohexanone, $4 \mathrm{~h}(86 \%)$; (b) TBAF, THF, reflux, $2 \mathrm{~h}$ (84\%); (c) POCl $, \mathrm{DMF}, \mathrm{rt}$, $1 \mathrm{~h}(88 \%) ;$ (d) $\mathrm{NH}_{2} \mathrm{OH} \cdot \mathrm{HCl}, \mathrm{NaAcO}$, dioxane, reflux, $24 \mathrm{~h}$ (78\%); (e) $\mathrm{Pd} / \mathrm{C}$, 1,2- $\mathrm{Cl}_{2} \mathrm{C}_{6} \mathrm{H}_{4}$, reflux, $20 \mathrm{~h}(88 \%) ;$ (f) (1) Mel, DMF, $80{ }^{\circ} \mathrm{C}, 1 \mathrm{~h}$; (2) $\mathrm{Na}_{2} \mathrm{CO}_{3}$ (85\%).

due to the deactivating effect of the sulfonyl moiety toward the final electrophilic attack.

Synthesis by Mohan et al.. The Mohan group developed photochemical approaches to the synthesis of several heteroannelated acridines, ${ }^{124}$ including indoloacridines. ${ }^{125}$ In 2002, they extended their strategy to the total synthesis of isocryptolepine. $^{89 a}$ The synthetic sequence employed simple and readily available starting materials, and involved the reaction of indole-3-carbaldehyde (90) with aniline (58) in glacial $\mathrm{AcOH}$ to afford $85 \%$ yield of the Schiff base 91 , which exhibits a 1,3,5hexatriene motif (Scheme 21). Then, 91 was dissolved in benzene-methanol and exposed to short wavelength UV-light $(254 \mathrm{~nm})$ in the presence of iodine, to give the tetracyclic system 1. ${ }^{126 a}$ It is worth noting that a visible-light-mediated aerobic tandem dehydrogenative Povarov/aromatization reaction with iodine ${ }^{\mathbf{1 2 6 b}}$ for the synthesis of isocryptolepines has been recently reported and the use of indole-3-carbaldehyde (90) as a precursor for the synthesis of bioactive alkaloids has been recently reviewed..$^{127}$

Mechanistically, 91 first underwent photo-isomerization of the $E$-isomer to its $Z$-congener; then, the excited S1 state of the $Z$-isomer underwent an orbital symmetry-controlled conrotatory ring closure to the tetracyclic intermediate $\mathbf{A}$.
These types of dihydro intermediates are sensitive to oxygen; ${ }^{121}$ therefore, A underwent aromatization by way of the loss of the allylic hydrogens to form 1 in $67 \%$ yield, in the presence of iodine which acted as a mild oxidizing agent.

The final regioselective methylation of 1 with $\mathrm{Me}_{2} \mathrm{SO}_{4}$ in MeCN, in the presence of $\mathrm{K}_{2} \mathrm{CO}_{3}$, gave isocryptolepine in $83 \%$ yield. This total synthesis was complemented in 2006 with a three step photoannulation approach, which started from a quinoline derivative. ${ }^{10 b}$

Synthesis by Miki et al. The Miki group observed that indole-2,3-dicarboxylic anhydrides are useful synthons to access complex natural products. ${ }^{128}$ In 2007 , they devised an intramolecular decarboxylative Heck-type reaction for the new total synthesis of isocryptolepine, employing this type of heterocycle (Scheme 22). ${ }^{129}$ In their approach, the anhydride moiety of the benzenesulfonyl derivative $\mathbf{9 2}$ was selectively opened upon

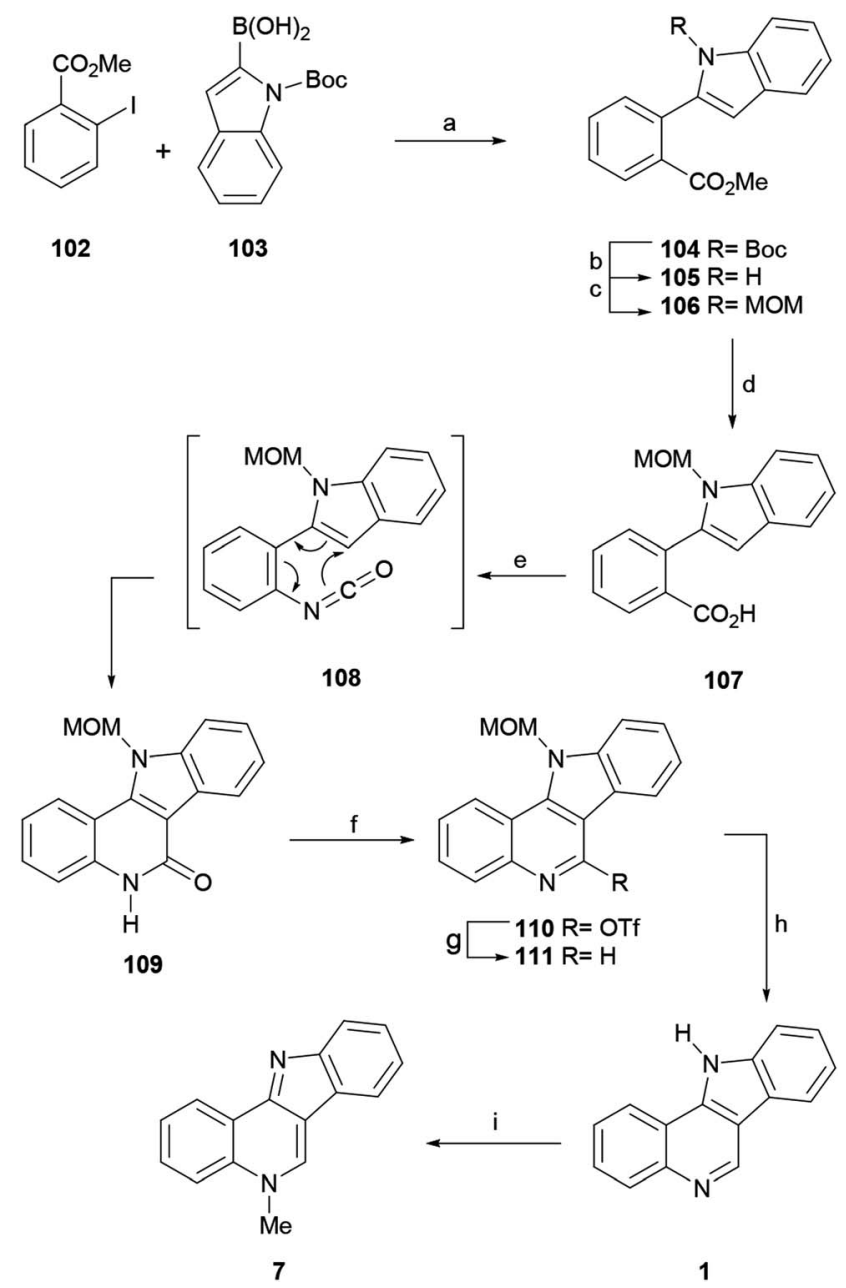

Scheme 24 Reagents and conditions: (a) $\mathrm{Pd}\left(\mathrm{PPh}_{3}\right)_{4}, \mathrm{Na}_{2} \mathrm{CO}_{3}, \mathrm{DME}$, reflux, 12 h (99\%); (b) TFA, $\mathrm{CH}_{2} \mathrm{Cl}_{2}$, rt, 12 h (94\%); (c) MOMCl, NaH, DMF, rt, 12 h (91\%); (d) $1 \mathrm{M} \mathrm{LiOH}, \mathrm{THF}, 60{ }^{\circ} \mathrm{C}, 12 \mathrm{~h}(98 \%) ;(\mathrm{e}) \mathrm{DPPA}, \mathrm{Et}_{3} \mathrm{~N}$, $\mathrm{PhMe}, \mathrm{MW}, 100{ }^{\circ} \mathrm{C}, 10 \mathrm{~min}$ (99\%); (f) $\mathrm{Tf}_{2} \mathrm{O}, \mathrm{Py}, \mathrm{CH}_{2} \mathrm{Cl}_{2}, \mathrm{rt}, 30 \mathrm{~min}$ (83\%); (g) $\mathrm{Et}_{3} \mathrm{SiH}, \mathrm{Pd}(\mathrm{OAc})_{2}, \mathrm{dppp}, \mathrm{DMF}, 60{ }^{\circ} \mathrm{C}, 1 \mathrm{~h}(91 \%)$; (h) $\mathrm{MeOH}$, $\mathrm{HC}(\mathrm{OMe})_{3}, \mathrm{CF}_{3} \mathrm{SO}_{3} \mathrm{H}, \mathrm{MeNO}_{2}, 100{ }^{\circ} \mathrm{C}, 30 \mathrm{~min}$ (96\%); (i) (1) Mel, PhMe, reflux, $2 \mathrm{~h}$; (2) $28 \% \mathrm{NH}_{4} \mathrm{OH}(90 \%)$. 
exposure to $N$-methyl-2-iodoaniline (93) in $\mathrm{MeCN}$ at room temperature, to afford amide $\mathbf{9 4}$ in $77 \%$ yield.

Next, a projected decarboxylative Heck-type cyclization was executed following the protocol of Myers, by treatment of $\mathbf{9 4}$ with $20 \mathrm{~mol} \% \mathrm{Pd}(\mathrm{TFA})_{2}$ and $\mathrm{Ag}_{2} \mathrm{CO}_{3}$ in a mixture of $5 \% \mathrm{DMSO}$ and DMF at $50{ }^{\circ} \mathrm{C}$ for $48 \mathrm{~h},{ }^{\mathbf{1 3 0}}$ to give lactam 95 in $50 \%$ yield. Interestingly, a similar Heck cyclization was reported earlier by the Mérour group. ${ }^{131}$ In that process, lactam 95 was desulfonylated in $80 \%$ yield, by treatment with TBAF in THF at room temperature for $6 \mathrm{~h},{ }^{54}$ and the resulting tetracycle 37 was further reductively deoxygenated to isocryptolepine in $98 \%$ yield, by treatment with $\mathrm{LiAlH}_{4}$ in hot dioxane.

Synthesis by Hingane and Kusurkar. In 2011, Hingane and Kusurkar reported an imaginative $6 \pi$-electrocyclization approach toward isocryptolepine, starting from $\mathrm{N}$-phenylsulfonyl indole (96). ${ }^{\mathbf{1 3 2}}$ In their synthetic sequence, 96 was metallated with LDA and reacted with cyclohexanone to furnish the alcohol 97 (Scheme 23). Next, the hydrolytic $N$-desulfonylation of $\mathbf{9 7}$ was executed by treatment with TBAF in THF under reflux for $2 \mathrm{~h}$, and took place with the concomitant dehydration of the tertiary alcohol moiety to afford $\mathbf{9 8}$ in $84 \%$ yield. ${ }^{133}$

The subsequent Vilsmeier-Haack formylation of $\mathbf{9 8}$ gave $\mathbf{9 9}$ in $88 \%$ yield, while attempted oximation of the latter with hydroxylamine in refluxing dioxane surprisingly furnished the tetracycle 101, presumably as a result of the initial formation of oxime 100 followed by a thermal intramolecular $6 \pi$ electrocyclization/elimination process. Therefore, the sequence continued with the dehydrogenation of 101 using Pd/ $\mathrm{C}$ in ortho-dichlorobenzene, which afforded $\mathbf{1}$ in good yield. Finally, treatment of $\mathbf{1}$ with methyl iodide to afford the methiodide and sodium carbonate to free the base, gave 7 in $37 \%$ overall yield.

Synthesis by Hibino et al.. In 2012, the Hibino group reported the total synthesis of isocryptolepine (7) via a microwaveassisted tandem Curtius rearrangement-electrocyclization of a 2-aza $6 \pi$-electron system (Scheme 24). ${ }^{\mathbf{1 3 4}}$

Following the procedure of Beaumont, these authors subjected the 2-iodobenzoate $\mathbf{1 0 2}$ and the indole-2-boronic acid $\mathbf{1 0 3}$ to a Suzuki-Miyaura cross-coupling reaction and obtained $\mathbf{1 0 4}$ in $99 \%$ yield. Since Boc proved to be an unsuitable protecting group for the advanced stages of the synthesis, $\mathbf{1 0 4}$ was exposed to TFA, resulting in the deprotection of the $N$-Boc group in $94 \%$ yield (105). ${ }^{\mathbf{1 3 5}}$ After trying different protecting groups, the authors selected the MOM group, which has minimum steric demand, to pursue the synthesis.

Hence, treatment of $\mathbf{1 0 5}$ with $\mathrm{MOMCl}$ in the presence of $\mathrm{NaH}$ gave the $N$-MOM-indolylbenzoate 106 in 91\% yield and subsequent basic hydrolysis of the ester moiety with $1 \mathrm{M} \mathrm{LiOH}$ furnished the carboxylic acid $\mathbf{1 0 7}$ in 98\% yield. The microwaveassisted Curtius rearrangement of the latter with DPPA in toluene at $100{ }^{\circ} \mathrm{C}$ quickly provided tetracycle 109 , resulting from a subsequent one-pot thermal $6 \pi$-azaelectrocyclic reaction, in an optimized $99 \%$ yield, without the isolation of the isocyanate intermediate $\mathbf{1 0 8}$.

The deoxygenation of the lactam, required to complete the total synthesis, was achieved by treatment of 109 with triflic anhydride and pyridine, which afforded triflate 110 in 83\%

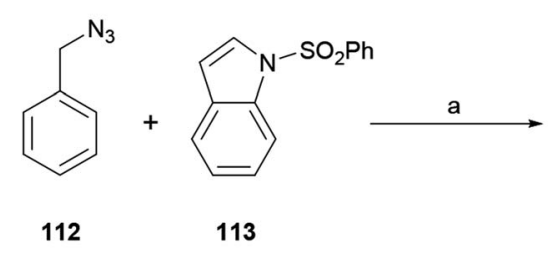<smiles>O=S(=O)(O)N1c2ccccc2[C@H]2CNc3ccccc3[C@H]21</smiles>

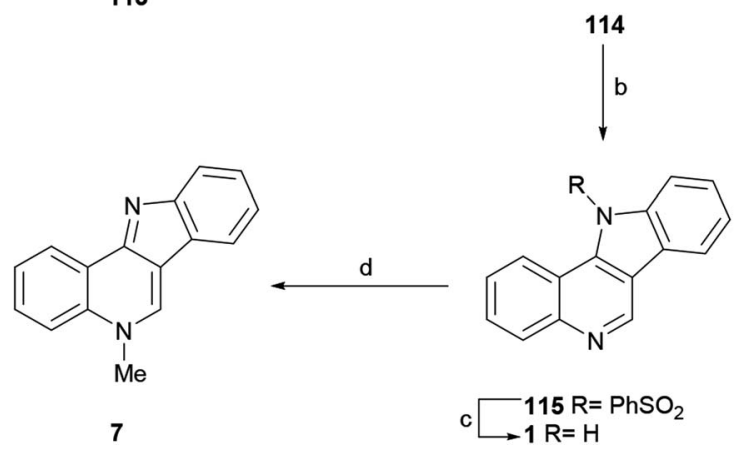

Scheme 25 Reagents and conditions: (a) $\mathrm{TfOH}, \mathrm{CH}_{2} \mathrm{Cl}_{2}, \mathrm{rt}, 14 \mathrm{~h}$ (94\%); (b) $\mathrm{DDQ}, \mathrm{CH}_{2} \mathrm{Cl}_{2}$, rt (94\%); (c) $2 \mathrm{M} \mathrm{NaOH}, \mathrm{MeOH}$, reflux (95\%); (d) (1) $\mathrm{Me}_{2} \mathrm{SO}_{4}, \mathrm{MeCN} ;(2) \mathrm{K}_{2} \mathrm{CO}_{3}(78 \%)$.

yield. Next, the subsequent reductive cleavage of the latter with $\mathrm{Et}_{3} \mathrm{SiH}$ under Pd catalysis, according to the procedure of Katsuki, ${ }^{136}$ provided the $N$-MOM-indoloquinoline 111 (91\% yield), which was deprotected with triflic acid and trimethyl orthoformate in $\mathrm{MeOH}$ and nitromethane, ${ }^{\mathbf{1 3 7}}$ to give indolo[3,2-c] quinoline 1 in $96 \%$ yield. The final methylation of 1 with MeI in toluene ${ }^{59}$ furnished isocryptolepine in $90 \%$ yield after release of the base.

Synthesis of Tummatorn et al. Azides are known to easily extrude diatomic nitrogen and undergo migration of alkyl and aryl groups to the remaining electrophilic nitrogen atom. These migrations can be advantageously used to easily build structural complexity. The Pearson group demonstrated that the reaction

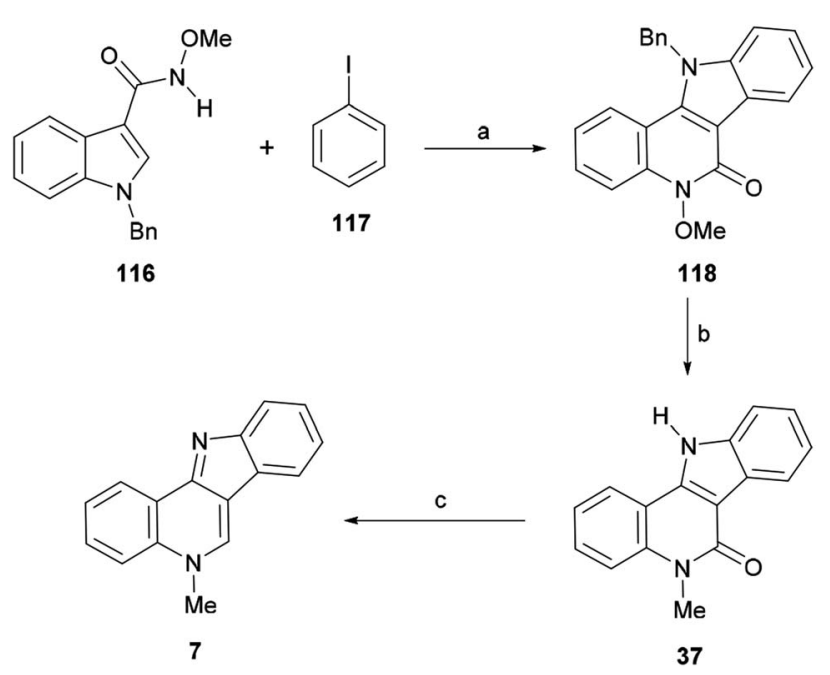

Scheme 26 Reagents and conditions: (a) $\mathrm{Pd}(\mathrm{OAc})_{2}$ (10 mol\%), $\mathrm{PPh}_{3}$ (20 mol\%), $\mathrm{Ag}_{2} \mathrm{CO}_{3}$ (2 equiv.), $\mathrm{AcOH}, \mathrm{DMA}(3: 1, \mathrm{v} / \mathrm{v}), 100{ }^{\circ} \mathrm{C}, 6 \mathrm{~h}(67 \%)$; (b) (1) $\mathrm{NaH}, \mathrm{DMF}, 120{ }^{\circ} \mathrm{C}, 30 \mathrm{~min}$; (2) Mel, rt, $5 \mathrm{~h}$; (3) $\mathrm{NaH}, 140{ }^{\circ} \mathrm{C}, 6 \mathrm{~h}$ (77\%); (c) (1) $\mathrm{NaBH}_{4}, \mathrm{BF}_{3} \cdot \mathrm{Et}_{2} \mathrm{O} \mathrm{THF}, \mathrm{rt}, 30 \mathrm{~min}$; (2) reflux, $12 \mathrm{~h}(84 \%)$. 
of azides with electrophiles under acidic conditions gives iminium ions, which can be trapped by alkenes and alkynes. ${ }^{138}$

Speculating that the iminium ion could react with an aromatic nucleophile through an electrophilic aromatic substitution to afford a $N$-arylmethyl arene, in 2012 the Tummatorn group devised the four-step total synthesis of isocryptolepine (Scheme 25). ${ }^{\mathbf{1 3 9}}$

In their synthetic sequence, benzyl azide (112) and $N$-phenylsulfonyl indole (113) were exposed to $\mathrm{TfOH}$ in $\mathrm{CH}_{2} \mathrm{Cl}_{2}$ to afford the tetracyclic compound 114 in 94\% yield. Presumably, this reaction involved two sequential steps, namely the nucleophilic addition to the iminium ion followed by the intramolecular annulation of the resulting intermediate, resulting in a formal aza-[4+2]-cycloaddition.

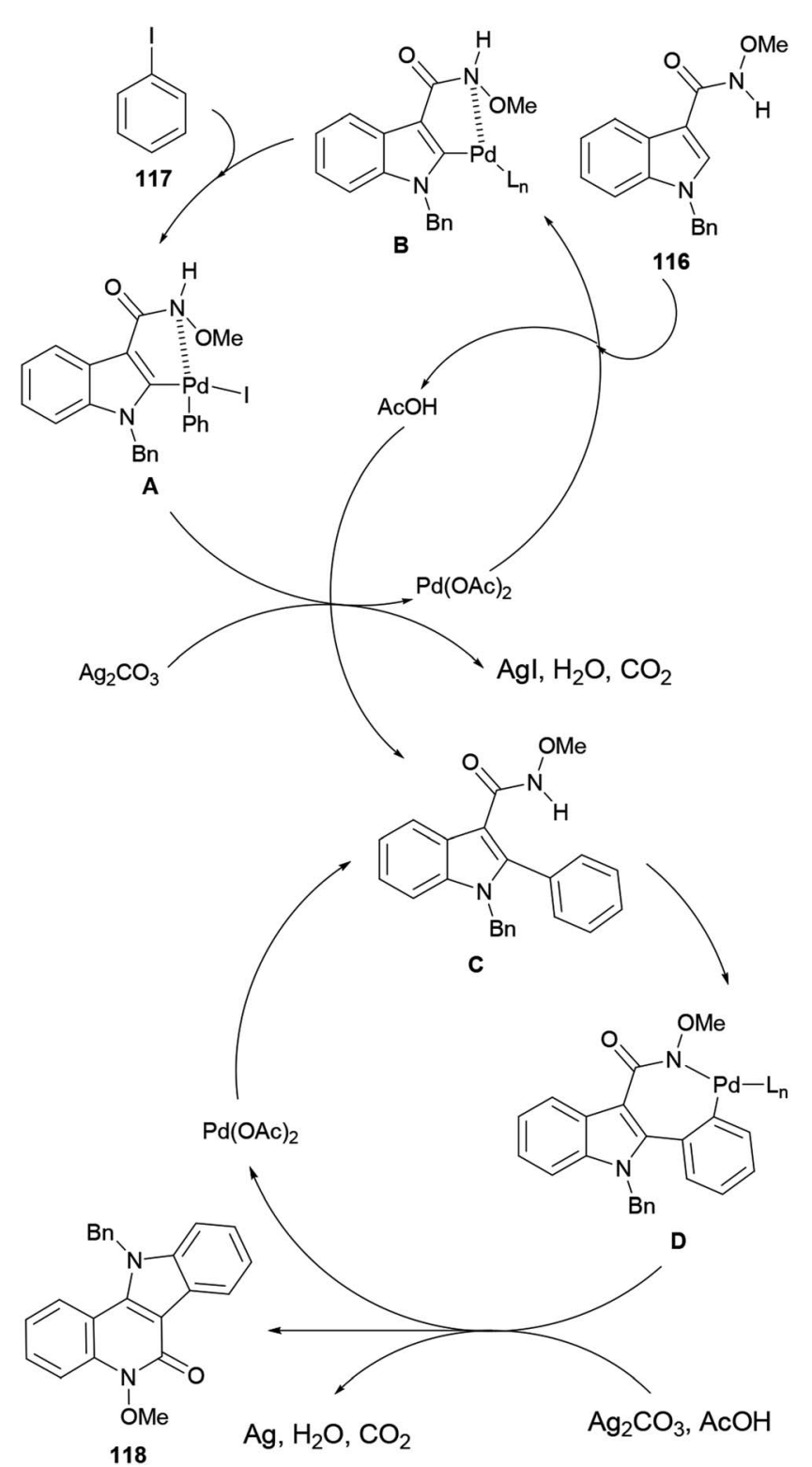

Scheme 27 Proposed reaction mechanism for the tandem $\mathrm{C}-\mathrm{C} / \mathrm{C}-\mathrm{N}$ bond formation reaction.
Dehydrogenation of 114 with DDQ afforded 115 in 94\% yield, which was desulfonylated in $95 \%$ yield with $2 \mathrm{M} \mathrm{NaOH}$ in refluxing $\mathrm{MeOH}$ to give the related indoloquinoline $\mathbf{1}$. The regioselective methylation of the latter with methyl sulfate finally furnished isocryptolepine in $78 \%$ yield. Functionalization of the precursor 114 has also been reported. ${ }^{\mathbf{1 4 0}}$ On the other hand, the basic synthetic sequence was employed as a key strategy toward the development of analogs of the natural product. ${ }^{141}$

Synthesis by Lin et al. Transition-metal catalyzed tandem C$\mathrm{C} / \mathrm{C}-\mathrm{N}$ bond coupling reactions are an interesting strategy en route to nitrogenous compounds. ${ }^{142}$ In 2010, Jiao's group reported a $\operatorname{Pd}(\mathrm{II})$-catalyzed direct dehydrogenative annulation of indolecarboxamides with internal alkynes via $\mathrm{C}-\mathrm{H} / \mathrm{N}-\mathrm{H}$ bond cleavage. Shortly after, in 2014, Cui and coworkers developed a Rh(III)-catalyzed tandem coupling of $\mathrm{N}$-methoxy- $1 H$-indolecarboxamide and aryl boronic acids. ${ }^{143}$

The Lin group studied the palladium-catalyzed coupling of $N$-methoxycarboxamides with iodobenzene (117). ${ }^{\mathbf{1 4 4}}$ They found that the reaction is capable of forming both $\mathrm{C}-\mathrm{C}$ and $\mathrm{C}-\mathrm{N}$ bonds in the presence of a suitable ligand, an oxidant and an indispensable silver source. $\mathrm{PPh}_{3}$ proved to be one of the best ligands<smiles>Cn1cc(C(=O)c2ccccc2)c2ccccc21</smiles>

119

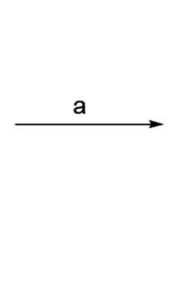

B<smiles>C[SiH2]C(C)C(C)C</smiles><smiles>CSC(C)(c1ccccc1)c1cn(C)c2ccccc12</smiles>

A<smiles>COn1cc(C2(c3ccccc3)CO2)c2ccccc21</smiles><smiles>Cn1cc(C(=O)Nc2ccccc2)c2ccccc21</smiles><smiles>[Y17]CCC</smiles>

Scheme 28 Reagents and conditions: (a) $\mathrm{NH}_{2} \mathrm{OH} \cdot \mathrm{HCl}, \mathrm{NaOAC}$, $\mathrm{MeOH}: \mathrm{H}_{2} \mathrm{O}(10: 3, \mathrm{v} / \mathrm{v})$, reflux, $24 \mathrm{~h}(88 \%)$; (b) $\left(\mathrm{NH}_{4}\right)_{2} \mathrm{~S}_{2} \mathrm{O}_{8}, \mathrm{DMSO}$, dioxane, $6 \mathrm{~h} \mathrm{(51 \% );} \mathrm{(c)} \mathrm{Pd}(\mathrm{OAc})_{2}, \mathrm{Cu}(\mathrm{OAc})_{2}, \mathrm{AcOH}, 18 \mathrm{~h}(66 \%)$; (d) $4 \mathrm{~N}$ $\mathrm{HCl}$, dioxane, $4 \mathrm{~h}(95 \%)$. 
to activate the metal, ${ }^{\mathbf{1 4 5}}$ whereas silver carbonate proved to be the most appropriate source of silver, also acting as an oxidant.

These authors applied the developed method to a new total synthesis of isocryptolepine (Scheme 26). Thus, the methoxyamide 116 was coupled with iodobenzene (117) under the optimized conditions to afford the tetracycle 118 in 67\% yield. A mixed AcOH-DMA solvent was required in order to avoid decomposition of the starting material due to the considerable acidity of the solvent at the required high temperature. ${ }^{\mathbf{1 4 6}}$

Next, the latter was exposed to $\mathrm{MeI}$ and an excess of $\mathrm{NaH}$ at elevated temperature, in order to achieve simultaneous debenzylation and selective $N$-methylation with concomitant demethoxylation and afford the key intermediate 37 in $77 \%$ yield. ${ }^{147}$ The final deoxygenation of the lactam in $\mathbf{3 7}$ was accomplished by partial reduction with $\mathrm{NaBH}_{4}$ in THF under the assistance of $\mathrm{BF}_{3} \cdot \mathrm{Et}_{2} \mathrm{O}$, followed by the in situ dehydration of the resulting lactol to afford 7 in $84 \%$ yield.

The reaction mechanism for the tandem $\mathrm{C}-\mathrm{C} / \mathrm{C}-\mathrm{N}$ bond formation reaction (Scheme 27) involves the reaction of the starting material 116 with $\mathrm{Pd}(\mathrm{OAc})_{2}$ to form a five-membered palladacycle A, which undergoes oxidative addition of iodobenzene (117) to form the $\mathrm{Pd}^{\mathrm{IV}}$ species B. Next, B suffers a reductive elimination to give the arylated intermediate $\mathbf{C}$, regenerating the catalyst.

Subsequent deprotonation of the amine in $\mathbf{C}$ and $\mathbf{C}-\mathbf{H}$ activation affords the seven-membered palladacycle $\mathrm{D},{ }^{\mathbf{1 4 8}}$ which undergoes a reductive elimination to furnish 118 and $\mathrm{Pd}^{0}$ species. The latter is finally oxidized by $\mathrm{Ag}_{2} \mathrm{CO}_{3}$ to regenerate the active $\mathrm{Pd}^{\mathrm{II}}$ species for the next catalytic cycle.

Synthesis by Mhaske et al.. Mhaske and coworkers reported the application of $\left(\mathrm{NH}_{4}\right)_{2} \mathrm{~S}_{2} \mathrm{O}_{8}-\mathrm{DMSO}$ as an inexpensive,

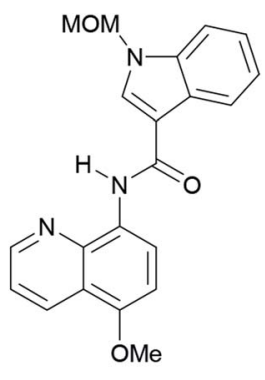

123
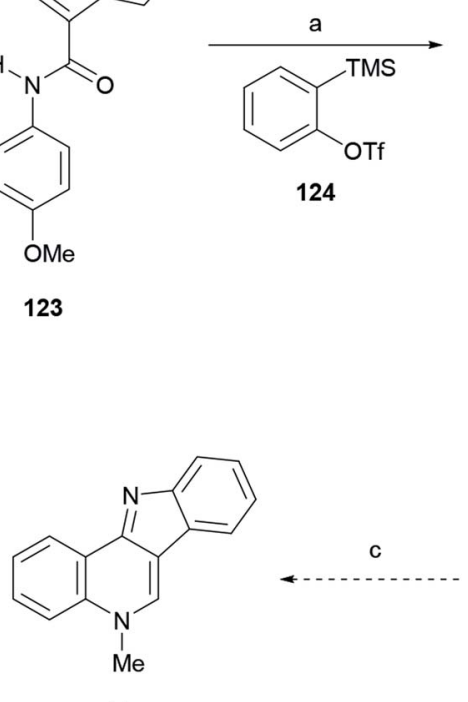

45

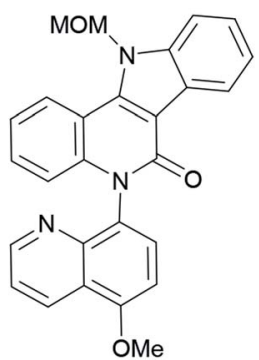

125

b

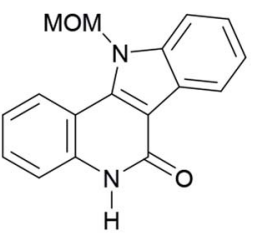

109
Scheme 29 Reagents and conditions: (a) 124, $\mathrm{Cu}(\mathrm{OAc})_{2}, \mathrm{CsF}, \mathrm{TBAl}$, DMF : MeCN (1 : 1, v/v), $\mathrm{O}_{2}, 80^{\circ} \mathrm{C}, 12 \mathrm{~h} \mathrm{(62 \% );} \mathrm{(b)} \mathrm{(1)} \mathrm{BBr}_{3}, \mathrm{CH}_{2} \mathrm{Cl}_{2}(67 \%)$; (2) $\mathrm{K}_{2} \mathrm{Cr}_{2} \mathrm{O}_{7}, \mathrm{AcOH}: \mathrm{H}_{2} \mathrm{O}(1: 1, \mathrm{v} / \mathrm{v})(65 \%)$; (c) see ref. 134. environmentally benign and safe reagent under mild neutral conditions, for the synthesis of imides, methylene bis-amides, diarylmethanes, and also for the Mannich reaction. ${ }^{\mathbf{1 4 9}}$ The usefulness of the developed protocol was demonstrated by a formal total synthesis of isocryptolepine (Scheme 28). ${ }^{150}$

The synthetic sequence commenced with 3-benzoylindole, ${ }^{151}$ which in the successful synthetic sequence was protected with a MOM group to afford 119, since electron withdrawing protecting groups (benzoyl, tosyl) failed during more advanced stages. In turn, 119 was converted to oxime $\mathbf{1 2 0}$ in $88 \%$ yield under conventional conditions, and the latter was subjected to the standard oxidation protocol to furnish the radical Beckmann rearrangement product, the amide 121, in moderate yield (51\%).

A mechanism for this rearrangement was proposed. It was suggested that the $\left(\mathrm{NH}_{4}\right)_{2} \mathrm{~S}_{2} \mathrm{O}_{8}$-DMSO system is a source of methylsulfanyl radicals $\left(\mathrm{MeS}^{*}\right)$, which can attack the oxime moiety of $\mathbf{1 2 0}$ and afford the radical intermediate $\mathbf{A}$. The latter can undergo a rearrangement to $\mathbf{B}$ and be further converted into the oxaziridine $\mathbf{C},{ }^{152}$ with the loss of $\mathrm{MeSH}$.

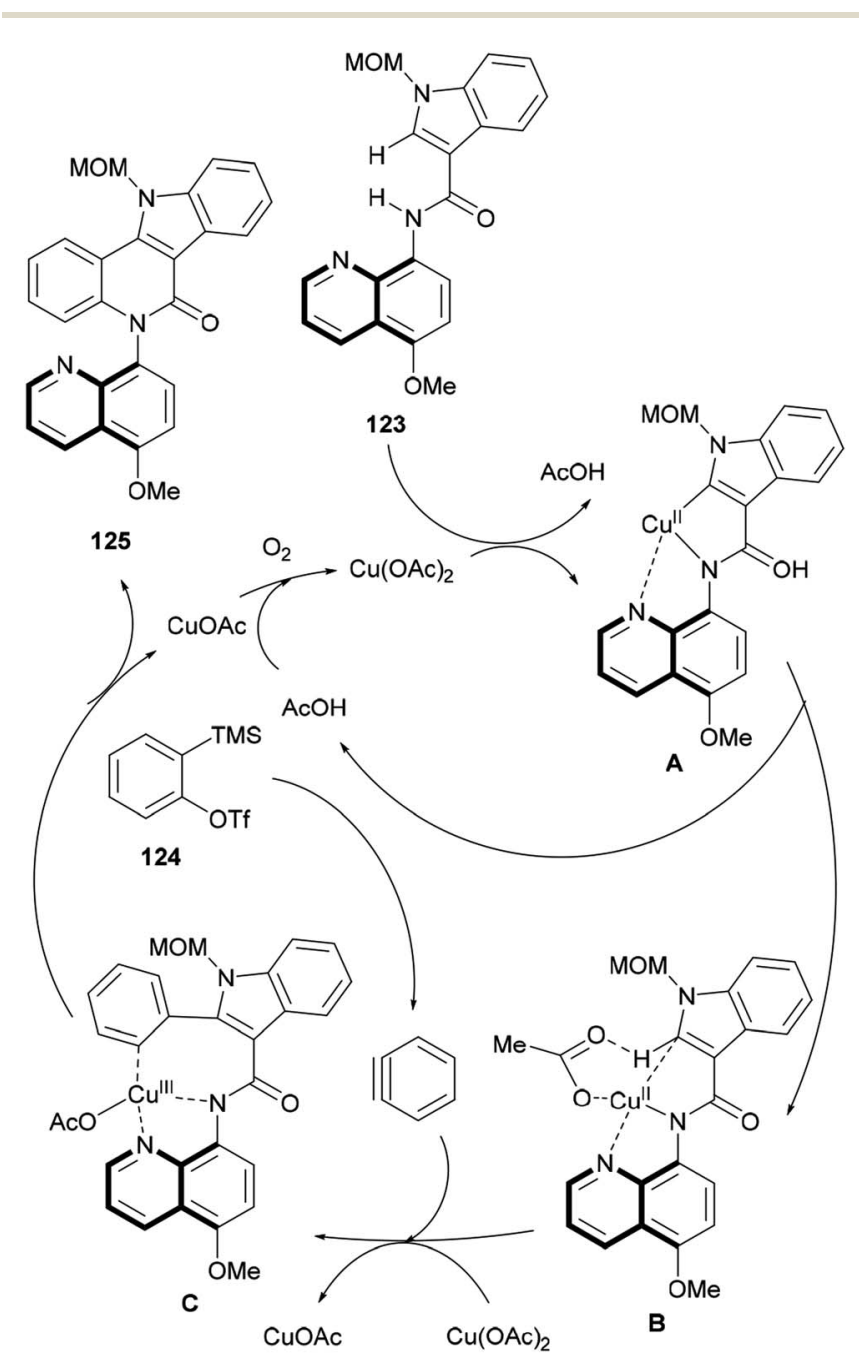

Scheme 30 Proposed reaction mechanism for the copper(॥)-mediated selective cascade $\mathrm{C}-\mathrm{H} / \mathrm{N}-\mathrm{H}$ annulation strategy. 
Table 1 Chronological summary of the total syntheses and relevant formal total syntheses of isocryptolepine

\begin{tabular}{|c|c|c|c|c|c|c|}
\hline Year & Group & Class $^{a}$ & No. of steps & Main reaction(s) in the strategy & $\begin{array}{l}\text { Yield } \\
(\%)\end{array}$ & Ref. \\
\hline 1950 & Kermack & Q & 4 & Graebe-Ullmann of 4-benzotriazolylquinoline & 29.5 & 43 \\
\hline 1955 & Mann & $\mathrm{Q}$ & 3 & Fischer indolization of $N$-methyl tetrahydroquinolin-4-one & $<15$ & $45 a$ \\
\hline 1993 & Alvarez-Builla & $\mathrm{Q}$ & $2^{b}$ & Graebe-Ullmann of 4-benzotriazolylquinoline & 54 & 49 \\
\hline 1996 & Novikov & B & 6 & Fischer indolization of $\mathrm{N}$-tosyl tetrahydroquinolin-4-one & 15.5 & 50 \\
\hline 1997 & Tímari & $\mathrm{Q}$ & 5 & Suzuki cross-coupling; nitrene cyclization & 46.7 & 97 \\
\hline 1998 & Joule & I & 3 & Suzuki coupling; Vilsmeier closure & 45.6 & 122 \\
\hline 1999 & Molina & B & 11 & Cyanate and nitrene cyclizations & 24.6 & $54 a$ \\
\hline 2002 & Mohan & I & 3 & Photochemical ring closure & 47.3 & $89 a$ \\
\hline 2003 & Maes & $\mathrm{Q}$ & 3 & Buchwald-Hartwig; intramolecular direct arylation & 43.9 & 104 \\
\hline 2005 & Mohan & $\mathrm{Q}$ & 3 & Fisher indolization of $N$-methyl tetrahydroquinolin-2,4-dione & 45.5 & 114 \\
\hline 2006 & Mohan & $\mathrm{Q}$ & 3 & Heteroatom directed photoannulation & 64.7 & $10 b$ \\
\hline 2007 & Miki & I & 4 & Decarboxylative Heck-cyclization & 30.2 & 129 \\
\hline 2008 & Maes & $\mathrm{Q}$ & 2 & Auto-tandem Pd-catalyzed consecutive $\mathrm{C}-\mathrm{N}$ and $\mathrm{C}-\mathrm{C}$ bond formation & 46.7 & 112 \\
\hline 2009 & Kundu & $\mathrm{B}$ & $2^{b}$ & Modified Pictet-Spengler & 86 & 59 \\
\hline 2009 & Kumar & Q & 1 & Fisher indolization; oxidation of $N$-methyl tetrahydroquinolin-4-one & 83 & 120 \\
\hline 2010 & Kraus & B & 5 & Electrocyclization of the anion of a Schiff base & 47.8 & 68 \\
\hline 2010 & Kraus & $\mathrm{B}$ & $4^{c}$ & Intramolecular Wittig reaction & 60.8 & 69 \\
\hline 2011 & Kusurkar & I & 6 & $6 \pi$-Electrocyclization & 37.1 & 132 \\
\hline 2012 & Butin & B & 4 & Furan to indole recyclization; Michael addition & 11.6 & 73 \\
\hline 2012 & Hibino & I & 9 & Curtius rearrangement; $6 \pi$-electrocyclization & 53.6 & 134 \\
\hline 2012 & Tummatorn & I & 4 & Aza-[4+2]-cycloaddition & 65.5 & 139 \\
\hline 2013 & Bogányi & B & $7^{b}$ & Buchwald-Hartwig amination; Heck-type biaryl coupling & 21.8 & 76 \\
\hline 2014 & Lin & I & 3 & $\operatorname{Pd}(\mathrm{II})$-Catalyzed direct dehydrogenative annulation & 43.3 & 144 \\
\hline 2016 & $\mathrm{Lu} \& \mathrm{Xu}$ & $\mathrm{B}$ & 4 & Electrosynthesis. Cyclization of acetylenic acetal via amidyl radicals & 36.2 & 85 \\
\hline 2016 & Mhaske & I & $4^{d}$ & Radical Beckmann rearrangement; Pd-catalyzed double $\mathrm{C}-\mathrm{H}$ activation & 29.6 & 150 \\
\hline 2017 & Aksenov \& Rubin & $\mathrm{B}$ & 2 & Fischer indolization; Vilsmeier reaction with triazine & 83 & 90 \\
\hline 2018 & Zhang & I & $2^{e}$ & Selective cascade $\mathrm{C}-\mathrm{H} / \mathrm{N}-\mathrm{H}$ annulations & 27 & 156 \\
\hline
\end{tabular}

${ }^{a}$ Classification according to the structure of the starting material. $\mathrm{B}=$ benzenoid; $\mathrm{Q}=$ quinoline; $\mathrm{I}=$ indole. ${ }^{b}$ Formal total synthesis. Data correspond to the synthesis of the unsubstituted tetracycle $1 .{ }^{c}$ Formal total synthesis. Data correspond to the synthesis of the azide 36 , an intermediate in the synthesis of Molina et al. ${ }^{d}$ Formal total synthesis. Data correspond to the synthesis of 109, the tetracyclic intermediate of Hibino. ${ }^{e}$ Formal total synthesis. Data correspond to the synthesis of $\mathbf{1 0 9}$, the tetracyclic intermediate of Hibino.

In turn, the latter intermediate finally undergoes a rearrangement to afford amide 121. Radical intermediates have also been observed in the photochemically driven Beckmann rearrangement. ${ }^{153}$

The as-formed intermediate $\mathbf{1 2 1}$ was exposed to $\mathrm{Pd}(\mathrm{OAc})_{2}$ and $\mathrm{Cu}(\mathrm{OAc})_{2}$ in $\mathrm{AcOH}$ at $120{ }^{\circ} \mathrm{C}$, which promoted an intramolecular double $\mathrm{C}-\mathrm{H}$ activation, affording 109 in $66 \%$ yield. A similar $\mathrm{C}-\mathrm{C}$ bond formation under UV light irradiation (254 $\mathrm{nm}$ ) was reported earlier. ${ }^{154}$ Compound 109 is a key intermediate in Hibino's synthesis of isocryptolepine; ${ }^{\mathbf{1 3 4}}$ therefore, this sequence constitutes a formal total synthesis of isocryptolepine. Additionally, compound $\mathbf{1 0 9}$ was deprotected with $\mathrm{HCl}$ in dioxane to obtain indoloquinolinone 122, a well-known bioactive scaffold, in 95\% yield. ${ }^{147 a, 155}$

Synthesis by Zhang et al.. The Zhang group developed several copper-mediated syntheses of natural products and in 2018 reported a selective cascade $\mathrm{C}-\mathrm{H} / \mathrm{N}-\mathrm{H}$ annulation strategy toward the tetracyclic core of isocryptolepine, thus providing a new formal total synthesis of the natural product. ${ }^{156}$ The bond forming approach is mediated by a 8-aminoquinoline $\mathrm{N}, \mathrm{N}$ bidentate directing group ${ }^{157}$ and involves a reaction with a benzyne derivative under mild conditions.

The general transformation was optimized to use 0.35 equiv. of $\mathrm{Cu}(\mathrm{OAc})_{2}$ and 1.2 equiv. $\mathrm{CsF}$ as a base, in the presence of 0.5 equiv. of TBAI, which enhances the generation of benzyne at $80{ }^{\circ} \mathrm{C}$ in DMF : MeCN $(1: 1, \mathrm{v} / \mathrm{v})$. The reaction took place under oxygen as a final oxidant, for $12 \mathrm{~h}$. The synthetic sequence leading to the isocryptolepine precursor involved the use of 5methoxy-8-aminoquinoline as a removable sacrificial $N, N$ ligand ${ }^{158}$ and the Kobayashi benzyne precursor $124 .{ }^{159}$

In the synthetic sequence, $\mathbf{1 2 4}$ was induced to react with the indole-3-carboxamide derivative 123 to afford 125 in 62\% yield (Scheme 29), carrying a removable MOM group.

Then, the quinoline auxiliary was removed via a two-step protocol, including the selective $O$-demethylation of the quinolyl methyl ether with $\mathrm{BBr}_{3}$ to free the phenol group, which was further oxidized with $\mathrm{K}_{2} \mathrm{Cr}_{2} \mathrm{O}_{7}$ in $\mathrm{AcOH}: \mathrm{H}_{2} \mathrm{O}(1: 1, \mathrm{v} / \mathrm{v})$, to afford lactam 109 in $65 \%$ yield, Hibino's intermediate toward isocryptolepine..$^{\mathbf{1 3 4}}$

This reaction system avoids the use of sensitive and expensive noble metals and oxidants, and complements previous metal-based strategies.

A plausible mechanism for this $\mathrm{C}-\mathrm{H} / \mathrm{N}-\mathrm{H}$ cascade annulation was presented, where a $\mathrm{Cu}(\mathrm{III})$-mediated organometallic $\mathrm{C}-\mathrm{H}$ activation takes place (Scheme 30). ${ }^{\mathbf{1 6 0}}$ Thus, 123 coordinates with $\mathrm{Cu}(\mathrm{OAc})_{2}$ to generate an anionic complex A ligated by a $N, N$ bidentate directing group. ${ }^{161}$ Then, the complex undergoes acetate-assisted intramolecular $\mathrm{C}-\mathrm{H}$ concerted metalation/ 
deprotonation to afford the five-membered ring complex $\mathbf{B}$, which then undergoes carbocupration with the aryne generated from precursor $\mathbf{1 2 4}$ to furnish the intermediate $\mathrm{C}$. The final reductive elimination of CuOAc $\mathbf{C}$ provides the desired annulation product (125), with the catalyst being regenerated for the next cycle in the presence of oxygen.

\section{4e. Summary of the synthetic efforts toward isocryptolepine}

In general, the reported synthetic routes toward isocryptolepine required multistep linear sequences with the corresponding isolation and purification stages of the intermediate products. A comparison of them (Table 1), in terms of complexity and overall yield, is difficult and not straightforward, due to the variable nature and structural complexity of the starting materials. In addition, many syntheses of isocryptolepine are actually formal total syntheses, reaching only a previously known advanced intermediate toward the natural product.

However, it is worth noting that several very short approaches, consisting of just one to three steps using commercially available materials, have been reported, and various approaches have allowed access to the natural product in more than $60 \%$ overall yield.

\section{Conclusions and perspective}

The indoloquinoline heterocyclic system is strongly associated with the West African plant Cryptolepis sanguinolenta, although other natural sources are known. Cryptosanguinolentine (isocryptolepine) has been isolated twice from this plant, widely used in traditional medicine.

Its unique framework and interesting pharmacological properties have meant that over the last 20 years isocryptolepine has become a test ground for new synthetic approaches toward $\mathrm{C}-\mathrm{C}$ and $\mathrm{C}-\mathrm{N}$ bond formation, with or without the use of precious metal catalysts. The natural product has been the target of over 25 synthetic efforts, where the tetracycle was built from benzenoids, quinolines and/or indoles via the stepwise construction of the heterocyclic moieties or through the successive assembly of the remaining heterocyclic rings.

The natural product has also gained recognition as an important and privileged scaffold in drug discovery due to the broad spectrum of its biological activities. Hence, many of the developed strategies have proved to be useful for the synthesis of more complex analogs and derivatives of the natural product, embodied with more potent and/or selective activity, mainly as cytotoxic and antimalarial agents. Therefore, it can be foreseen that the virtuous cycle, which involves new chemistries and novel structures for improved bioactive compounds, will keep going in the future, meaning that novel total syntheses of isocryptolepine will keep being disclosed.

\section{Conflicts of interest}

There are no conflicts to declare

\section{Acknowledgements}

This work was financially supported by the Consejo Nacional de Investigaciones Científicas y Técnicas (CONICET, Grant PUE IQUIR 2016) and the Agencia Nacional de Promoción Científica y Tecnológica (ANPCyT, Grant PICT 2017-0149). E. N. T. thanks ANPCyT for her Doctoral Fellowship. The authors also gratefully acknowledge the Agencia Santafesina de Ciencia, Tecnología e Innovación Productiva (ASaCTeI) for the institutional grant AC 2015-0005 to IQUIR, which enabled the acquisition of a 400 MHz NMR spectrometer.

\section{Notes and references}

1 R. D. Firn and C. G. Jones, Nat. Prod. Rep., 2003, 20, 382391.

2 R. S. Bon and H. Waldmann, Acc. Chem. Res., 2010, 43, 1103-1114.

3 (a) L. Hoareau and E. J. Da Silva, Electron. J. Biotechnol., 1999, 2, 56-70; (b) G. Samuelsson, Drugs of Natural Origin: A Textbook of Pharmacognosy, Swedish Pharmaceutical Press, Stockholm, Sweden, 5th edn, 2004.

4 D. J. Newman and G. M. Cragg, J. Nat. Prod., 2012, 75, 311335.

5 J. Hong, Curr. Opin. Chem. Biol., 2011, 15, 350-354.

6 P. T. Parvatkar and P. S. Parameswaran, Curr. Org. Synth., 2016, 13, 58-72.

7 G. V. Subbaraju, J. Kavitha, D. Rajasekhar and J. I. Jimenez, J. Nat. Prod., 2004, 67, 461-462.

8 A. I. Calderón, A. Hodel, J.-L. Wolfender, M. P. Gupta, M. Correa and K. Hostettmann, Nat. Prod. Res., 2013, 27, 1335-1342.

9 O. S. Chaves, Y. C. F. Teles, M. M. de Oliveira Monteiro, L. G. Mendes Jr, M. de Fátima Agra, V. de Andrade Braga, T. M. S. Silva and M. F. V. de Souza, Molecules, 2017, 22, 94. 10 (a) S. Hostyn, B. U. W. Maes, L. Pieters, G. L. F. Lemière, P. Mátyus, G. Hajós and R. Dommisse, Tetrahedron, 2005, 61, 1571-1577; (b) T. Dhanabal, R. Sangeetha and P. S. Mohan, Tetrahedron, 2006, 62, 6258-6263; (c) M. O. Sydnes, Stud. Nat. Prod. Chem., 2020, 64, 59-84; (d) M. O. Sydnes, Targets Heterocycl. Syst., 2019, 23, 201-219.

11 J. Hutchinson and J. M. Dalziel, Flora of Tropical West Africa, The Whitefrairs Press Ltd., London, UK, 1963, p. 102.

12 E. Gellert, C. R. Raymond-Hamet and E. Schlittler, Helv. Chim. Acta, 1951, 34, 642-651.

13 (a) D. Dwuma-Badu, J. S. K. Ayim, N. Y. Y. Fiagbe, J. E. Knapp, P. L. Schiff Jr and D. J. Slatkin, J. Pharm. Sci., 1978, 67, 433-434; (b) M. V. Méndez, S. O. Simonetti, T. S. Kaufman and A. B. J. Bracca, New J. Chem., 2019, 43, 10803-10813.

14 R. C. Crouch, A. O. Davis, T. D. Spitzer, G. E. Martin, M. H. M. Sharaf, P. L. Schiff Jr, C. H. Phoebe and A. N. Tackie, J. Heterocycl. Chem., 1995, 32, 1077-1080.

15 (a) M. H. M. Sharaf, P. L. Schiff Jr, A. N. Tackie, C. H. Phoebe Jr and G. E. Martin, J. Heterocycl. Chem., 1996, 33, 239-243; (b) M. V. Méndez, D. A. Heredia, E. L. Larghi, A. B. J. Bracca and T. S. Kaufman, RSC Adv., 2017, 7, 28298-28307. 
16 J.-L. Pousset, M.-T. Martin, A. Jossang and B. Bodo, Phytochemistry, 1995, 39, 735-736.

17 (a) S. Y. Ablordeppey, C. D. Hufford, R. F. Borne and D. Dwama-Badu, Planta Med., 1990, 56, 416-417; (b) A. N. Tackie, M. H. M. Sharaf, P. L. Schiff Jr, G. L. Boye, R. C. Crouch and G. E. Martin, J. Heterocycl. Chem., 1991, 28, 1429-1435.

18 (a) C. E. Hadden, M. H. M. Sharaf, J. E. Guido, R. H. Robins, A. N. Tackie, C. H. Phoebe Jr, P. L. Schiff Jr and G. E. Martin, J. Nat. Prod., 1999, 62, 238-240; (b) D. M. Fort, J. Litvak, J. L. Chen, Q. Lu, P. W. Phuan, R. Cooper and D. E. Bierer, J. Nat. Prod., 1998, 61, 1528-1530.

19 A. Paulo, E. T. Gomes and P. J. Houghton, J. Nat. Prod., 1995, 58, 1485-1491.

20 (a) M. H. M. Sharaf, P. L. Schiff Jr, A. N. Tackie, C. H. Phoebe Jr, L. Howard, C. Myers, C. E. Hadden, S. K. Wrenn, A. O. Davis, C. W. Andrews, D. Minick, R. L. Johnson, J. P. Shockcor, R. C. Crouch and G. E. Martin, Magn. Reson. Chem., 1995, 33, 767-778; (b) K. Cimanga, T. de Bruyne, L. Pieters, M. Claeys and A. Vlietnick, Tetrahedron Lett., 1996, 37, 1703-1706; (c) K. Blinov, M. Elyashberg, R. Martirosian, S. G. Molodtsov, A. J. Williams, A. N. Tackie, M. H. M. Sharaf, P. L. Schiff Jr, R. C. Crouch, G. E. Martin, C. E. Hadden, J. E. Guido and K. A. Mills, Magn. Reson. Chem., 2003, 41, 577-584.

21 (a) M. H. M. Sharaf, P. L. Schiff Jr, A. N. Tackie, C. H. Phoebe Jr, R. L. Johnson, D. Minick, C. W. Andrews, R. C. Crouch and G. E. Martin, J. Heterocycl. Chem., 1996, 33, 789-797; (b) A. N. Tackie, G. L. Boye, M. H. M. Sharaf, P. L. Schiff Jr, R. C. Crouch, T. D. Spitzer, R. L. Johnson, J. Dunn, D. Minick and G. E. Martín, J. Nat. Prod., 1993, 56, 653-670.

22 J. E. Saxton, in The Alkaloids, Chemistry and Physiology, ed. R. H. F. Manske and H. L. Hoimes, Academic Press, New York, USA, 1965, vol. 8, p. 19.

23 G. L. Boye and O. Ampofo, Proceedings at the First International Symposium on Cryptolepine, University of Science and Technology, Kumasi, Ghana, 1983.

24 (a) M. Iwu, Handbook of African Medicinal Plants, CRC Press, Boca Raton, USA, 1993; (b) J. Kerharo, La Pharmacopée Sénégalaise Traditionnelle, Plantes Médicinales et Toxiques. Editions Vigot Frères, Paris, France, 1974; (c) J. M. Watt and M. G. Breyer-Brandwijk, The Medicinal and Poisonous Plants of Southern and Eastern Africa. E. \& S. Livingstone Ltd, London, UK, 1962, pp. 128-129; (d) K. Cimanga, T. de Bruyne, A. Lasure, B. Van Poel, L. Pieters, M. Claeys, D. Vanden Berghe, K. Kambu, L. Tona and A. J. Vlietinck, Planta Med., 1996, 62, 22-27.

25 B. Oliver-Bever, Medicinal Plants in Tropical West Africa, Cambridge University Press, Cambridge, UK, 1986, p. 41.

26 (a) E. L. Larghi, A. B. J. Bracca, A. A. Arroyo Aguilar, D. A. Heredia, J. L. Pergomet, S. O. Simonetti and T. S. Kaufman, Curr. Top. Med. Chem., 2015, 17, 16831707; (b) P. T. Parvatkar and S. G. Tilve, Bioactivities and Synthesis of Indoloquinoline Alkaloids: Cryptolepine, Isocryptolepine and Neocryptolepine in: Bioactive Heterocycles: Synthesis and Biological Evaluation, ed. K. L. Ameta, R. P. Pawar and A. J. Domb, Nova Science
Publishers, Inc., New York, USA, 2013, ch. 10, pp. 217-234; (c) E. V. K. S. Kumar, J. R. Etukala and S. Y. Ablordeppey, Mini-Rev. Med. Chem., 2008, 8, 538-554; (d) C. W. Wright, J. Pharm. Pharmacol., 2007, 59, 899-904.

27 H. de Diesbach, E. de Bie and F. Rubli, Helv. Chim. Acta, 1934, 17, 113-128.

28 A. N. Tackie, C. H. Phoebe Jr and G. E. Martin, J. Heterocycl. Chem., 1996, 33, 239-243.

29 J. Tousek, S. VanMiert, L. Pieters, G. Van Baelen, S. Hostyn, B. U. W. Maes, G. Lemiere, R. Dommisse and R. Marek, Magn. Reson. Chem., 2008, 46, 42-51.

30 E. Breitmaier and K. H. Spohn, Tetrahedron, 1973, 29, 11451152.

31 L. Grycova, R. Dommisse, L. Pieters and R. Marek, Magn. Reson. Chem., 2009, 47, 977-981.

32 P. Ghosh, S. S. Jaffer and P. Purkayastha, J. Phys. Chem. B, 2011, 115, 2046-2054.

33 W. Peczynska-Czoch, F. Pognan, L. Kaczmarek and J. Boratyriski, J. Med. Chem., 1994, 37, 3503-3510.

34 G. Van Baelen, S. Hostyn, L. Dhooghe, P. Tapolcsányi, P. Mátyus, G. Lemière, R. Dommisse, M. Kaiser, R. Brun, P. Cos, L. Maes, G. Hajós, Z. Riedl, I. Nagy, B. U. W. Maes and L. Pieters, Bioorg. Med. Chem., 2009, 17, 7209-7217.

35 J.-C. Li, R.-X. Wang, Y. Sun, J.-K. Zhu, G.-F. Hu, Y.-L. Wang, R. Zhou, Z.-M. Zhao, Y.-Q. Liu, J.-W. Peng, Y.-F. Yan and X.-F. Shang, Bioorg. Chem., 2019, 92, 103266.

36 (a) P. Grellier, L. Ramiaramanana, V. Millerioux, E. Deharo, J. Schrével, F. Frappier, F. Ikigalo, B. Bodo and J. L. Pousset, Phytother. Res., 1996, 10, 317-321; (b) S. Van Miert, S. Hostyn, B. U. W. Maes, K. Cimanga, R. Brun, M. Kaiser, P. Mátyus, R. Dommisse, G. Lemière, A. Vlietinck and L. Pieters, J. Nat. Prod., 2005, 68, 674-677; (c) N. Wang, K. J. Wicht, K. Imai, M.-Q. Wang, T. A. Ngoc, R. Kiguchi, M. Kaiser, T. J. Egan and T. Inokuchi, Bioorg. Med. Chem., 2014, 22, 2629-2642; (d) L. R. Whittell, K. T. Batty, R. P. M. Wong, E. M. Bolitho, S. A. Fox, T. M. E. Davis and P. E. Murray, Bioorg. Med. Chem., 2011, 19, 75197525; (e) K. Rujimongkon, M. Mungthin, J. Tummatorn, S. Ampawong, P. Adisakwattana, U. Boonyuen and O. Reamtong, PLoS One, 2019, 14, e0220871.

37 (a) G. Van Baelen, C. Meyers, G. L. F. Lemière, S. Hostyn, R. Dommisse, L. Maes, K. Augustyns, A. Haemers, L. Pieters and B. U. W. Maes, Tetrahedron, 2008, 64, 11802-11809; (b) N. Wang, M. Switalska, L. Wang, E. Shaban, M. I. Hossain, I. E. T. El Sayed, J. Wietrzyk and T. Inokuchi, Molecules, 2019, 24, 2121.

38 (a) A. Molina, J. J. Vaquero, J. L. García-Navio, J. AlvarezBuilla, B. Pascual-Teresa, F. Gago, M. M. Rodrigo and M. Ballesteros, J. Org. Chem., 1996, 61, 5587-5599; (b) P. Ghosh and P. Purkayastha, RSC Adv., 2014, 4, 2244222448.

39 M. E. Aggrey, H. H. Li, W.-Q. Wang, W. Song, Y. Wang and L.-J. Xuan, Rev. Bras. Farmacogn., 2017, 28, 654-657.

40 (a) P. Schmitt, C. H. Nguyen, J.-S. Sun, D. S. Grierson, E. Bisagni, T. Garestier and C. Hélène, Chem. Commun., 2000, 763-764; (b) J. Lavrado, S. A. Ohnmacht, I. Correia, C. Leitão, S. Pisco, M. Gunaratnam, R. Moreira, S. Neidle, 
D. J. V. A. dos Santos and A. Paulo, ChemMedChem, 2015, 10, 836-849; (c) J. Lavrado, H. Brito, P. M. Borralho, S. A. Ohnmacht, N.-S. Kim, C. Leitão, S. Pisco, M. Gunaratnam, C. M. P. Rodrigues, R. Moreira, S. Neidle and A. Paulo, Sci. Rep., 2015, 5, 9696; (d) H. Falke, A. Chaikuad, A. Becker, N. Loaëc, O. Lozach, S. A. Jhaisha, W. Becker, P. G. Jones, L. Preu, K. Baumann, S. Knapp, L. Meijer and C. Kunick, J. Med. Chem., 2015, 58, 3131-3143. 41 (a) N. Wang, K. J. Wicht, E. Shaban, T. A. Ngoc, M.-Q. Wang, I. Hayashi, M. I. Hossain, Y. Takemasa, M. Kaiser, I. E. T. El Sayed, T. J. Egan and T. Inokuchi, Med. Chem. Commun., 2014, 5, 927-931; (b) L. K. Filak, S. Göschl, P. Heffeter, K. G. Samper, A. E. Egger, M. A. Jakupec, B. K. Keppler, W. Berger and V. B. Arion, Organometallics, 2013, 32, 903914; (c) C.-M. Lu, Y.-L. Chen, H.-L. Chen, C.-A. Chen, P.-J. Lu, C.-N. Yang and C.-C. Tzeng, Bioorg. Med. Chem., 2010, 18, 1948-1957.

42 (a) A. B. J. Bracca, D. A. Heredia, E. L. Larghi and T. S. Kaufman, Eur. J. Org. Chem., 2014, 7979-8003; (b) M. V. Méndez, A. B. J. Bracca and T. S. Kaufman, Synthesis, 2018, 50, 1417-1429; (c) O. N. Nadein, D. A. Aksenov, G. M. Abakarov, N. A. Aksenov, L. G. Voskressensky and A. V. Aksenov, Chem. Heterocycl. Compd., 2019, 55, 905-932.

43 W. O. Kermack and N. E. Storey, J. Chem. Soc., Chem. Commun., 1950, 607-612.

44 G. R. Clemo and W. H. Perkin Jr, J. Chem. Soc., 1924, 125, 1608-1622.

45 (a) J. T. Braunholtz and F. G. Mann, J. Chem. Soc., 1955, 381392; (b) J. A. C. Allison, J. T. Braunholtz and F. G. Mann, J. Chem. Soc., 1955, 403-408; (c) J. T. Braunholtz and F. G. Mann, J. Chem. Soc., 1958, 3368-3377.

46 O. Roussel, P. Buu-Hop and P. Jacquignon, J. Chem. Soc., 1965, 5458-5464.

47 E. E. García, J. G. Riley and R. I. Fryer, J. Org. Chem., 1968, 33, 2868-2874.

48 R. I. Fryer, J. V. Earley and L. H. Sternbach, J. Chem. Soc., 1963, 4979-5004.

49 A. Molina, J. J. Vaquero, J. L. García-Navío and J. AlvarezBuilla, Tetrahedron Lett., 1993, 34, 2673-2676.

50 S. V. Dubovitskii, O. S. Radchenko and V. L. Novikov, Russ. Chem. Bull., 1996, 45, 2656-2657.

51 W. Hückel and L. Hagedorn, Chem. Ber., 1957, 90, 752-754.

52 W. S. Johnson and E. L. Woroch, J. Am. Chem. Soc., 1949, 71, 1901-1905.

53 P. S. Volvoikar and S. G. Tilve, Org. Lett., 2016, 18, 892-895. 54 (a) P. M. Fresneda, P. Molina and S. Delgado, Tetrahedron Lett., 1999, 40, 7275-7278; (b) P. M. Fresneda, P. Molina and S. Delgado, Tetrahedron, 2001, 57, 6197-6202.

55 P. Molina, M. Alajarin and A. Vidal, Tetrahedron, 1990, 46, 1063-1078.

56 W. Stadlbauer, A.-S. Karem and T. Kappe, Monatsh. Chem., 1987, 118, 81-89.

57 C. Narayana, P. Kumari and R. Sagar, Org. Lett., 2018, 20, 4240-4244.

58 P. Molina and M. J. Vilaplana, Synthesis, 1994, 1197-1218.
59 P. K. Agarwal, D. Sawant, S. Sharma and B. Kundu, Eur. J. Org. Chem., 2009, 292-303.

60 (a) B. Kundu, D. Sawant and R. Chhabra, J. Comb. Chem., 2005, 7, 317-321; (b) B. Kundu, D. Sawant, P. Partani and A. P. Kesarwani, J. Org. Chem., 2005, 70, 4889-4892; (c) S. Duggineni, D. Sawant, B. Saha and B. Kundu, Tetrahedron, 2006, 62, 3228-3241; (d) S. Sharma, B. Saha, D. Sawant and B. Kundu, J. Comb. Chem., 2007, 9, 783792; (e) S. Sharma, B. Saha, D. Sawant and B. Kundu, Tetrahedron, 2008, 64, 8676-8684.

61 (a) A. K. Kiang, A. F. Mann, A. F. Prior and A. Topham, J. Chem. Soc., 1956, 1319-1331; (b) R. L. Duncan, G. C. Helsey and R. F. Boswell, J. Heterocycl. Chem., 1973, 10, 65-70.

62 R. S. Stabler, Synth. Commun., 1994, 24, 123-129.

63 (a) M. A. J. Duncton, L. M. Smith, S. Burdzovic-Wizeman, A. Burns, H. Liu, Y. Mao, W. C. Wong and A. S. Kiselyov, J. Org. Chem., 2005, 70, 9629-9631; (b) L. Zheng, J. Xiang, Q. D. Daang and X. Bai, J. Comb. Chem., 2005, 7, 813-815; (c) E. David, P.-S. Rostaing and M. Lemaire, Tetrahedron, 2007, 63, 8999-9006; (d) X. L. Wang, X. F. Zheng, R. H. Liu, J. Reiner and J. B. Chang, Tetrahedron, 2007, 63, 3389-3394; (e) S. Gracia, J. Schulz, S. Pellet-Rostaing and M. Lemaire, Synlett, 2008, 1852-1856; $(f)$ X. Che, L. Zheng, Q. Dang and X. Bai, J. Org. Chem., 2008, 73, 1147-1149.

64 M. Xu, Q. Hou, S. Wang, H. Wang and Z.-J. Yao, Synthesis, 2011, 626-634.

65 (a) M. Alfonsi, A. Acradi, M. Aschi, G. Bianchi and F. Marinelli, J. Org. Chem., 2005, 70, 2265-2273; (b) A. Arcadi, G. Bianchi and F. Marinelli, Synthesis, 2004, 610-618.

66 S. Guo, L. Tao, W. Zhang, X. Zhang and X. Fan, J. Org. Chem., 2015, 80, 10955-10964.

67 G. A. Kraus and H. T. Guo, Org. Lett., 2008, 10, 3061-3063.

68 G. A. Kraus, H. Guo, G. Kumar, G. Pollock III, H. Carruthers, D. Chaudhary and J. Beasley, Synthesis, 2010, 1386-1393.

69 G. A. Kraus and H. Guo, Tetrahedron Lett., 2010, 51, 41374139.

70 J. Yang, H. Song, X. Xiao, J. Wang and Y. Qin, Org. Lett., 2006, 8, 2187-2190.

71 A. V. Butin, F. A. Tsiunchik, V. T. Abaev and V. E. Zavodnik, Synlett, 2008, 1145-1148.

72 A. V. Butin, M. G. Uchuskin, A. S. Pilipenko, F. A. Tsiunchik, D. A. Cheshkov and I. V. Trushkov, Eur. J. Org. Chem., 2010, 920-926.

73 M. G. Uchuskin, A. S. Pilipenko, O. V. Serdyuk, I. V. Trushkov and A. V. Butin, Org. Biomol. Chem., 2012, 10, 7262-7265.

74 (a) S. Cacchi, G. Fabrizi, P. Pace and F. Marinelli, Synlett, 1999, 620-622; (b) L. M. Werbel, S. J. Kesten and W. R. Turner, Eur. J. Med. Chem., 1993, 28, 837-852.

75 (a) K. D. Park, S. J. Cho, J. S. Moon and S. U. Kim, Bioorg. Med. Chem. Lett., 2010, 20, 6551-6554; (b) G. E. Lee, H.-S. Lee, S. D. Lee, J.-H. Kim, W.-K. Kim and Y.-C. Kim, Bioorg. Med. Chem. Lett., 2009, 19, 954-958; (c) O. Tsuge, S. Kanemasa and S. Takenaka, Bull. Chem. Soc. Jpn., 1987, 60, 1489-1495; (d) A. Katritzky, N. E. Grzeskowiak, 
J. Alvarez-Bulla and A. Tarraga-Tomas, J. Prakt. Chem., 1983, 325, 177-187.

76 B. Bogányi and J. Kámán, Tetrahedron, 2013, 69, 9512-9519.

77 R. Cassis, R. Tapia and J. A. Valderrama, Synth. Commun., 1985, 15, 125-133.

78 N. Boudet, J. R. Lachs and P. Knochel, Org. Lett., 2007, 9, 5525-5528.

79 (a) B. J. Margolis, K. A. Long, D. L. T. Laird, J. C. Ruble and S. R. Pulley, J. Org. Chem., 2007, 72, 2232-2235; (b) C. Wolf, G. E. Tumambac and C. N. Villalobos, Synlett, 2003, 18011804.

80 S. Hostyn, B. U. W. Maes, V. G. Baelen, A. Gulevskaya, C. Meyers and K. Sits, Tetrahedron, 2006, 62, 4676-4684.

81 (a) R. Francke and R. D. Little, Chem. Soc. Rev., 2014, 43, 2492-2521; (b) B. A. Frontana-Uribe, R. D. Little, J. G. Ibanez, A. Palma and R. Vasquez-Medrano, Green Chem., 2010, 12, 2099-2119; (c) J. Yoshida, K. Kataoka, R. Horcajada and A. Nagaki, Chem. Rev., 2008, 108, 22652299; (d) J. B. Sperry and D. L. Wright, Chem. Soc. Rev., 2006, 35, 605-621; (e) K. A. Ogawa and A. J. Boydston, Chem. Lett., 2015, 44, 10-16; (f) R. Francke, Beilstein J. Org. Chem., 2014, 10, 2858-2873; $(g)$ S. R. Waldvogel and B. Janza, Angew. Chem., Int. Ed., 2014, 53, 7122-7123; (h) S. R. Waldvogel and S. Möhle, Angew. Chem., Int. Ed., 2015, 54, 6398-6399.

82 (a) T. Morofuji, A. Shimizu and J. Yoshida, J. Am. Chem. Soc., 2014, 136, 4496-4499; (b) T. Morofuji, A. Shimizu and J. Yoshida, J. Am. Chem. Soc., 2015, 137, 9816-9819; (c) W. J. Gao, W. C. Li, C. C. Zeng, H. Y. Tian, L. M. Hu and R. D. Little, J. Org. Chem., 2014, 79, 9613-9618; (d) S. J. Yoo, L. J. Li, C. C. Zeng and R. D. Little, Angew. Chem., Int. Ed., 2015, 54, 3744-3747; (e) B. Elsler, D. Schollmeyer, K. M. Dyballa, R. Franke and S. R. Waldvogel, Angew. Chem., Int. Ed., 2014, 53, 52105213; (f) B. Elsler, A. Wiebe, D. Schollmeyer, K. M. Dyballa, R. Franke and S. R. Waldvogel, Chem.-Eur. J., 2015, 21, 12321-12325.

83 N. Fuentes, W. Kong, L. Fernandez-Sánchez, E. Merino and C. Nevado, J. Am. Chem. Soc., 2015, 137, 964-973.

84 L. Zhu, P. Xiong, Z. Y. Mao, Y. H. Wang, X. Yan, X. Lu and H.-C. Xu, Angew. Chem., Int. Ed., 2016, 55, 2226-2229.

85 Z.-W. Hou, Z.-Y. Mao, H.-B. Zhao, Y. Y. Melcamu, X. Lu, J. Song and H.-C. Xu, Angew. Chem., Int. Ed., 2016, 55, 9168-9172.

86 (a) Y. F. Wang, H. Chen, X. Zhu and S. Chiba, J. Am. Chem. Soc., 2012, 134, 11980-11983; (b) Z. Li, L. Song and C. Li, J. Am. Chem. Soc., 2013, 135, 4640-4643; (c) X. Q. Hu, J. R. Chen, Q. Wei, F. L. Liu, Q. H. Deng, A. M. Beauchemin and W. J. Xiao, Angew. Chem., Int. Ed., 2014, 53, 12163-12167; (d) G. J. Choi and R. R. Knowles, J. Am. Chem. Soc., 2015, 137, 9226-9229; (e) D. C. Miller, G. J. Choi, H. S. Orbe and R. R. Knowles, J. Am. Chem. Soc., 2015, 137, 13492-13495.

87 (a) U. Jahn and P. Hartmann, Chem. Commun., 1998, 209210; (b) F. Kafka, M. Holan, D. Hidasova, R. Pohl, I. Cisarova, B. Klepetarova and U. Jahn, Angew. Chem., Int. Ed., 2014, 53, 9944-9948.
88 (a) A. V. Aksenov, A. N. Smirnov, N. A. Aksenov, I. V. Aksenova, L. V. Frolova, A. Kornienko, I. V. Magedov and M. Rubin, Chem. Commun., 2013, 49, 9305-9307; (b) A. V. Aksenov, A. N. Smirnov, I. V. Magedov, M. R. Reisenauer, N. A. Aksenov, I. V. Aksenova, A. L. Pendleton, G. Nguyen, R. K. Johnston, M. Rubin, A. Carvalho, R. De Kiss, V. Mathieu, F. Lefranc, J. Correa, D. A. Cavazos, A. J. Brenner, B. A. Bryan, S. Rogelj, A. Kornienko and L. V. Frolova, J. Med. Chem., 2015, 58, 2206-2220; (c) A. V. Aksenov, A. N. Smirnov, N. A. Aksenov, I. V. Aksenova, A. S. Bijieva and M. Rubin, Org. Biomol. Chem., 2014, 12, 9786-9788; (d) A. V. Aksenov, A. N. Smirnov, N. A. Aksenov, I. V. Aksenova, J. P. Matheny and M. Rubin, RSC Adv., 2015, 5, 8647-8656.

89 (a) R. N. Kumar, T. Suresh and P. S. Mohan, Tetrahedron Lett., 2002, 43, 3327-3328; (b) A. V. Aksenov, D. A. Aksenov, G. D. Griaznov, N. A. Aksenov, L. G. Voskressensky and M. Rubin, Org. Biomol. Chem., 2018, 16, 4325-4332.

90 A. V. Aksenov, D. A. Aksenov, N. A. Orazova, N. A. Aksenov, G. D. Griaznov, A. De Carvalho, R. Kiss, V. Mathieu, A. Kornienko and M. Rubin, J. Org. Chem., 2017, 82, 30113018.

91 H. Z. Alkhathlan, M. A. Al-Saad, H. M. Al-Hazimi, K. A. AlFarhan and A. A. Mousa, J. Chem. Res., 2002, 587-588.

92 (a) A. V. Aksenov, N. A. Aksenov, Z. V. Dzhandigova, D. A. Aksenov and M. Rubin, RSC Adv., 2015, 5, 106492106497; (b) N. A. Aksenov, A. Z. Gasanova, G. M. Abakarov, I. V. Aksenova and A. V. Aksenova, Russ. Chem. Bull., 2019, 68, 836-840.

93 N. A. Aksenov, A. V. Aksenov, A. Kornienko, A. de Carvalho, V. Mathieu, D. A. Aksenov, S. N. Ovcharov, G. D. Griaznove and M. Rubin, RSC Adv., 2018, 8, 36980-36986.

94 C. Xie, Z. Zhang, D. Li, J. Gong, X. Han, X. Liu and C. Ma, J. Org. Chem., 2017, 82, 3491-3499.

95 (a) A. R. Katritzky, X. Lan, O. Yang and O. V. Denisko, Chem. Rev. , 1998, 98, 409-584; (b) J. Chen, B. Liu, D. Liu, S. Liu and J. Cheng, Adv. Synth. Catal., 2012, 354, 2438-2442; (c) H. Fei, J. Yu, Y. Jiang, H. Guo and J. Cheng, Org. Biomol. Chem., 2013, 11, 7092-7095; (d) Z. Zhang, Q. Tian, J. Qian, Q. Liu, T. Liu, L. Shi and G. Zhang, J. Org. Chem., 2014, 79, 81828188; (e) J. Qian, Z. Zhang, Q. Liu, T. Liu and G. Zhang, Adv. Synth. Catal., 2014, 356, 3119-3124.

96 (a) V. Traynelis and W. Hergenrother, J. Org. Chem., 1964, 29, 221-222; (b) K. Tasneem and K. Z. Khan, Asian J. Chem., 2008, 20, 929-933.

97 G. Tímari, T. Soos and G. Hajos, Synlett, 1997, 1067-1068. 98 N. Miyaura and A. Suzuki, Chem. Rev., 1995, 95, 2457-2483. 99 W. Fuhrer and H. W. Gschwend, J. Org. Chem., 1979, 44, 1133-1136.

100 P. Molina, A. Lorenzo and E. Aller, Tetrahedron, 1992, 48, 4601-4616.

101 F. Trecourt, F. Mongin, M. Mallet and G. Queguiner, Synth. Commun., 1995, 25, 4011-4024.

102 H. Gao, Q.-L. Xu, M. Yousufuddin, D. H. Ess and L. Kürti, Angew. Chem., Int. Ed., 2014, 53, 2701-2705. 
103 K. S. Håheim, I. T. U. Helgeland, E. Lindbäck and M. O. Sydnes, Tetrahedron, 2019, 75, 2949-2957.

104 T. H. M. Jonckers, B. U. W. Maes, G. L. F. Lemière, G. Rombouts, L. Pieters, A. Haemers and R. A. Dommisse, Synlett, 2003, 615-618.

105 (a) D. Barañano, G. Mann and J. F. Hartwig, Curr. Org. Chem., 1997, 1, 287-305; (b) C. G. Frost and P. Mendonça, J. Chem. Soc., Perkin Trans. 1, 1998, 2615-2623; (c) J. F. Hartwig, Angew. Chem., Int. Ed., 1998, 37, 2046-2067; (d) A. R. Muci and S. L. Buchwald, Top. Curr. Chem., 2002, 219, 131-201.

106 (a) D. E. Ames and D. Bull, Tetrahedron, 1982, 38, 383-387; (b) T. Iwaki, A. Yasuhara and T. Sakamoto, J. Chem. Soc., Perkin Trans. 1, 1999, 1505-1510; (c) R. B. Bedford and C. S. Cazin, Chem. Commun., 2002, 2310-2311.

107 C. Wolf and R. Lerebours, J. Org. Chem., 2003, 68, 70777084 .

108 J. Yin, M. M. Zhao, M. A. Huffman and J. M. McNamara, Org. Lett., 2002, 4, 3481-3484.

109 P. Fitton and E. A. Rick, J. Organomet. Chem., 1971, 28, 287291.

110 (a) A. F. Littke and G. C. Fu, J. Org. Chem., 1999, 64, 10-11; (b) A. Z. Ehrentraut and M. Beller, Synlett, 2000, 1589-1592.

111 I. V. Seregin and V. Gevorgyan, Chem. Soc. Rev., 2007, 36, 1173-1193.

112 C. Meyers, G. Rombouts, K. T. . J. Loones, A. Coelho and B. U. W. Maes, Adv. Synth. Catal., 2008, 350, 465-470.

113 (a) L. Ackermann and A. Althammer, Angew. Chem., Int. Ed., 2007, 46, 1627-1629; (b) R. B. Bedford and M. Betham, J. Org. Chem., 2006, 71, 9403-9410.

114 T. Dhanabal, R. Sangeetha and P. S. Mohan, Tetrahedron Lett., 2005, 46, 4509-4510.

115 S. Sunder and N. P. Peet, J. Heterocycl. Chem., 1978, 15, 1379-1382.

116 P. Pitchai, P. S. Mohan and R. M. Gengan, Indian J. Chem., Sect. B, 2009, 48, 692-696.

117 R. Saari, J. C. Toermae and T. Nevalainen, Bioorg. Med. Chem., 2011, 19, 939-950.

118 (a) K. M. Kasiotis, N. Fokialakis and S. A. Haroutounian, Synthesis, 2006, 1791-1802; (b) S. Chandrasekhar, K. Vijeender and C. Sridhar, Tetrahedron Lett., 2007, 48, 4935-4937.

119 K. Matsumoto, A. Tanaka, I. Yukio, N. Hayashi, M. Toda and R. A. Bulman, Heterocycl. Commun., 2003, 9, 9-12.

120 D. Kumar, M. Kumar and V. S. Rao, Chem. Lett., 2009, 38, 156-157.

121 K. A. Muszkat and E. Fischer, J. Chem. Soc. B, 1967, 662-678.

122 P. E. Murray, K. Mills and J. A. Joule, J. Chem. Res., Synop., 1998, 377; J. Chem. Res., Miniprint, 1998, 1435-1447.

123 P. Strazzolini, A. G. Giumanini and S. Cauci, Tetrahedron, 1990, 46, 1081-1118.

124 (a) S. T. Selvi and P. S. Z. Mohan, Z. Naturforsch., B: J. Chem. Sci., 1999, 54, 1337-1341; (b) S. T. Selvi and P. S. Mohan, Heterocycl. Commun., 1999, 6, 533-535.

125 S. T. Selvi and P. S. Mohan, Indian J. Chem., Sect. B: Org. Chem. Incl. Med. Chem., 1999, 38, 1118-1120.
126 (a) L. Jayabalan and P. Shanmugam, Synthesis, 1991, 217220; (b) E. Schendera, L.-N. Unkel, P. P. Huyen Quyen, G. Salkewitz, F. Hoffmann, A. Villinger and M. Brasholz, Chem.-Eur. J., 2020, 26, 269-274.

127 E. R. El-Sawy, A. B. Abdelwahab and G. Kirsch, Synthesis, 2018, 50, 4525-4538.

128 (a) Y. Miki, Y. Tsuzaki, H. Hibino and Y. Aoki, Synlett, 2004, 2206-2208; (b) Y. Miki, Y. Aoki, H. Miyatake, T. Minematsu and H. Hibino, Tetrahedron Lett., 2006, 47, 5215-5218.

129 Y. Miki, M. Kuromatsu, H. Miyatake and H. Hamamoto, Tetrahedron Lett., 2007, 48, 9093-9095.

130 (a) D. Tanaka, S. P. Romeril and A. G. Myers, J. Am. Chem. Soc., 2005, 127, 10323-10333; (b) D. Tanaka and G. Myers, Org. Lett., 2004, 6, 433-436; (c) A. G. Myers, D. Tanaka and M. R. Mannion, J. Am. Chem. Soc., 2002, 124, 1125011251.

131 A. Mouladdib, B. Joseph, A. Hasnaoui and J. Mérour, Synthesis, 2000, 549-556.

132 D. G. Hingane and R. S. Kusurkar, Tetrahedron Lett., 2011, 52, 3686-3688.

133 A. Yasuhara and T. Sakamoto, Tetrahedron Lett., 1998, 39, 595-596.

134 (a) K. Hayashi, T. Choshi, K. Chikaraishi, A. Oda, R. Yoshinaga, N. Hatae, M. Ishikura and S. Hibino, Tetrahedron, 2012, 68, 4274-4279; (b) D. F. Vargas, E. L. Larghi and T. S. Kaufman, Nat. Prod. Rep., 2019, 36, 354-401.

135 S. Beaumont, P. Retailleau, P. Dauban and R. H. Dodd, Eur. J. Org. Chem., 2008, 5162-5175.

136 H. Katsuki, P. K. Datta, H. Hayakawa and H. Suenaga, Synthesis, 1995, 1348-1350.

137 T. Kuwada, M. Fukui, M. Hirayama, J. Nobuhiro, T. Choshi and S. Hibino, Heterocycles, 2002, 58, 326-332.

138 W. H. Pearson and W. K. Fang, Isr. J. Chem., 1997, 37-39.

139 J. Tummatorn, C. Thongsornkleeb and S. Ruchirawat, Tetrahedron, 2012, 68, 4732-4739.

140 T. Maibunkaew, C. Thongsornkleeb, J. Tummatorn, A. Bunrit and S. Ruchirawat, Synlett, 2014, 25, 1769-1775.

141 P. Aroonkit, C. Thongsornkleeb, J. Tummatorn, S. Krajangsri, M. Mungthin and S. Ruchirawat, Eur. J. Med. Chem., 2015, 94, 56-62.

142 (a) Z. Shi, D. C. Koester, M. Boultadakis-Arapinis and F. Glorius, J. Am. Chem. Soc., 2013, 135, 12204-12207; (b) S. Ding, Z. Shi and N. Jiao, Org. Lett., 2010, 12, 15401543; (c) N. Guimond, S. I. Gorelsky and K. Fagnou, J. Am. Chem. Soc., 2011, 133, 6449-6457; (d) S. Rakshit, C. Grohmann, T. Besset and F. Glorius, J. Am. Chem. Soc., 2011, 133, 2350-2353; (e) B. Ye and N. Cramer, Science, 2012, 338, 504-506; (f) C. Zhu, R. Wang and J. R. Falck, Chem.-Asian J., 2012, 7, 1502-1514; $(g)$ N. Kuhl, N. Schröder and F. Glorius, Adv. Synth. Catal., 2014, 356, 1443-1460.

143 (a) Z. Shi, Y. Cui and N. Jiao, Org. Lett., 2010, 12, 2908-2911; (b) J. Zheng, Y. Zhang and S. Cui, Org. Lett., 2014, 16, 35603563.

144 X. Chen, P. Sun, J. Xu, X. Wu, L. Kong, H. Yao and A. Lin, Tetrahedron Lett., 2014, 55, 7114-7117. 
145 E. T. Nadres, A. Lazareva and O. Daugulis, J. Org. Chem., 2011, 76, 471-483.

146 J. Karthikeyan and C. H. Cheng, Angew. Chem., Int. Ed., 2011, 50, 9880-9883.

147 (a) X. Zhang, D. Zhang-Negrerie, J. Deng, Y. Du and K. Zhao, J. Org. Chem., 2013, 78, 12750-12759; (b) H. Zhong, D. Yang, S. Wang and J. Huang, Chem. Commun., 2012, 3236-3238.

148 (a) O. Daugulis and V. G. Zaitsev, Angew. Chem., Int. Ed., 2005, 44, 4046-4048; (b) A. Lazareva and O. Daugulis, Org. Lett., 2006, 8, 5211-5213.

149 (a) P. S. Mahajan, S. D. Tanpure, N. A. More, J. M. Gajbhiye and S. B. Mhaske, RSC Adv., 2015, 5, 101641-101646; (b) D. N. Garad, S. D. Tanpure and S. B. Mhaske, Beilstein J. Org. Chem., 2015, 11, 1008-1016.

150 P. S. Mahajan, V. T. Humne, S. D. Tanpure and S. B. Mhaske, Org. Lett., 2016, 18, 3450-3453.

151 A. M. Cook and C. Wolf, Chem. Commun., 2014, 50, 31513154 .

152 (a) A. Lattes, E. Oliveros, M. Riviere, C. Belzeck, D. Mostowicz, W. Abramskj, C. Piccinni-Leopardi, G. Germain and M. Van Meersschel, J. Am. Chem. Soc., 1982, 104, 3929-3934; (b) T. Oine and T. Mukai, Tetrahedron Lett., 1969, 10, 157-160.

153 (a) O. E. Hutt, T. L. Doan and G. I. Georg, Org. Lett., 2013, 15, 1602-1605; (b) B. T. Smith, J. A. Wendt and J. Aube, Org. Lett., 2002, 4, 2577-2584; (c) Y. Ogata, K. Takagi and K. Mizuno, J. Org. Chem., 1982, 47, 3684-3687; (d) T. Sasaki, S. Eguchi and T. Toru, J. Chem. Soc. D, 1970, 1239-1240.

154 V. Dave and E. W. Warnhoff, Tetrahedron, 1975, 31, 12551258.
155 (a) Y. L. Chen, C. H. Chung, I. L. Chen, P. H. Chen and H. Y. Jeng, Bioorg. Med. Chem., 2002, 10, 2705-2712; (b) Z. L. Xiao, N. C. Waters, C. L. Woodard, Z. Y. Li and P. K. Li, Bioorg. Med. Chem. Lett., 2001, 11, 2875-2878; (c) A. Walser, G. Silverman, T. Flynn and R. I. Fryer, J. Heterocycl. Chem., 1975, 12, 351-358.

156 T. Y. Zhang, C. Liu, C. Chen, J. X. Liu, H. Y. Xiang, W. Jiang, T. M. Ding and S. Y. Zhang, Org. Lett., 2018, 20, 220-223.

157 (a) V. G. Zaitsev, D. Shabashov and O. Daugulis, J. Am. Chem. Soc., 2005, 127, 13154-13155; (b) M. Corbet and F. De Campo, Angew. Chem., Int. Ed., 2013, 52, 9896-9898; (c) G. Rouquet and N. Chatani, Angew. Chem., Int. Ed., 2013, 52, 11726-11743; (d) O. Daugulis, J. Roane and L. D. Tran, Acc. Chem. Res., 2015, 48, 1053-1064; (e) G. He, B. Wang, W. A. Nack and G. Chen, Acc. Chem. Res., 2016, 49, 635-645.

158 (a) G. He, S. Y. Zhang, W. A. Nack, Q. Li and G. Chen, Angew. Chem., Int. Ed., 2013, 52, 11124-11128; (b) C. Yamamoto, K. Takamatsu, K. Hirano and M. Miura, J. Org. Chem., 2016, 81, 7675-7684.

159 Y. Himeshima, T. Sonoda and H. Kobayashi, Chem. Lett., 1983, 12, 1211-1214.

160 (a) A. E. King, L. M. Huffman, A. Casitas, M. Costas, X. Ribas and S. S. Stahl, J. Am. Chem. Soc., 2010, 132, 12068-12073; (b) R. J. Phipps, N. P. Grimster and M. J. Gaunt, J. Am. Chem. Soc., 2008, 130, 8172-8174.

161 (a) A. E. Wendlandt, A. M. Suess and S. S. Stahl, Angew. Chem., Int. Ed., 2011, 50, 11062-11087; (b) A. M. Suess, M. Z. Ertem, C. J. Cramer and S. S. Stahl, J. Am. Chem. Soc., 2013, 135, 9797-9804. 